\title{
Comparative analyses of olfactory systems in terrestrial crabs (Brachyura): Evidence for aerial olfaction?
}

Jakob Krieger, Philipp Braun, Nicole T Rivera, Christoph D Schubart, Carsten HG Müller, Steffen Harzsch

Adaptations to a terrestrial lifestyle occurred convergently multiple times during the evolution of the arthropods. This holds also true for the "true crabs" (Brachyura), a taxon that includes several lineages that invaded land independently. During an evolutionary transition from sea to land, animals have to develop a variety of physiological and anatomical adaptations to a terrestrial life style related to respiration, reproduction, development, circulation, ion and water balance. In addition, sensory systems that function in air instead of in water are essential for an animal's life on land. Besides vision and mechanosensory systems, on land, the chemical senses have to be modified substantially in comparison to their function in water. Among arthropods, insects are the most successful ones to evolve aerial olfaction. Various aspects of terrestrial adaptation have also been analyzed in those crustacean lineages that evolved terrestrial representatives including the taxa Anomala, Brachyura, Amphipoda, and Isopoda. We are interested in how the chemical senses of terrestrial crustaceans are modified to function in air. Therefore, in this study, we analyzed the brains and more specifically the structure of the olfactory system of representatives of brachyuran crabs that display different degrees of terrestriality, from exclusively marine to mainly terrestrial. The methods we used included immunohistochemistry, detection of autofluorescence- and confocal microscopy, as well as three-dimensional reconstruction and morphometry. Our comparative approach shows that both the peripheral and central olfactory pathways are reduced in terrestrial members in comparison to their marine relatives, suggesting a limited function of their olfactory system on land. We conclude that for arthropod lineages that invaded land, evolving aerial olfaction is no trivial task. 


\section{J. Krieger ${ }^{1^{*}}$, P. Braun ${ }^{1^{*}}$, N. T. Rivera ${ }^{2}$, C. D. Schubart ${ }^{2}$, C. H. G. Müller ${ }^{3}$, S.

Affiliations:

91 Zoological Institute and Museum, Department of Cytology and Evolutionary Biology,

10 University of Greifswald, Soldmannstrasse 23, D-17487 Greifswald, Germany

$11{ }^{2}$ Institute for Zoology, Department of Zoology \& Evolution, University of Regensburg, D-93040

12 Regensburg, Germany

$13{ }^{3}$ Zoological Institute and Museum, Department of General and Systematic Zoology, University of

14 Greifswald, Anklamer Straße 20, D-17489 Greifswald, Germany 
15

\section{$\underline{\text { Abstract }}$}

Adaptations to a terrestrial lifestyle occurred convergently multiple times during the evolution of the arthropods. This holds also true for the "true crabs" (Brachyura), a taxon that includes several lineages that invaded land independently. During an evolutionary transition from sea to land, animals have to develop a variety of physiological and anatomical adaptations to a terrestrial life style related to respiration, reproduction, development, circulation, ion and water balance. In addition, sensory systems that function in air instead of in water are essential for an animal's life on land. Besides vision and mechanosensory systems, on land, the chemical senses have to be modified substantially in comparison to their function in water. Among arthropods, insects are the most successful ones to evolve aerial olfaction. Various aspects of terrestrial adaptation have also been analyzed in those crustacean lineages that evolved terrestrial representatives including the taxa Anomala, Brachyura, Amphipoda, and Isopoda. We are interested in how the chemical senses of terrestrial crustaceans are modified to function in air. Therefore, in this study, we analyzed the brains and more specifically the structure of the olfactory system of representatives of brachyuran crabs that display different degrees of terrestriality, from exclusively marine to mainly terrestrial. The methods we used included immunohistochemistry, detection of autofluorescence- and confocal microscopy, as well as three-dimensional reconstruction and morphometry. Our comparative approach shows that both the peripheral and central olfactory pathways are reduced in terrestrial members in comparison to their marine relatives, suggesting a limited function of their olfactory system on land. We conclude that for arthropod lineages that invaded land, evolving aerial olfaction is no trivial task.

\section{$\underline{\text { Introduction }}$}

Land-living crustaceans are fascinating animals that adapted during a relatively short evolutionary time period to a number of highly diverse terrestrial habitats in which they have become highly successful, and in some cases the predominant life forms (Hansson et al., 2011). Representatives in not less than five major malacostracan crustacean taxa have conquered the terrestrial habitat independently. Because the successful transition from a marine or freshwater 
42 habitat to terrestrial life requires a number of physiological adaptations which are important for survival out of water, terrestrial crustaceans constitute an excellent animal group to study evolutionary adaptations related to the invasion of land. Such adaptations include changes to gas exchange, salt and water balance, nitrogenous excretion, thermoregulation, molting, and reproduction (reviews in Bliss \& Mantel, 1968; Burggren \& McMahon, 1988; Greenaway, 1988, 1999, 2003; McMahon \& Burggren, 1988; Powers \& Bliss, 1983). The Brachyura (short-tailed crabs or "true crabs") include several lineages that invaded land. The degree of terrestrial adaptation in crustaceans has been categorized into five classes ranging from $T_{1}$ to $T_{5}$ depending on the degree of independence from immersion in water and the animal's need to access water for reproduction (Hartnoll, 1988; Greenaway, 1999; Powers \& Bliss, 1983; but see Schubart et al., 2000 for an alternative classification). In this traditional classification, several brachyuran taxa have been ranked within the two highest grades of terrestrial adaptation (e.g. Gecacinidae, and some representatives of the Sesarmidae, Potamidae, Gecarcinidae, Potamonautidae, Pseudothelphusidae, and Trichodactylidae), whereas many amphibious freshwater forms and supra-littoral species are ranked in less terrestrialized categories.

The phylogenetic relationships of Brachyura and the systematics of brachyuran taxa are the topic of ongoing research (Scholtz \& Richter, 1995; Dixon, Ahyong \& Schram, 2003; Ahyong \& O’Meally, 2004; Ng, Guinot \& Davie, 2008; Tsang et al., 2014; Brösing, Richter \& Scholtz, 2007; Fig. 1) but there is increasing evidence that the conquest of land occurred several times independently amongst Brachyura as suggested by Powers and Bliss (1983) and Hartnoll (1988). All members of the Gecarcinidae (with the exception of the genus Epigrapsus) and representatives of the grapisd genus Geograpsus have achieved complete terrestriality as adults, but larval development, which is not abbreviated, takes place in the oceans. The family Sesarmidae (sensu Schubart, Cuesta \& Felder, 2002) includes crabs such as Sesarma jarvisi, $S$. cookei, and S. verleyi, which radiated into a broad range of terrestrial habitats, including mountainous rain forest and caves on Jamaica (Wolcott, 1988; Schubart, Diesel \& Hedges, 1998; Diesel \& Schubart, 2000; Diesel, Schubart \& Schuh, 2000). The bromeliad crab Metopaulias depressus raises its offspring in water-filled leaf axils of bromeliads and certainly has evolved one of the most notable reproductive adaptations to terrestrial habitats (Diesel \& Schubart, 2000), but remains immersed in water for extended time periods. The Ocypodidae comprise the genera Ocypode, Uca, and Ucides; and some of its representatives were qualified to reach terrestrial grade $T_{3}$ by Powers and Bliss (1983). In the phylogenetic analysis based on stomach ossicles by 
74 Brösing et al. (2007), several taxa with terrestrial tendencies, the Potamonautidae, Ocypodidae,

75 Gecarcinidae, Grapsidae, and Mictyridae cluster together with other taxa in the proposed taxon

76 Neobrachyura, suggesting a close relationship of those brachyuran groups which include

77 terrestrial forms, but this grouping is not recovered in the newest and most comprehensive phylogeny by Tsang et al. (2014), so that it appears to be based on convergences. The paraphyletic superfamily Grapsoidea (comprising 88 genera with over 480 species including the Gecarcinidae (6 genera with 19 species) include intertidal to supratidal as well as limnic forms in addition to terrestrial ones, so that there is increasing evidence that the colonization of inland habitats evolved in several lineages (Schubart et al., 2000, 2006; Tsang et al., 2014).

An essential physiological adaptation to master a terrestrial lifestyle during and after an evolutionary transition from sea to land includes the need for sensory organs to function in air instead of in water (Greenaway, 1999, 2003; Hansson et al., 2011). Mechanosensory systems must detect stimuli that propagate in air versus in water, and visual systems must operate in media with different refractive properties. In olfaction, a transition from sea to land means that molecules need to be detected in or bound from gas phase instead of being transmitted directly from one water solution (e.g. sea water) into another one (receptor lymphs). Marine crustaceans live in a world full of chemical information. It is well established that they use chemical cues to locate mates, signal dominance, recognize individual conspecifics, find favored food and appropriate habitats, and assess threats such as the presence of predators (reviews e.g. Derby et al., 2001; Grasso \& Basil, 2002; Derby \& Sorensen, 2008; Hazlett, 2011; Thiel \& Breithaupt, 2011; Wyatt, 2011; Derby \& Weissburg, 2014). However, aquatic versus land-living animals must detect highly different semiochemicals, because the medium places different demands on the compounds used. In water, molecules have to be more or less water-soluble and stable enough to travel from one individual to another. On land, semiochemicals have to be light enough to form a gas in the ambient temperatures where animals live (discussed in Stensmyr et al., 2005). These molecules also have to be sufficiently chemically stable to reach the sensory receptor cells. These new selection pressures take part together in reshaping the sense of smell during the invasion of new, terrestrial habitats (reviews Hansson et al., 2011; Hay, 2011; Weissburg, 2011).

Malacostracan crustaceans living in aquatic habitats use several systems for detecting chemicals, 103 and these are distributed over their entire body surface, walking appendages, and mouthparts, but 104 are also concentrated on two pairs of antennae (reviews e.g. Hallberg, Johansson \& Elofsson, 
105 1992; Hallberg \& Skog, 2011; Schmidt \& Mellon, 2011). The first antennal pair (the antennules)

106 is equipped with specialized olfactory sensillae (aesthetascs) in addition to bimodal chemo- and

107 mechanosensilla (contact chemoreceptors), whereas the second pair of antennae is only equipped

108 with the latter. The tips of the first antennae (more specifically the lateral flagella) bear a tuft

109 region with arrays of aesthetascs that house branched dendrites of olfactory sensory neurons

110 (reviews by Hallberg, Johansson \& Elofsson, 1992; Hallberg \& Hansson, 1999; Mellon, 2007;

111 Hallberg \& Skog, 2011; Schmidt \& Mellon, 2011; Derby \& Weissburg, 2014). Schmidt and

112 Mellon (2011) pointed out that in aquatic crustaceans, chemical information is received and

113 processed in two fundamentally different modes. The first mode is "olfaction" defined as

114 chemoreception mediated by the aesthetasc pathway; the second mode is called "distributed

115 chemoreception" defined as chemoreception mediated by contact chemoreceptors on all

116 appendages (Schmidt \& Mellon, 2011). Chemosensory neurons associated with the aesthetascs

117 versus the contact chemoreceptors on the first antenna of malacostracan crustaceans innervate

118 distinct regions in the brain. The axons of the olfactory sensory neurons associated with the

119 aesthetascs target the deutocerebral chemosensory lobes (DCLs; also called olfactory lobes),

120 whereas the axons associated with non-aesthetasc sensilla innervate the lateral antenna 1 neuropil

121 (LAN; Schachtner, Schmidt \& Homberg, 2005; Schmidt \& Mellon, 2011; Strausfeld, 2012;

122 Loesel et al., 2013). As for the different functions of these two modes of aquatic chemoreception,

123 Schmidt and Mellon (2011) suggested that "the essence of olfaction" is to provide a detailed

124 representation of the complex chemical environment integrating chemical signals from a variety

125 of interesting sources (...) without reference to the location of stimuli (...). In contrast, the

126 essence of "distributed chemoreception" is to form representations of only few key chemicals

127 (food-related chemicals, pheromones) within a somatotopic context provided by

128 mechanoreception. The integration of chemo- and mechanosensory information permits

129 pinpointing the location of chemical stimuli...”.

130 Independently of insects, chelicerates, and myriapods, terrestrial Crustacea provide a fascinating 131 chance to look on a wonderful evolutionary experiment by analyzing which potential alternative 132 solutions arthropods have evolved to explore the terrestrial olfactory landscape (Hansson et al., 133 2011). We have previously analyzed the olfactory system of land hermit crabs (Anomala, 134 Coenobitidae) including their peripheral (Stensmyr et al., 2005; Tuchina et al., 2014) and central 135 olfactory pathway (Harzsch \& Hansson, 2008; Krieger et al., 2010; Polanska et al., 2012; Wolff 136 et al., 2012; Tuchina et al., 2015), in addition to behavioral and physiological aspects (Stensmyr 
137 et al., 2005; Krång et al., 2012). These studies provided evidence for coenobitids having a superb

138 sense of aerial olfaction. In this paper, we ask whether terrestrial brachyuran crabs also evolved

139 the neuronal basis for aerial olfaction. Therefore, we compare the anatomy of the central

140 olfactory pathway of selected species of brachyuran crustaceans featuring a rather terrestrial

141 lifestyle to that of their marine relatives.

\section{Material and methods}

143 Experimental animals

144 We analyzed representatives of several different species of brachyurans representing aquatic

145 species (four exclusively marine and one freshwater crab species) as well as four brachyuran

146 species featuring different grades of terrestrial adaptation (Tab. 1; Fig. 2-3). For simplification,

147 the four latter brachyurans are referred as terrestrial brachyurans throughout this text, although all

148 nine species feature terrestrial adaptions at various degrees (Tab. 1). After shipping, living

149 specimens of Cardisoma armatum, Geosesarma tiomanicum, and Uca tangeri were kept in tanks

150 providing both a water and a land part. Husbandry as well as observation and documentation of

151 these species were conducted between 5 to 14 days until dissection in the laboratory. Before

152 dissection, animals were sexed, and the carapace width as well as the wet weight of each animal

153 was measured. The collection of specimens of Gecarcoidea natalis was permitted by Christmas

154 Island National Park (Australian Government; Department of the Environment; Parks Australia;

155 Permit No.: AU_COM 2010-090-1).

156 Table 1.) Investigated species including the sexes, numbers, grades of terrestriality $\left(\mathrm{T}_{1}-\mathrm{T}_{5}\right.$, where

$157 \mathrm{~T}_{1}$ is the lowest grade and $\mathrm{T}_{5}$ the highest), and origins of specimens:

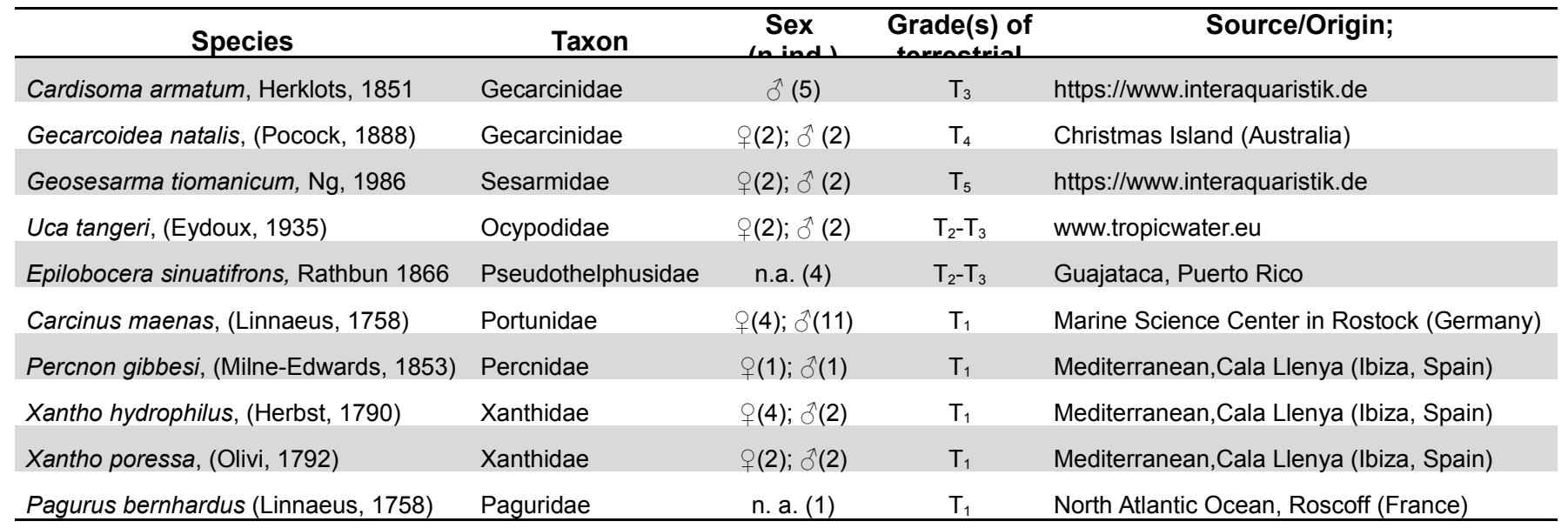

\section{Analysis of antennae and aesthetascs}


159 The first pairs (antennules) and the second pairs (antennae) of post-ocular appendages were cut

160 off prior to brain dissection and were transferred into $70 \%$ ethanol (G. natalis and two animals of $161 \mathrm{G}$. tiomanicum) or in $2 \%$ glutaraldehyde in $0.1 \mathrm{M}$ phosphate buffered saline (PBS; further 162 specimens of $G$. tiomanicum, C. armatum, and $U$. tangeri). Micrographs of these appendages 163 were documented in PBS with a Nikon Eclipse 90i microscope equipped with a digital camera 164 (Nikon DS2-MBWc) and analyzed by the use of the software package NIS-Elements AR. 165 Cuticular auto-fluorescence of the first and second antennae was excited with ultraviolet light 166 (UV) with a wavelength of 340-380 nm eliciting light emissions with a wavelength of 435-485 167 nm. Aesthetascs of marine specimens such as of Pagurus bernhardus (Linnaeus, 1758), Carcinus 168 maenas, Xantho hydrophilus, X. poressa and Percnon gibbesi were cut off from the lateral 169 flagella with a razor blade and counted on an object slide using UV-excitation as well as bright 170 field illumination.

\section{Histochemistry, immunohistochemistry, and microscopy}

172 The animals were anaesthetized by cooling on ice for $1 \mathrm{~h}$ before dissection. Following the 173 protocol by Ott (2008), the dissected brains were fixed in toto for approximately 20 hours (room temperature) in $3.7 \%$ formaldehyde/zinc-fixative (the ready-to-use formaldehyde/zinc-fixative was obtained via Electron Microscopy Sciences. Cat. No. 15675). For whole-mount preparations, the brains and eyestalk ganglia were dissected, and the retina including all pigments was removed. The whole-mounts were washed three times in HEPES-buffered saline (HBS) for 15 min, subsequently transferred to Dent's fixative (80 \% methanol / $20 \%$ DMSO), and post-fixated for two hours at room temperature. Specimens were then transferred to $100 \%$ methanol and stored overnight in the refrigerator and rehydrated stepwise for 10 min each in $90 \%, 70 \%, 50 \%$, $30 \%$ methanol in $0.1 \mathrm{M}$ Tris-HCl-buffer, and finally in pure $0.1 \mathrm{M}$ Tris-HCl-buffer ( $\mathrm{pH} 7.4)$. Alternatively, for preparing horizontal brain sections, after anaesthetizing the animals by cooling on ice for $1 \mathrm{~h}$, the brains were dissected and fixed in $4 \%$ paraformaldehyde (PFA) in $0.1 \mathrm{M}$ PBS overnight. The dissected brains were washed for 4 hours in several changes of PBS and sectioned (80 to $100 \mu \mathrm{m}$ sections) horizontally at room temperature using a vibratome (Zeiss Hyrax V590). For permeation of cell membranes, both brain whole-mounts as well as brain sections were then preincubated for 90 minutes in PBS-TX (1 \% Bovine-Serum-Albumine, $0.3 \%$ TritonX-100, 0.05 $\%$ Na-acide, in 0.1 M PBS; pH 7.4). In contrast to the protocol of Ott (2008), PBS-TX was used instead of PBSd-NGS. Finally, the samples were incubated at $4{ }^{\circ} \mathrm{C}$ for $84 \mathrm{~h}$ (whole-mounts) or 
190 191

overnight (sections) in the primary antisera. The following sets of reagents were used (compare Krieger et al. 2012):

Set A: rabbit anti-Dip-allatostatin 1 (AST-A; final dilution 1:2,000 in PBS-TX; antibody provided by H. Agricola, Friedrich-Schiller Universität Jena, Germany); monoclonal mouse anti-synapsin "SYNORF1"antibody (final dilution 1:30 in PBS-TX; antibody provided by E. Buchner, Universität Würzburg, Germany) detected by anti- mouse Cy3 (CyTM3-conjugated AffiniPure Goat Anti-Mouse IgG Antibody, Jackson ImmunoResearch Laboratories Inc.).

Set B: polyclonal rabbit anti-FMRFamid (in PBS-TX; final dilution 1:2,000; Acris/Immunostar; Cat. No. 20091) detected by anti-rabbit Alexa Flour 488 (IgG Antibody, invitrogen, Molecular Probes); monoclonal mouse anti-synapsin "SYNORF1"antibody (in PBS-TX; final dilution 1:30; antibody provided by E. Buchner, Universität Würzburg, Germany) detected by anti- mouse Cy3 (CyTM3-conjugated AffiniPure Goat Anti-Mouse IgG Antibody, Jackson ImmunoResearch Laboratories Inc.).

Set C: monoclonal mouse anti-synapsin "SYNORF1"antibody (in PBS-TX; final dilution 1:30; antibody provided by E. Buchner, Universität Würzburg, Germany) detected by antimouse Alexa Flour 488 (IgG Antibody, invitrogen, Molecular Probes); counterstain: phallotoxins conjugated to Alexa Fluor 546 (Molecular Probes; concentration 200 units $/ \mathrm{ml}$ ) as a high-affinity probe for f-actin.

In all three sets, the tissues were incubated in mixture containing the secondary antisera and the nuclear marker HOECHST (33242;0.1 $\mathrm{\mu g} / \mathrm{ml}$ ) for 2.5 days at $4{ }^{\circ} \mathrm{C}$ (whole-mounts) or for $4 \mathrm{~h}$ at room temperature (sections). Finally, the brain sections were washed for at least 2 hours in several changes of PBS at room temperature and mounted in Mowiol ${ }^{\circledR}$ (Calbiochem) between two coverslips. After secondary antibody incubation, the whole-mounts were dehydrated in changes of ascending glycerol concentrations ( $1 \%, 2 \%, 4 \%$ ( $2 \mathrm{~h}$ each), $8 \%, 15 \%, 30 \%, 50 \%$, $60 \%, 70 \%$, and $80 \%$ (1 h each) glycerol diluted in Tris- $\mathrm{HCl}$ buffer, with DMSO to $1 \%$ final concentration). After the last step of dehydration, the whole-mounts were washed twice for 30 min in $99.6 \%$ denatured ethanol. The ethanol was then underlyed by the same volume of methylsalicylate for clearing of the whole-mount brains. After the brains were cleared, the supernatant liquid was removed and the samples were and then mounted in customized chambers 
220 (a custom washer from the hardware store was glued between two coverslips as spacer) filled 221 with methylsalicylate and sealed with Mowiol®. The triple-labeled and sectioned tissues were 222 analyzed using a Nikon eclipse 90i microscope equipped with a digital camera (Nikon DS2$223 \mathrm{MBWc}$ ). The whole-mounts were analyzed by using a confocal laser scanning microscope (clsm; 224 Leica TCS SP5II). The pictures were then processed using the NIS-Elements AR software and 225 Adobe Photoshop CS4. Only global picture enhancement features of Photoshop elements (black 226 to white inversion, brightness, and contrast) were used for all experiments. Three-dimensional 227 (3D) brain reconstructions in addition to volumetric analysis based on optical section series of 228 clsm data were performed using the reconstruction software Amira ${ }^{\circledR}$ (FEI Visualization Science 229 Group).

Raw data of brain section series will be available on https://www.morphdbase.de under a combination of the short title: "Brachyura_Krieger_2015", and an identifier according to the species and ID of the specimen.

Three-dimensional reconstructions of brains and substructures are based on tomographies of three specimens per species for C. armatum, G. tiomanicum and U. tangeri. For each specimen, surfaces of one DCL including the corresponding olfactory glomeruli and the ipsilateral AcN were generated by manual labeling. Finally, the computed 3D surfaces were slightly smoothed and resulting parameters such as the glomerular number and volume as well as the volume of the whole DCL were analyzed.

\section{Antibody specificity}

\section{Synapsin}

The monoclonal mouse anti-Drosophila synapsin "SYNORF1" antibody (provided by E. Buchner, Universität Würzburg, Germany) was raised against a Drosophila GST-synapsin fusion protein and recognizes at least four synapsin isoforms (ca. 70, 74, 80, and $143 \mathrm{kDa}$ ) in western blots of Drosophila head homogenates (Klagges et al., 1996). In western blot analysis of crayfish homogenates, this antibody stains a single band at ca. $75 \mathrm{kDa}$ (see Sullivan et al., 2007). Harzsch and Hansson (2008) conducted western blot analysis comparing brain tissue of Drosophila and the hermit crab Coenobita clypeatus which is closely related to the species studied in this contribution. The antibody provided identical results for both species, staining one strong band around 80 to $90 \mathrm{kDa}$ and a second weaker band slightly above $148 \mathrm{kDa}$ (see Harzsch \& Hansson, 
250 2008). Their analysis strongly suggests that the epitope which SYNORF 1 recognizes is strongly

251 conserved between the fruit fly and the hermit crab. Similar to Drosophila, the antibody

252 consistently labels brain structures in representatives of all major subgroups of the malacostracan

253 crustaceans (see Beltz et al., 2003; Harzsch, Anger \& Dawirs, 1997; Harzsch et al., 1998, 1999;

254 Harzsch \& Hansson, 2008; Vilpoux, Sandeman \& Harzsch, 2006; Krieger et al., 2010, 2012) in a

255 pattern that is consistent with the assumption that this antibody labels synaptic neuropils in

256 Crustacea. In the crustacean first visual neuropil (the lamina), synapsin labeling is weak

257 compared to the other brain neuropils (Harzsch, Anger \& Dawirs, 1997; Harzsch \& Hansson,

258 2008). Similarly, in Drosophila melanogaster labeling of the lamina is weak, because

259 photoreceptors R1 to R6 which have their synapses in the lamina contain very little of the

260 presently known synapsin isoforms (Klagges et al., 1996). The antibody also labels

261 neuromuscular synapses both in Drosophila and in Crustacea (Harzsch, Anger \& Dawirs, 1997).

262 These close parallels in the labeling pattern of SYNORF1 between Drosophila and various

263 Crustacea strengthen the claim that it also recognizes crustacean synapsin homologues. This

264 antibody even labels synaptic neuropil in an ancestral clade of protostomes, the Chaetognatha

265 (Harzsch \& Müller, 2007) suggesting that the epitope recognized by this antiserum is conserved

266 over wide evolutionary distances.

\section{Allatostatin $\boldsymbol{A}$}

268 The A-type allatostatins (A-ASTs; synonym dip-allatostatins) constitute a large family of 269 neuropeptides that were first identified from the cockroach Diploptera punctata and that share the 270 C-terminal motif -YXFGLamide (reviews Stay, Tobe \& Bendena, 1995; Nässel \& Homberg, 271 2006; Stay \& Tobe, 2007). In decapod crustaceans, almost 20 native A-ASTs and related peptides

272 were initially identified from extracts of the thoracic ganglia of the shore crab Carcinus maenas 273 (Duve et al., 1997), and shortly after several other A-ASTs were isolated from the freshwater 274 crayfish Orconectes limosus (Dircksen et al., 1999). Meanwhile, the family of crustacean A-ASTs 275 has substantially grown to several dozens of representatives (review Christie, Stemmler \& 276 Dickinson, 2010) with additional members being discovered in the prawns Penaeus monodon 277 (Duve et al., 2002) and Macrobrachium rosenbergii (Yin et al., 2006), in the brachyuran crabs 278 Cancer borealis (Huybrechts et al., 2003) and Cancer productus (Fu, Christie \& Li, 2005), 279 Carcinus maenas (Ma et al., 2009a), the crayfish Procambarus clarkii (Yasuda-Kamatani \& 280 Yasuda, 2006), the lobster Homarus americanus (Cape et al., 2008; Ma et al., 2008, 2009b) the 
281 shrimps Litopenaeus vannamei (Ma et al., 2010) as well as a non-malacostracan crustacean, the 282 copepod Calanus finmarchicus (Christie et al., 2008).

283 We used an antiserum that was raised against the Diploptera punctata (Pacific beetle cockroach) 284 A-type Dip-allatostatin I, APSGAQRLYGFGLamide, coupled to bovine thyroglobulin using 285 glutaraldehyde (Vitzthum, Homberg \& Agricola, 1996) that was kindly provided by H. Agricola 286 (Friedrich-Schiller Universität Jena, Germany) and that previously has been used to localize A287 ASTs in crustacean and insect nervous systems (e.g. Vitzthum, Homberg \& Agricola, 1996; 288 Dircksen et al., 1999; Skiebe, 1999; Utting et al., 2000; Kreissl, Strasser \& Galizia, 2010). 289 Competitive ELISA with DIP-allatostatin I, II, III, IV and B2 showed that the antiserum is two 290 orders of magnitude more sensitive to Dip-allatostatin I than to Dip-allatostatins II, III, IV, and 291 B2 (Vitzthum, Homberg \& Agricola, 1996). Vitzthum et al. (1996) have reported that the 292 antiserum displays no cross-reactivity with corazonin, CCAP, FMRFamide, 293 leucomyosuppression, locustatachykinin 11, perisulfakinin, and proctolin as tested by non294 competitive ELISA. Preadsorption of the diluted antisera against Dip-allatostatin I, GMAP and 295 Manduca sexta allatotropin with $10 \mu \mathrm{M}$ of their respective antigens abolished all immunostaining 296 in brain sections of Schistocerca gregaria (Vitzthum, Homberg \& Agricola, 1996). A sensitive 297 competitive enzyme immunoassay (EIA) confirmed the high specificity of the antiserum for A298 type Dip-allatostatin I (Dircksen et al., 1999). In the brains of the honey bee Apis mellifera, 299 preadsorption controls with AST I and AST VI completely abolished all staining of the antiserum 300 (Kreissl, Strasser \& Galizia, 2010). Sombke et al. (2011) repeated a preadsorption test in 301 Scutigera coleoptrata and preincubated the antiserum with $200 \mu \mathrm{g} / \mathrm{ml}$ A-type allatostatin I 302 (Sigma, A9929; $16 \mathrm{~h} 4{ }^{\circ} \mathrm{C}$ ) and this preincubation abolished all staining. Preadsorption of the 303 antiserum with AST-3 was reported to abolish all labeling in the stomatogastric nervous system of 304 the crab Cancer pagurus, the lobster Homarus americanus and the crayfish Cherax destructor 305 and Procambarus clarki (Skiebe, 1999). It seems safe to assume that this antiserum most likely 306 binds to all A-ASTs that share a -YXFGLamide core. However, the term "allatostatin-like 307 immunoreactivity" is used throughout this work, because it may possible that the antibody also 308 binds related peptides.

\section{RFamide-related peptides}

310 The tetrapeptide FMRFamide and FMRFamide-related peptides (FaRPs) are prevalent among 311 invertebrates and vertebrates and form a large neuropeptide family with more than 50 members 312 all of which share the RFamide motif (Price \& Greenberg, 1989; Greenberg \& Price, 1992; 
313 Nässel, 1993; Homberg, 1994; Dockray, 2004; Nässel \& Homberg, 2006; Zajac \& Mollereau, 314 2006). In malacostracan Crustacea, at least twelve FaRPs have been identified and sequenced 315 from crabs, shrimps, lobsters, and crayfish (Huybrechts et al., 2003; Mercier, Friedrich \& Boldt, 316 2003), which range from seven to twelve amino acids in length and most of them share the 317 carboxy-terminal sequence Leu-Arg-Phe-amide. The utilized antiserum was generated in rabbit 318 against synthetic FMRFamide (Phe-Met-Arg-Phe-amide) conjugated to bovine thyroglobulin 319 (DiaSorin, Cat. No. 20091, Lot No. 923602). According to the manufacturer, 320 immunohistochemistry with this antiserum are completely eliminated by pretreatment of the diluted antibody with $100 \mu \mathrm{g} / \mathrm{ml}$ of FMRFamide. Harzsch and Hansson (2008) repeated this experiment in the anomalan Coenobita clypeatus which is closely related to the species studied here, specifically to the hermit crabs, and preincubated the antiserum with $100 \mu \mathrm{g} / \mathrm{ml}$ FMRFamide (Sigma; $16 \mathrm{~h}, 4^{\circ} \mathrm{C}$ ) resulting in a complete abolishment of all staining. Because the crustacean FaRPs know so far all share the carboxy-terminal sequence LRFamide, we conclude that the DiaSorin antiserum that we used most likely labels any peptide terminating with the sequence RFamide. Therefore, we will refer to the labeled structures in our specimens as "RFamide-like immunoreactivity" throughout the paper.

\section{Nomenclature}

330 The neuroanatomical nomenclature used in this manuscript is based on Sandeman et al. (1992) and Richter et al. (2010) with some modifications adopted from Harzsch and Hansson (2008) and Loesel et al. (2013). In favor of a consistent terminology, here we suggest avoiding the term "optic neuropils" (Hanström, 1925; Sombke \& Harzsch, 2015) as well as "optic lobes" (Kenyon, 1896). Even if the Greek "optikos" and the Latin term "visus" have the identical meaning, nowadays, "optic" in the field of visional anatomy and physiology refers to the physically refractive components of the eye for the reception of light. To emphasize the perceptive character of these neuropils, we suggest using the term "visual neuropils" which is consistent with, e.g., the visual cortex in mammals, formerly also termed "optic" cortex (Spiller, 1898). All post-retinal components that are related to vision, such as the "optic tract" and the "inner" as well as the "outer optic chiasm" should be consequently renamed, too. Here, we suggest to use "visual tract" (VT) and the "inner" (iCh) as well as the "outer visual chiasm" (oCh) accordingly. However, for all pre-retinal components that are related to vision, the term "optic", as for example in the 343 dioptric apparatus of the ommatidia, should be maintained. We also discourage the commonly used terms "eyestalk neuropils" (Bliss \& Welsh, 1952; Polanska, Yasuda \& Harzsch, 2007), 
345 “optic ganglia" (Medan et al., 2015), or “eyestalk ganglia” (Harzsch \& Dawirs, 1996; Techa \& 346 Chung, 2015), usually summarizing the visual neuropils as well as the neuropils of the TM/HN347 complex, because these neuropils together can be located more proximal to the central brain and 348 not in the eyestalk in some species, and thus are part of the central brain as exemplified below. 349 Furthermore, the neuropils of the lateral protocerebrum (visual neuropils $+\mathrm{TM} / \mathrm{HN}$-complex) do 350 not fulfill the definition of a ganglion (see Richter et al., 2010). The traditional nomenclature of 351 the visual neuropils lamina ganglionaris, medulla interna, and medulla externa has been modified 352 as suggested by Harzsch (2002) to lamina, medulla, and lobula. Because we could not detect any 353 border between the cell body clusters (9) and (11) of olfactory interneurons as described in 354 Sandeman et al. (1992), we collectively refer to them as cluster (9/11) (see Krieger et al., 2010). 355 The term "oesophageal connective" and the corresponding abbreviation OC (British English) are 356 maintained here for simplicity. The olfactory neuropil (ON or OL) is now named the 357 deutocerebral chemosensory lobe (DCL), and the olfactory globular tract (OGT) is now named 358 the projection neuron tract (PNT) according to Loesel et al. (2013). Consequently, the olfactory 359 globular tract neuropil OGTN is now named projection neuron tract neuropil (PNTN). For 360 simplification, the neuroanatomical descriptions are kept restricted to only one hemisphere of the 361 brain and hold true for all specimens studied if not stated otherwise.

362 The data presented in this study are drawn from different sets of triple-labeling 363 immunofluorescence experiments as laid out above. The localizations of synapsins provides a 364 general labeling of all neuropils in the brain whereas staining of actin is better suited to label 365 neurite bundles and fiber tracts. The two antisera against allatostatin and FMRFamide label 366 specific neuronal subsets and were chosen for a better comparison with other studies that have 367 used the same markers (e.g. Harzsch \& Hansson, 2008; Krieger et al., 2010, 2012). The following 368 abbreviations (color-coded in the figures) identify the markers:

369 SYN synapsin-like immunoreactivity (magenta or black)

370 RFA RFamid-like immunoreactivity (green or black)

371 PHA actin labeling by the use of phalloidin (green or black)

372 AST allatostatin-like immunoreactivity (green or black)

373 NUC nuclear counterstain with HOECHST-dye H 33258 (cyan or black) 


\section{The antennae}

376 In general, the first antennae in brachyuran crustaceans each consists of two branches called the

377 median and the lateral flagellum (Fig. 4). Both flagella are composed of several units, the 378 flagellomeres. Each flagellomere of the lateral flagellum is equipped with one row of the typical 379 unimodal chemosensory sensilla, the aesthetascs, in both marine and terrestrial brachyurans (Fig. 380 5). A quantification of aesthetasc numbers is provided in Tab. 2. The shape of the aesthetascs in 381 marine versus terrestrial brachyurans displays marked differences. In the marine species, the 382 aesthetascs are long and slender, whereas in all species featuring a rather terrestrial lifestyle, they 383 are short and blunt (Fig. 5). The second antennae consist of one articulated branch only, 384 composed of multiple antennomeres, and with the low-resolution light microscopic methods used 385 here, we could not detect any striking differences in the sensillar equipment between the marine 386 and terrestrial representatives (Fig. 6).

387 Table 2.) Morphometric data of structures within the peripheral olfactory pathway and of the 388 primary olfactory centers in the brain of decapod crustaceans

\begin{tabular}{|c|c|c|c|c|c|c|c|c|}
\hline Taxon & Species & $\begin{array}{c}n \\
\text { ind. }\end{array}$ & $\begin{array}{c}\text { Aesth. } \\
\text { number }\end{array}$ & $\begin{array}{c}\text { Aesth. } \\
\text { length } \\
(\mu \mathrm{m})\end{array}$ & $\begin{array}{c}\mathrm{DCL} \\
\text { volume } \\
\left(10^{3} \mu^{3}\right)\end{array}$ & $\begin{array}{c}\text { Glom. } \\
\text { volume } \\
\left(10^{3} \mu \mathrm{m}^{3}\right)\end{array}$ & $\begin{array}{c}\text { Glom. } \\
\text { number }\end{array}$ & Reference \\
\hline \multirow[t]{3}{*}{ Achelata } & Panulirus interruptus & 2 & 1,786 & - & 344,922 & 288 & 1,202 & Beltz et al. (2003) \\
\hline & Panulirus argus & - & - & - & - & - & $\approx 750$ & Blaustein et al. (1988) \\
\hline & Panulirus argus & - & - & - & - & - & $\approx 1100$ & Schmidt \& Ache (1997) \\
\hline Homarida & Homarus americanus & - & - & - & - & - & 90-200 & Helluy et al. (1996) \\
\hline \multirow[t]{3}{*}{ Astacida } & Cherax destructor & 3 & 130 & - & 24,187 & 111 & 230 & Beltz et al. (2003) \\
\hline & Cherax destructor & - & - & - & - & - & $\approx 100$ & Sandeman \& Luff (1973) \\
\hline & Cherax quadricarinatus & 3 & 237 & - & 24,736 & 74 & 334 & Beltz et al. (2003) \\
\hline \multirow[t]{6}{*}{ Anomala } & Pagurus bernhardus & 1 & 736 & $\approx 1,200$ & - & 170 & - & Krieger et al. (2012) \\
\hline & Pagurus bernhardus & - & 673 & - & - & - & 536 & Tuchina et al. (2015) \\
\hline & Coenobita clypeatus & $3(* 1)$ & 519 & *80 -100 & 120,352 & 154 & 799 & Beltz et al. (2003) \\
\hline & Birgus latro & $1(* 2)$ & 1700 & ${ }^{*} 100-200$ & 374,682 & 280 & 1,338 & Krieger et al. (2010) \\
\hline & Birgus latro & 1 & 780 & - & - & - & - & Harms (1932) \\
\hline & Petrolisthes coccnicus & 3 & 328 & - & 12,359 & 19 & 655 & Beltz et al. (2003) \\
\hline Brachyura & Cancer borealis & 2 & 540 & - & 165,731 & 230 & 733 & Beltz et al. (2003) \\
\hline
\end{tabular}




\begin{tabular}{|c|c|c|c|c|c|c|c|}
\hline Carcinus maenas & 1 & 285 & $\approx 700$ & - & 230 & - & Krieger et al. (2012) \\
\hline Xantho hydrophilus & 2 & 206 & $\approx 750$ & - & - & - & this paper \\
\hline Xantho poressa & 2 & 222 & $\approx 600$ & - & - & - & this paper \\
\hline Libinia dubia & 3 & 319 & - & 20,327 & 39 & 454 & Beltz et al. (2003) \\
\hline Percnon planissimum & 3 & 555 & - & 28,765 & 59 & 495 & Beltz et al. (2003) \\
\hline Percnon gibbesi & 2 & 165 & $\approx 700$ & - & - & - & this paper \\
\hline Paragrapsus gaimardii & - & $160-170$ & 600 & - & - & - & Snow (1973) \\
\hline Sesarma sp. & 3 & 33 & - & 6,617 & 15 & 446 & Beltz et al. (2003) \\
\hline Gecarcoidea natalis & $1(* 3)$ & *113 & *100-125 & 9,432 & 49 & 193 & this paper \\
\hline Geosesarma tiomanicum & $3\left({ }^{*} 5\right)$ & *26 & *60-80 & 4,253 & 21 & 61 & this paper \\
\hline Uca tangeri $(q+1)$ & $3\left({ }^{*} 6\right)$ & *38 & ${ }^{*} 90-110$ & 5,355 & $42 \pm 29$ & 64 & this paper \\
\hline Uca tangeri ( & $2(* 3)$ & *36 & & 5,300 & $20 \pm 6$ & 78 & this paper \\
\hline Uca pugnax & 3 & 26 & - & 3,012 & 8 & 374 & Beltz et al. (2003) \\
\hline
\end{tabular}

Note that volumes of DCLs and olfactory glomeruli (glom.) are estimates based on a variety of different neuroanatomical methods (for further information see references). All volumes are averaged for one single structure (one DCL per hemisphere or one average glomerulus), rounded to the nearest $1,000 \mu \mathrm{m}^{3}$, and are thus slightly modified from the original literature. Note that for each individual investigated, the number of aesthetascs (aesth.) per antenna are based on one randomly chosen antenna per pair. The table is compiled after Beltz et al. (2003), Schachtner et al. (2005), and Krieger et al. (2010) and complemented with data of other authors (see reference column) as well as with our own data (in bold) in addition of aesthetasc lengths. Note that the aesthetasc lengths in B. latro (upper range estimated from Stensmyr et al. (2005) and lower range from unpublished data) and C. clypeatus (unpublished data) are estimated based on scanning electron micrographs. Associated subsets of morphometric data apart from the main data set are indicated by asterisks.

\section{The brain}

\subsection{General arrangement of neuropils in the brachyuran brain}

The general morphology of the brachyuran brain, as in other Malacostraca, is composed of three consecutive neuromeres, the proto-, deuto-, and tritocerebrum as extensively reported in previous studies (reviewed in Harzsch, Sandeman \& Chaigneau, 2012; Schmidt, 2015). In some anomalan species, such as Birgus latro or Petrolisthes lamarckii as well as in the axiid shrimp Callianassa australiensis, the bilaterally paired visual neuropils and the neuropils of the terminal 
408 medulla/hemiellipsoid body - complex (TM/HN-complex) are located anteriorly adjacent to the 409 "central" brain as a consequence of elongated axons composing the optic nerve. In all 410 brachyurans studied so far, however, these neuropils are located within the eyestalks, thus being 411 situated at some distance from the central portion of the syncerebrum. Note that in the 412 comparative Fig. 3, for simplicity, only outlines of the central portions of the brains, in the 413 following simply termed the "central brain" - are drawn, without the neuropils of the lateral 414 protocerebrum. In horizontal sections, this central brain appears broader than elongated along the 415 neuraxis (Fig. 3C). The species studied here displayed markedly different carapace widths 416 ranging from $14 \mathrm{~mm}$ in G. tiomanicum up to $90 \mathrm{~mm}$ in G. natalis. In contrast, the general brain 417 dimensions are rather similar across species as indicated by a range of brain width between 1.4 $418 \mathrm{~mm}$ in G. tiomanicum to $2.5 \mathrm{~mm}$ in G. natalis and $2.7 \mathrm{~mm}$ in C. maenas. Hence, there seems to 419 be only a weak correlation between brain size and body size.

420 Contrary to most other decapods analyzed so far (see e.g. Sandeman, Scholtz \& Sandeman, 421 1993), a distinct compartmentalization of the brain neuropils is less obvious in brachyurans. For 422 instance, the neuropil boundaries in true crabs are much less distinct than in Anomala (compare 423 Krieger et al., 2012). However, the general organization of the brachyuran brain and arrangement 424 of its subunits can be deduced from anatomical data by tracing nerves as well as interconnecting 425 tracts between the corresponding neuropils as outlined below:

426 The protocerebral tract (PT) is composed of neurites originating in neuropils of the lateral 427 protocerebrum (IPC). The PT interconnects these neuropils with the proximal part of the brain, 428 the median protocerebrum (mPC). The median protocerebrum is composed of the anterior 429 (AMPN) and the posterior medial protocerebral neuropil (PMPN), which together resemble the 430 shape of a butterfly in horizontal brain sections (compare Figs. 3, 9D, E, 11D, E, 13C-G, 15A-D, 431 16A1-C1, and 17). Both neuropils are almost completely fused anterioposteriorly as well as 432 across the midline with their contralateral counterparts into one single neuropil mass in the 433 brachyuran brain, but they appear separated in horizontal sections at the level of the central body 434 (Figs. 11E-F, 13D, 15B, F). Furthermore, the median protocerebrum includes neuropils of the 435 central complex, namely from anterior to posterior: the unpaired protocerebral bridge (PB), the 436 unpaired central body (CB), and the bilaterally paired lateral accessory lobes (Lals).

437 In all brachyuran species investigated, the neuropils of the deutocerebrum (DC) that extend 438 posteriorly adjacent to the median protocerebrum consist of the unpaired median antenna I 439 neuropil (MAN), the bilaterally paired antenna I neuropils (LANs), the deutocerebral 
440 chemosensory lobes (DCLs; formerly referred as olfactory lobes or olfactory neuropils), the

441 accessory lobes (AcNs) and the projection neuron tract neuropils (PNTNs; formerly referred as 442 olfactory globular tract neuropils or OGTNs). Each DCL consists of several to hundreds of 443 barrel-shaped subunits of synaptic neuropil, the olfactory glomeruli (OG) which are arranged in a 444 radial, palisade-like array in the periphery of the lobe. Medially to each DCL, a cluster of somata 445 (9/11) of hundreds of interneurons of varying sizes is present. These neurons extend neurites 446 which enter the DCL via the median foramen $(\mathrm{mF})$, one of three gaps in the palisade-like array of 447 olfactory glomeruli. Furthermore, several hundreds of somata of olfactory projection neurons are 448 grouped in cell cluster (10) posteriorly to each DCL. Their neurites enter each DCL via the 449 posterior foramen $(\mathrm{pF})$, innervate the olfactory glomeruli, and project axons that exit each lobe 450 via its median foramen $(\mathrm{mF})$ in a large bundle that constitutes the projection neuron tract (PNT). 451 The axons of the PNT interconnect each DCL with the ipsilateral as well as contralateral 452 hemiellipsoid body within the lateral protocerebrum by forming a chiasm dorsally of the central 453 body.

454 The tritocerebrum (TC) posteriorly adjoins the neuropils of the deutocerebrum and is composed 455 of the bilaterally paired antenna II neuropils (AnNs) and further dorsally, of the tegumentary 456 neuropils (TNs).

2.2 Lateral protocerebrum: The visual neuropils and the terminal medulla/hemiellipsoid body complex (TM/HN-complex)

The eyestalks of most malacostracan crustaceans each contain three successive retinotopic neuropils. These three main visual neuropils process visual input and from distal to proximal are termed the lamina, medulla, and lobula. An additional (fourth) neuropil can be found adjacent to the lobula referred to as lobula plate. If present, the lobula plate adheres the lobula. The architecture of these visual neuropils which often are referred to as optic neuropils is best known in crayfish and lobsters (review Harzsch et al. 2012) but was also analyzed in a number of marine and amphibious brachyurans including Chasmagnathus granulatus, Hemigrapsus oregonensis 466 (Sztarker, Strausfeld \& Tomsic, 2005; Sztarker et al., 2009; Berón de Astrada, Medan \& Tomsic, 467 2011; Berón de Astrada et al., 2013), and Carcinus maenas (Elofsson \& Hagberg, 1986; Krieger 468 et al., 2012). Although the visual neuropils are not the focus of the present study, successful 469 eyestalk preparations from C. armatum (Fig. 7A-D), G. natalis (Fig. 9A-C), G. tiomanicum (Fig. $47011 \mathrm{~A}, \mathrm{~B})$, and $U$. tangeri (Fig. 13A) show that these terrestrial species display well developed 
471 visual neuropils that show distinct synapsin-like immunoreactivity (SYN). Distinct clusters of

472 somata become clearly visible distal to each visual neuropil. According to their appearance from

473 distal to proximal and based on nuclear counterstaining, we distinguish cluster (1) associated with

474 the lamina; cluster (2) associated with the medulla; cluster (3) associated with the lobula (Fig.

475 7A, 9A, 11A, 13A). Their arrangement and layered architecture closely correspond to those of

476 their marine relatives. In the lobula, we could resolve three main layers in all four species (Fig.

$4777 \mathrm{~B}, 9 \mathrm{~B}, 11 \mathrm{~A}, 13 \mathrm{~A})$ suggesting that at the level of resolution we analyzed, the visual neuropils

478 show a high level of similarity.

479 The most proximal neuropils of the lateral protocerebrum, the terminal medulla (TM; also termed 480 medulla terminalis) and the hemiellipsoid body $(\mathrm{HN})$, which are considered multimodal 481 associative areas (Wolff et al., 2012), are located within the eyestalk and together constitute an 482 almost spherical neuropil mass (TM/HN-complex) in the species studied. They are identifiable in 483 preparations of C. armatum (Fig. 7A-E), G. natalis (Fig. 9A-C), G. tiomanicum (Fig. 11A-C2), 484 and $U$. tangeri (Fig. 13A-B) showing distinct SYN, but were also described in Chasmagnatus 485 granulatus (Berón de Astrada \& Tomsic, 2002), Hemigrapsus oregonensis (Sztarker, Strausfeld $486 \&$ Tomsic, 2005), and C. maenas (Krieger et al., 2012). A clear distinction between these two 487 neuropils is difficult because they are tightly adjoined. Therefore, a comparative volumetric 488 analysis was impractical. Nevertheless, our preparations indicate that in $U c a$, the TM/HN489 complex is markedly smaller in diameter compared to all other crabs being analyzed (compare 490 Fig. 13A with Figs. 7A-E, 9A-C, 11A-B). A compartmentalization of the hemiellipsoid body into 491 one cap and 1-2 core neuropil masses is obvious in G. natalis (Fig. 9C) and in G. tiomanicum 492 (Fig. 11B-C2), whereas such a subdivision could not be resolved in the other crabs analyzed. 493 According to Sandeman et al. (1992), each of these neuropils is associated with a cluster of 494 neurons, namely cluster (4), which is located closely to the terminal medulla and cluster (5), 495 which is adjacent to the hemiellipsoid body in decapods and contains hundreds of interneurons of 496 minute diameter. However, in the brachyurans studied, a clear separation of these two clusters 497 was impossible. Rather, the TM/HN -complex is surrounded by a confluent cortex of somata 498 which therefore will be referred to as cluster (4/5) here (Figs. 7C, 9C, 11B, 13A-B). 
500 The median protocerebrum is composed of the closely fused AMPN and PMPN and appears 501 broader than long. In all brachyuran crabs studied, it has a butterfly-shape in horizontal sections 502 (Fig. 3C). The AMPN and the PMPN are identifiable by showing distinct SYN (Figs. 7F, H-J, 503 9D-E, 11D-F, 13C-E, 15A-D, 16A1-C2, and 17), weaker RFA (Figs. 11D-F, 13D-E, G, 16A1-C2, 504 and 17) and AST in the periphery (Figs. 9D-E, 15A-D, 17). Although allatostaninergic and 505 RFamidergic fibers innervate the whole brain, the V-shaped protocerebral bridge (PB) and 506 especially the cylindrical or cigar-shaped central body (CB) further posteriorly show the densest 507 RFA as well as AST (Figs. 7F-I, 9E, 11D-F, 13D, G, 15A-D, 16A2-C2, 18) besides distinct SYN 508 (Figs. 7H-J, 9E, 11E-F, 13D-E, 15A-D, 16A2-C2, 17). In sections at the level of the CB, the 509 separation of the AMPN from the PMPN becomes visible (Figs. 7H, 9E, 11F, G, 13D, F, 15B, 510 17). Anterior to the PB, the nuclear marker reveals hundreds of somata of varying diameters (5$51110 \mu \mathrm{m}$ in all species studied) that are grouped within the cell cluster (6). This cluster also 512 comprises a subset of few somata with a markedly larger diameter that display distinct RFA 513 (diameters approx. $30 \mu \mathrm{m}$ in C. armatum, $25 \mu \mathrm{m}$ in G. tiomanicum, and $20 \mu \mathrm{m}$ in U. tangeri) and 514 AST (approx. $30 \mu \mathrm{m}$ in E. sinuatifrons and G. natalis). The neuropils of the median 515 protocerebrum are regularly pierced by blood vessels of the circulatory system (e.g. the cerebral 516 artery (CA); Figs. 9D-E, 11D, F, 13C, E) and by large tracts of neurites (e.g. the projection 517 neuron tract (PNT); Figs. 7H, 9D, 11D-G, 13C-E, G, 15B, D, 16A1, B1-2) and can be inferred 518 from the negative imprint due to the absence of immunoreactivity against the tested antisera. The 519 projection neuron tract consists of neurites of olfactory projection neurons whose cell bodies are 520 located in the somata clusters (10) situated posterior-lateral to each DCL. These neurites connect 521 each DCL to the ipsilateral as well as the contralateral TM/HN-complex within the lateral protocerebrum and constitute a chiasm dorsally to the central body. The cerebral artery (CA) 523 located between median protocerebrum (posterior to the PMPN) and deutocerebrum (anterior to 524 the median antenna I neuropil) is identifiable by the nuclear counterstain of the perivascular cells (Figs. 9D-E, 11F, 13F, 15A-B) in horizontal sections. The dorsoventral course of the CA through 526 the central brain could be confirmed in all crabs as it has been shown for C. maenas (Sandeman, 527 1967) but not its ramifications. 
531 displaying distinct SYN as well as AST and RFA. The border between PMPN and MAN is rather

532 confluent but is identifiable due to the clear position of the CA (compare Fig. 9D and E).

533 Besides the deutocerebral chemosensory lobe (DCL) and the accessory lobe (AcN), other 534 neuropils of the lateral deutocerebrum can be found within the confluent mass of the central brain 535 composed of parts of the proto-, deuto- as well as the tritocerebrum (compare Fig. 17) such as the 536 lateral antenna I neuropil (LAN; Figs. 7F, 9D, 11D, 13D-E, 15B) and in a few preparations, the 537 projection neuron tract neuropil (PNTN; Figs. 15B, 16A1). However, a complete, in-depth 538 reconstruction of their definite outlines remains challenging. In all species investigated, the AcN 539 and, in particular the DCL are the most delimited structures within the otherwise confluent 540 brachyuran brain. The DCL is composed of several dozens (60-80 in G. sesarma, U. tangeri and 541 C. armatum up to almost 200 in G. natalis - see Tab. 2 for further information) of barrel-like to 542 conical cardridges, termed olfactory glomeruli (OG), of varying sizes (see Fig. 18). From a 543 limited number of investigated specimens of $U$. tangeri, it appeared that in two males analyzed 544 the number of olfactory glomeruli exceeded that of one female by a factor of ca. 2 (36 OG in $q$ 545 versus $76-80$ OG in $\widehat{\jmath}$ ), whereas the males featured approximately a third of the average female 546 glomerular volume (see Tab. 2) resulting in an almost equal volume of the entire DCL in both 547 sexes. In all marine brachyuran species studied, the numbers as well as the average volumes of 548 olfactory glomeruli markedly exceed those of the co-studied terrestrial brachyurans (Tab. 2, Fig. 549 18), though the general brain dimensions are somewhat similar (see Figs. 3 and 17). In brain sections of aquatic representatives of Brachyura (in the four exclusively marine; and to some

551 degree, in the freshwater species E. sinuatifrons), the olfactory glomeruli are larger and more 552 elongated compared to those of the terrestrial species studied here. A clear regionalization of each 553 olfactory glomerulus into a cap, a subcap, and a base region (from the periphery of the DCL to its 554 center) appears more pronounced in aquatic brachyurans than in the terrestrial species (Fig. 18). 555 The cap and base regions show stronger SYN (Fig. 8A, D1, 14E, 15E, 16A1, B1, 17 and 18) than 556 the subcap region in these species. In a subset of experiments, the subcap region shows distinct 557 RFA, but RFA is weaker in the base region and is absent in the cap region (i.e. in P. gibbesi, X. 558 hydrophilus, X. poressa, U. tangeri; Fig. 18A-B), whereas the subcap region shows the most 559 distinct AST and becomes absent towards the base region in each OG (in E. sinuatifrons, Fig. 560 18A-B; G. natalis, not shown; and in C. maenas, see Krieger et al., 2012). Anteriomedial to the 561 median foramen of each DCL, the accessory lobe $(\mathrm{AcN})$ becomes visible, consisting of dozens of 562 microglomeruli that show distinct SYN but widely lack RFA as well as AST. The diameter of the 563 almost spherical AcN ranges from $50 \mu \mathrm{m}$ (in U. tangeri, X. hydrophilus, X. poressa, and $P$. 
564 gibbesi; Figs. 14A, D-E, 16A3-C3) up to $100 \mu \mathrm{m}(75 \mu \mathrm{m}$ in C. armatum, $100 \mu \mathrm{m}$ in G. natalis as

565 well as G. tiomanicum; Figs. 7F, 8A, E, 9D, 10C, 12A, D, and F). Further medial and between the

566 PMPN and the AcN, a somata cluster of hundreds of interneurons (ca. 5-8 $\mu \mathrm{m}$ in diameter) 567 appears. This cell cluster (9/11) is clearly revealed by the nuclear counterstaining (Fig. 8C, 9E, 568 10A, E, 15B) and contains subpopulations of several to dozens of allatostatinergic (Fig. 9E, 15B) 569 and RF-amidergic interneurons (Figs. 7G, 12A-C, 13D-E, 16A1, A3, B1) that are markedly larger 570 in diameter (from $12 \mu \mathrm{m}$ in $U$. tangeri; and $16 \mu \mathrm{m}$ in $X$. hydrophilus; up to $30 \mu \mathrm{m}$ in $G$. 571 tiomanicum; i.e. see Fig. 12C). Neurites of cell cluster (9/11) enter each DCL via the median 572 foramen (mF; Figs. 7F, 8C, 10B, 12B, 14A-C, 15B, 16A1, B1, and 17). Lateroposterior to each 573 DCL, a group of hundreds to thousands of olfactory projection neurons house their somata within 574 cell cluster (10). These neurites of projection neurons enter the DCL via the posterior foramen 575 (pF; Figs. 8B-C, 9D, 10D, 12C, 14B-C, 15B), connect with the olfactory glomeruli, exit the DCL 576 via the median foramen (Figs. 8C, 12B, 14C, 15B, 16A1, B1, 17), and finally project to the 577 ipsilateral as well as the contralateral TM/HN-complex by forming a chiasm at the dorsal level of 578 the central body (not shown). The entirety of neurites of projection neurons constitute the 579 projection neuron tract (PNT) whose somata are housed within cell cluster (10). According to its 580 position, the projection neuron tract neuropil (PNTN) becomes visible medial to the $\mathrm{mF}$ in a few 581 preparations showing distinct SYN (Fig. 15B, 16A1, 17).

The tritocerebral antenna II neuropil (AnN) and further dorsally the tegumentary neuropil (TN) compose the posteriormost parts of the central brain, being located anterolaterally to the esophagus. An identification of the neuropil borders is difficult due to their confluent connection to the deutocerebrum. The $\mathrm{AnN}$ that receives chemosensory as well as mechanosensory input from the second antenna, is identifiable in a few preparations by tracing back the course of the antenna II nerve $\left(\mathrm{A}_{\mathrm{II}} \mathrm{Nv}\right.$; Fig. 9D-E). Since we were unable to trace back the course of the presumably thin tegumentary nerve $(\mathrm{TNv})$, the precise position and shape of the tegumentary 590 neuropil remains uncertain.

\section{Discussion}


592 In this study, we compare the neuroanatomy of the brain in four brachyurans that display different

593 levels of terrestrial adaptations using the antisera against presynaptic proteins, the neuropeptides

594 FMRFamide, and allatostatin as well as markers for actin and DNA. In the following, we will

595 compare and discuss the results of these four brachyuran species with each other as well as with

596 one freshwater and four marine brachyurans. Special attention is given to the primary olfactory

597 system and related structures to highlight differences between terrestrial brachyurans and their 598 aquatic relatives.

599 In contrast to other reptant Malacostraca such as Anomala, which display a clear separation of 600 their deutocerebral neuropils (e.g. Harzsch \& Hansson, 2008; Krieger et al., 2010, 2012), these 601 neuropils are widely confluent and therefore often become indistinguishable in brachyurans.

602 Sandeman, Scholtz and Sandeman (1993) and Krieger et al. (2012) discussed the possible 603 connection between brain "condensation", the fusion of synaptic neuropils, and evolutionary 604 success in these groups. The condensation of nervous tissue may have coincided with a process 605 that is sometimes called "carcinisation" (Borradaile, 1916), or "brachyurisation" (Števčić, 1971). 606 These synonyms circumscribe a hypothesis of how the condensed crab shape may have 607 developed (McLaughlin \& Lemaitre, 1997), both concerning the overall brachyuran habitus as 608 well as internal consolidation of organs like the fusion of the first three ganglia of the ventral 609 nerve cord into one joint complex (Števčić, 1971). According to Števčić (1971), it was also 610 assumed that this process mainly leads to a more complex behavior and better coordination in 611 semiterrestrial and terrestrial crabs, since neuropil condensation and shortening of connections 612 within the central nervous system may improve the performance of the system, e.g., in terms of 613 processing speed. The fusion is most conspicuous in the posterior part of the brain, where the 614 neuropils of the deutocerebrum adjoin those of the tritocerebrum.

\section{Visual ecology and the protocerebrum}

616

617 Terrestrial brachyurans have been prime examples to study visual ecology in crustaceans 618 (reviews by Zeil \& Hemmi, 2006, 2014; Hemmi \& Tomsic, 2012). Visual orientation has been 619 very well studied in members of the genus Uca but poorly in any of the other ocypodid species 620 (Zeil \& Hemmi, 2014 and references therein). Field experiments for individuals of U. tangeri 621 have shown that they can recognize predators at greater distance, triggering an escape behavior. 
622 In addition, the animals react to their own mirror image and can visually distinguish the gender of 623 their conspecifics (Altevogt, 1957, 1959; von Hagen, 1962; Korte, 1965; Land \& Layne, 1995; 624 Zeil \& Al-Mutairi, 1996). Representatives of the genus Uca can also distinguish colors (Korte, 625 1965; Hyatt, 1975; Detto, 2007), which is an important factor for social interactions (Detto et al., 626 2006; Detto, 2007). Ultraviolet light, for example, is reflected by the claw of Uca-males which 627 attracts females (Detto \& Backwell, 2009). Aspects of homing and path integration were also 628 thoroughly analyzed in members of the genus Uca (e.g Hemmi \& Zeil, 2003; Layne, Barnes \& 629 Duncan, 2003a,b; Walls \& Layne, 2009). Clearly, vision plays an essential role in the ecology of $630 U c a$.

631 In all species examined here, the neuropils of the lateral protocerebrum are located within the 632 eyestalks in some distance to the central brain (compare Sandeman et al., 1992; Sandeman, 633 Scholtz \& Sandeman, 1993). In this study, the three visual neuropils (lamina, medulla, and 634 lobula) could be identified in all individuals of the different species, and their location and 635 anatomy matches that of other described brachyuran species (Tsvileneva, Titova \& Kvashina, 636 1985; Sandeman et al., 1992; Sandeman, Scholtz \& Sandeman, 1993; Sztarker, Strausfeld \& 637 Tomsic, 2005; Sztarker et al., 2009; Krieger et al., 2012; Berón de Astrada et al., 2013). However, 638 the small lobula plate, the fourth visual neuropil, could not be found in any of the analyzed 639 species, most likely because of technical difficulties but was previously identified in other 640 brachyuran species such as Chasmagnathus granulatus, Hemigrapsus oregonensis (Sztarker, 641 Strausfeld \& Tomsic, 2005; Sztarker et al., 2009) and C. maenas (Krieger et al., 2012). The 642 terminal medulla (or medulla terminalis) and the hemiellipsoid body are considered to function as 643 secondary higher-order neuropils (Wolff et al., 2012; Wolff \& Strausfeld, 2015). They integrate 644 different modalities such as visual and olfactory information that were already preprocessed in 645 the primary sensory brain centers (visual neuropils and deutocerebral chemosensory lobes; 646 reviewed in Schmidt, 2015). Furthermore, the TM/HN-complex receives input from the ventral 647 nerve cord (VNC) and other regions of the central brain. The terminal medulla and especially the 648 hemiellipsoid body are also referred to as centers of learning and memory that functionally 649 correspond to the mushroom bodies in hexapods. For the brachyurans studied here, there were 650 only few species-specific differences visible in our preparations. We conclude that all terrestrial 651 brachyurans examined here have well developed visual neuropils. Thus, they possess a neuronal 652 substrate for a sophisticated analysis of the compound eye input. Therefore, as in their marine 
653 counterparts, visual cues most likely play important roles in the terrestrial brachyurans' behaviors

654 such as food search, mating, and orientation.

655 Chemical senses: the peripheral olfactory pathway

656 It is well established that marine crustaceans use chemical cues to locate mates, signal 657 dominance, recognize individual conspecifics, find favored foods and appropriate habitats, and 658 assess threats such as the presence of predators (reviews e.g. Derby et al., 2001; Grasso \& Basil, 659 2002; Derby \& Sorensen, 2008; Thiel \& Breithaupt, 2011; Wyatt, 2011; Derby \& Weissburg, 660 2014). Malacostracan crustaceans that live in aquatic habitats use several systems for detecting 661 chemicals, and these are distributed over their body surface, walking appendages, and 662 mouthparts. We will focus our discussion on those sensilla concentrated on the two pairs of 663 antennae (reviews e.g. Hallberg, Johansson \& Elofsson, 1992; Hallberg \& Skog, 2011; Schmidt $664 \&$ Mellon, 2011). The first antennal pair (the antennules) is equipped with specialized olfactory 665 sensilla (aesthetascs) in addition to bimodal chemo- and mechanosensilla, functioning as contact666 chemoreceptors, whereas the second pair of antennae is only equipped with the latter. The tips of 667 the first antennae (more specifically the lateral flagellum) bear a tuft region with arrays of 668 aesthetascs that house branched dendrites of olfactory sensory neurons (reviews by Hallberg, 669 Johansson \& Elofsson, 1992; Hallberg \& Hansson, 1999; Mellon, 2007; Hallberg \& Skog, 2011; 670 Schmidt \& Mellon, 2011; Derby \& Weissburg, 2014). There are multiple studies on the 671 ultrastructure of these aesthetascs (e.g. Ghiradella, Case \& Cronshaw, 1968a,b; Snow, 1973; 672 Wasserthal \& Seibt, 1976; Tierney, Thompson \& Dunham, 1986; Spencer \& Linberg, 1986; 673 Grünert \& Ache, 1988; Gleeson, McDowell \& Aldrich, 1996), but unfortunately none of these studies includes any of the species analyzed in the present work.

675 We observed that all four terrestrial brachyurans studied here have shorter antennae in relation to their body sizes, and feature markedly fewer and shorter aesthetascs compared to their marine relatives (Tab. 2; Fig. 3A, B, 4-5). These findings suggest that possessing short and hidden first antennae equipped with few, short, and blunt aesthetascs seems to be a shared feature and most likely a specific adaptation in all terrestrial brachyurans. We suggest that this feature may be an adaptation to minimize water loss across the cuticle. Furthermore, a typical marine (brachyuran) array of long and slender aesthetascs will likely collapse out of water and most likely will be non-

682 functional on land. Studies on other terrestrial crustacean taxa such as representatives of the 683 Isopoda and Anomala support the idea that all terrestrial crustaceans share a size reduction of 
684 antennal sensilla including the aesthetascs (compare Hansson et al., 2011). The aesthetascs of 685 terrestrial hermit crabs of the taxon Coenobitidae, for example, display striking differences to 686 those of marine hermit crabs in that they appear short and blunt (compare Ghiradella, Case \& 687 Cronshaw, 1968; Stensmyr et al., 2005). In robber crabs, Birgus latro, the largest known land 688 arthropods, they are confined to the ventral side of the primary flagella and are flanked by 689 presumably bimodal contact-chemoreceptive sensilla. A preliminary analysis using classical 690 histology and transmission electron microscopy (TEM) revealed that, in contrast to marine 691 crustaceans, the aesthetascs of Coenobitidae have an asymmetric profile, with the protected side 692 lined with a thick cuticle (Tuchina et al., 2015). The exposed side is covered with a thinner 693 cuticle, a feature that most likely is necessary to enable the passage of odors (Stensmyr et al., 694 2005). These and other morphological features were interpreted as mechanisms to minimize 695 water evaporation while maintaining the ability to detect volatile odorants in gaseous phase 696 (Stensmyr et al., 2005). Furthermore, antennal olfaction at least in coenobitids is assumed to 697 depend on activity of the asthetasc-associated epidermal glands discharging their secretion to the 698 base of related aesthetascs. By the aid of the mucous secretion covering the entire thinner cuticle, 699 aesthetascs are provided with a moist, sticky layer essential for binding, sampling, and finally 700 perceiving (after transcuticular passage) volatile odors (Tuchina et al., 2014).

701 However, in terrestrial Anomala, contrary to terrestrial Brachyura, the first antennae are 702 extensively enlarged and the number of aesthetascs markedly increased as compared to marine 703 representatives (Tab. 2), and there is evidence that Coenobitidae may have evolved good 704 terrestrial olfactory abilities (Greenaway, 2003). In fact, behavioral studies have suggested that 705 these animals are very effective in detecting food from a distance and in responding to volatile 706 odors (Rittschof \& Sutherland, 1986; Vannini \& Ferretti, 1997; Stensmyr et al., 2005). These 707 omnivorous crabs are attracted by volatiles emitted by many different sources such as seawater, 708 wellwater, distilled water (Vannini \& Ferretti, 1997), crushed conspecifics or snails (Thacker, 709 1994), fruits, seeds, flowers (Rittschof \& Sutherland, 1986; Thacker, 1996, 1998), and finally 710 even horse faeces and human urine (Rittschof \& Sutherland, 1986). By conducting a two-choice 711 bioassay with Coenobita clypeatus using an arena with a centrally placed shelter with two pit712 falls on each side, Krång et al. (2012) found that the animals were strongly attracted to natural 713 odors from banana and apple. Furthermore, wind-tunnel experiments with C. clypeatus suggest 714 that these animals display a behavior that may be described as odor-gated anemotaxis (Missbach, 715 Krieger, Harzsch, Hansson; unpublished results). Furthermore, electrophysiological studies using 
716 electroantennograms in $B$. latro confirmed that the aesthetascs respond to volatile substances

717 (Stensmyr et al., 2005). In aquatic crustaceans, antennular flicking enhances odorant capture by 718 shedding the boundary layer (Koehl, 2011; Reidenbach \& Koehl, 2011; Mellon Jr. \& Reidenbach, 719 2012). Coenobitidae also show flicking behavior similar to that seen in their marine relatives, 720 thus maximizing odor sampling (Stensmyr et al., 2005). Mellon and Reidenbach (2012) 721 suggested that considering the higher kinematic viscosity of air versus water and the resulting 722 lower Reynolds numbers, the aesthetascs of Coenobitidae nevertheless operate in a range where 723 boundary layer shedding could be effectively achieved by antennular flicking. Taken together, 724 these behavioral and morphological observations suggest that terrestrial Anomala evolved aerial 725 olfaction and actively use their first pair of antennae to detect volatile odors.

726 In contrast to this highly sophisticated olfaction-related behavior of Coenobitidae, our limited 727 observations in the laboratory of the terrestrial brachyurans C. armatum, G. tiomanicum, and $U$. 728 tangeri suggest that their first pair of antennae extended and that flicking behavior occurred only 729 if animals were immersed in water but the antennae were not exposed to the air. This holds also 730 true for the second pair of antennae, except for Uca tangeri. In Gecarcoidea natalis, we did not 731 observe that the first as well as the second pair of antennae were exposed in their terrestrial 732 habitat as observed in three field trips to Christmas Island (Krieger, Drew, Hansson, Harzsch; 733 unpublished observations). These animals enter the water only during the spawning season 734 (Orchard, 2012). As laid out above, crabs orient very well on land, and many studies have 735 suggested vision to be the dominating sense in terrestrial Brachyura. Our morphological results 736 and preliminary behavioral observations suggest that, contrary to Anomala, the detection of 737 volatile substances plays only a minor role in the sensory ecology of Brachyura while on land. If 738 it holds true that the first antennae in brachyurans are only functional in an aquatic environment, 739 we may expect to see this reflected in the organization of primary processing areas within the 740 brain. With respect to the critical cost-benefit ratio of maintaining the highly energy-demanding 741 nervous tissue, providing processing capacities for poorly used sensory modalities may be too 742 costly, so that these brain areas become reduced during evolution.

\section{Chemical senses: the central olfactory pathway}

744 The chemosensory neurons associated with the aesthetascs versus the bimodal non-aesthetasc 745 sensillae (contact-chemoreceptors) on the first antennae of malacostracan crustaceans innervate 746 distinct regions in the brain (see review of Schmidt \& Mellon, 2011; Derby \& Weissburg, 2014). 
747 The axons of the olfactory sensory neurons (OSNs) associated with the aesthetascs target the 748 deutocerebral chemosensory lobes (in our previous studies termed olfactory lobes), whereas the 749 axons associated with non-aesthetasc sensilla innervate the lateral antenna 1 neuropil (LAN; for 750 other crustacean chemosensory systems see Schmidt \& Mellon, 2011). For all species studied in 751 this paper, the deutocerebral chemosensory lobes of the deutocerebrum, the accessory neuropils, 752 the lateral antenna I neuropil and the median antenna I neuropil were well identifiable. Their 753 structure and arrangement corresponds to that described in other Brachyura (Sandeman et al., 754 1992; Krieger et al., 2012). Also, the projection neuron tract and the cerebral artery could be 755 depicted as characteristic landmarks. In all species investigated, the deutocerebral chemosensory 756 lobes (DCL) share the typical malacostracan organization, featuring a radial array of barrel- to 757 wedge-shaped olfactory glomeruli that form the thick synaptic layer of the lobe, with their apices 758 pointing inwards (compare Schachtner, Schmidt \& Homberg, 2005; Schmidt \& Mellon, 2011). 759 Although the DCLs of the species studied here have a similar overall organization, the relative 760 size of the DCL to the central brain displays the most striking difference between aquatic and 761 terrestrial brachyurans. While in all aquatic brachyurans studied, the DCLs are comparably large, 762 they are conspicuously much smaller within terrestrial brachyurans, an observation also made in 763 the land crab Chiromantes haematocheir (Honma et al., 1996). This relation also applies to the 764 number and size (length especially) of olfactory glomeruli which are higher in all aquatic 765 brachyuran species studied (see Tab. 2). These morphological aspects seem to be strongly 766 correlated with the reduction of aesthetasc number and size as discussed above and therefore may 767 represent another adaptation to terrestrialization (compare Fig. 17 and 18). However, a linear 768 correlation between the number of aesthetascs and number of olfactory glomeruli could not be 769 identified here, which is in accordance with the varying convergence ratios 770 (aesthetascs/glomeruli) reported by Beltz et al. (2003). In summary, morphometric quantifications 771 of neuronal structures have indeed to be considered as rough estimates to infer sensory 772 processing performance of a species, and the species-dependent lifestyles play of course a large 773 role for the evaluation of olfactory capacity.

774 Although we have analyzed admittedly only few specimens (two males and one female), our 775 findings nevertheless hint at a sexual dimorphism of the DCL of $U$. tangeri. In addition to 776 numerous reports of sexual dimorphism of insect brains (e.g. Koontz \& Schneider, 1987; 777 Homberg, Christensen \& Hildebrand, 1989; Rospars \& Hildebrand, 2000; Jundi et al., 2009; 778 Streinzer et al., 2013; Montgomery \& Ott, 2015) especially of the primary olfactory system, such 
779 a sexual dimorphism in crustaceans is well described from the DCLs in Euphausidacea and 780 Mysidacea (Johansson \& Hallberg, 1992). Furthermore, Loesel (2004) suggested a sexual 781 dimorphism in central body architecture in the genus Uca. However, further investigation of 782 sexual dimorphic features within the brain of crustaceans is crucial to understand the general 783 principles in crustacean communication and their underlying structures. Their pronounced sex784 specific external morphology regarding courtship behavior (e.g. the conspiciuous heterochely and 785 eye stalk extensions in males) indicates that representatives of the genus Uca can serve as 786 favorable study organisms to explore such aspects.

787 It has been well documented in aquatic malacostracans including crayfish, clawed and clawless 788 lobsters, marine brachyurans, and hermit crabs (Schachtner, Schmidt \& Homberg, 2005; Schmidt 789 \& Mellon, 2011; Krieger et al., 2012; Polanska et al., 2012) that the olfactory glomeruli are 790 regionalized along their long axis to provide an outer cap, a subcap, and a base region. The 791 subcap region of decapod olfactory glomeruli displays another level of subdivision when viewed 792 in cross-sections and is separated into a central rod, a core region, and an outer ring. These 793 patterns of subdivision of decapod olfactory glomeruli have been suggested to mirror a functional 794 subdivision (Schmidt \& Ache, 1997). Such a regionalization was not very obvious in the 795 terrestrial brachyuran glomeruli which we analyzed. In conclusion, it seems obvious that the 796 reduced sensory input to the deutocerebral sensory lobe in terrestrial brachyurans decreases the 797 processing demands in the system, which in turn is reflected in the small size of olfactory 798 glomeruli in addition to the lowered structural and functional complexity therein. These findings 799 are also supported by the behavioral observations described above and support the idea that, 800 while on land, olfaction is subordinate to vision in brachyurans. Along these lines, 801 neuroanatomical studies of the olfactory system in marine versus terrestrial isopod crustaceans 802 also suggested that in the terrestrial animals the deutocerebral chemosensory system has lost 803 some of its importance during the evolutionary transition from water to land (Harzsch et al., 804 2011; Kenning \& Harzsch, 2013).

805 Contrarywise, neuroanatomical studies analyzing the central olfactory pathway in terrestrial 806 Anomala including Coenobita clypeatus (Harzsch \& Hansson, 2008; Polanska et al., 2012; Wolff 807 et al., 2012), and Birgus latro (Krieger et al., 2010) in comparison to several marine anomalan 808 taxa of the subgroup Paguroidea (Krieger et al., 2012) suggested that in both terrestrial species, 809 the primary olfactory centers targeted by antenna 1 aesthetasc afferents strongly dominate the 
810 brain and display conspicuous side lobes that are not present in the marine representatives,

811 suggesting that a significant elaboration of brain areas involved in olfactory processing has taken

812 place. The DCLs are markedly enlarged, and the number of olfactory glomeruli is increased 813 compared to other marine anomalans studied (Tab. 2).

\section{The tritocerebrum: antenna II neuropil and flow detection}

815 In arthropods, the detection of flow is essential for tracking odor sources but also for anemotaxis, 816 and in crustaceans, antenna 2 most likely plays a major role in detecting flow. In many 817 malacostracan crustaceans, the second pair of antennae bear mostly mechanosensory sensilla as 818 well as bimodal chemo- and mechanosensory sensilla (Schmidt \& Mellon, 2011) presumably 819 working as contact-chemoreceptors. This pair of appendages is associated with the tritocerebral neuromere, and its afferents target the bilaterally paired antenna 2 neuropils (AnN) that extend posterolaterally to either side of the esophageal foramen (Fig.9D-E, 11D, 13E, 15B). In some representatives of Decapoda, this neuropil is transversely divided into segment-like synaptic fields, suggesting a somato- or spatiotopic representation of the mechanoreceptors along the length of the second antenna (reviewed in Krieger et al., 2012). In the marine anomalan Pagurus bernhardus, this neuropil is elongate and the transverse segmentation is very obvious (Krieger et al., 2012), enforcing the idea that the sensory array of antenna 2 may be mapped along its length. In terrestrial Anomala, the antenna 2 neuropils of $C$. clypeatus and $B$. latro are rather inconspicuous, as is a transverse segmentation (Harzsch \& Hansson, 2008; Krieger et al., 2010). In isopods, which are considered the most successful terrestrialized crustaceans, a transverse segmentation of the prominent $\mathrm{AnN}$, as has been shown for hermit crabs, is clearly identifiable in marine but indistinct in terrestrial isopods (Harzsch et al., 2011). Since in terrestrial isopods, the first pair of antennae is highly reduced in size and the associated DCL seems to be absent, the idea arose that the pronounced second pair of antennae and its associated antenna 2 neuropils together may function as the major sensory organ (Harzsch et al., 2011; Kenning \& Harzsch, 2013). Contrarywise, in both marine (Krieger et al., 2012) as well as terrestrial brachyurans, the antenna 2 neuropil is part of a large neuropil mass that is composed of both deuto- and tritocerebral portions, thus making the antenna 2 neuropil hardly identifiable. A transverse segmentation has not been detected so far, neither in marine nor in terrestrial brachyurans. From these data and especially from behavioral observations in Brachyura, one could argue that flow 
841 antennae. Undoubtedly, further analyses are required to clarify the functional relevance of the

842 second pair of antennae and to check for structural as well as functional differences that may

843 represent adaptations for detecting flow in water versus in air.

\section{Conclusions}

845 During a relatively short evolutionary time period, several crustacean lineages have convergently 846 adapted to a number of highly diverse terrestrial habitats in which they have become highly 847 successful (reviews of Bliss \& Mantel, 1968; Powers \& Bliss, 1983; Greenaway, 1988, 1999;

848 Hartnoll, 1988). We are interested in which crustacean lineages successfully evolved aerial 849 olfaction during this evolutionary transition (Hansson et al., 2011). As far as isopod crustaceans 850 are concerned, it appears that their deutocerebral neuronal substrate for distance olfaction has 851 largely eroded away in the terrestrial species, whereas there is good evidence for contact 852 chemoreception using the tritocerebral pair of antennae (e.g. Harzsch et al., 2011; Kenning \& 853 Harzsch, 2013). For representatives of the Coenobitidae (Anomala), however, there is compelling 854 evidence from neuranatomical, physiological, transcriptomic, and behavioral studies that aerial 855 olfaction plays a major role in the animal's behavioral repertoire (Harzsch \& Hansson, 2008; 856 Krång et al., 2012; Polanska et al., 2012; Groh et al., 2014; Tuchina et al., 2014). Brachyura take 857 an intermediate position, and the question arises which aspects of the terrestrial olfactory 858 landscape they are able to detect with their reduced peripheral and central olfactory pathway. In 859 addition to volatile chemicals, humidity and $\mathrm{CO}_{2}$-concentration may be crucial cues for these 860 animals. As with terrestrial species analyzed, a clear correlation between the specific brain 861 anatomy and the degree of terrestriality could not be deduced. Furthermore, our study raises the 862 possibility that in the semi-aquatic Uca tangeri sex-specific differences regarding average size 863 and number of olfactory glomeruli exist, which may indicate that communication via sexual 864 pheromones could be a possible function in some land crab species. Alternatively, those taxa with 865 a mostly amphibious lifestyle may use their olfactory system while submersed in water. This idea 866 most likely does not apply to G. natalis which, when immersed in water for a short amount of 867 time will drown. Since there are more brachyuran taxa that independently succeeded in evolving 868 a terrestrial life-style than those representatives examined here (Fig. 1), an ongoing comparative 869 analysis of brachyuran neuroanatomy remains an exciting topic. Therefore, further studies to 870 evaluate and compare general aspects of terrestrialization within brachyurans as well as with 871 those of other crustacean lineages are promising. 
872 Only a few lineages within Crustacea have independently evolved terrestrial olfaction to different 873 degrees, suggesting that the evolution of effective olfactory systems (or sensory systems more 874 generally) on land is highly challenging. As for amphibious olfaction in secondarily aquatic 875 insects, Hodgson (1953) reported that in the amphibious beetle, Laccophilus maculosus, 876 specimens are capable to perceive the same chemical compounds in air as well as under water, 877 even though sensitivity in air is increased by a factor of 5 to 10 in comparison to underwater 878 sensitivity. Supported by morphological data, bioassays using antennal ablations in L. maculosus 879 suggest an amphibious chemoreception which is most likely based on the antennal sensilla 880 basiconica (Hodgson, 1953). However, an effective amphibian olfaction in brachyurans with terrestrial adaptations like in the secondarily aquatic L. maculosus could not be verified here.

When comparing different taxa within Crustacea that conquered land, it becomes obvious that they feature a variety of terrestrial adaptations to different degrees; and from a scientific point of view, the objective to evaluate those different degrees is logical. The proposed levels of terrestrial adaptation from $T_{1}$ to $T_{5}$ for land crabs after Powers and Bliss (1983) are commonly used to date, but it was also reported that this classification is "far from perfect" (see review Hartnoll, 1988). Derived from general biological considerations this classification features five gradual levels of terrestrialness. These features include the time of day and the total periods spent actively on land (intertidal species), the requirement of regular immersion or drinking of water, and the (sea) water-dependency for larval development. Albeit this classification comprised several aspects of terrestriality, it is not possible to assign each species to a unique level in either case because the conquest of land is a gradual process that demands for diverse different adaptations. Therefore, Schubert and co-workers (2000) proposed three simplified degrees of terrestrialization referring to adult life in addition to larval development as follows: A) terrestrial adults with marine larvae, B) limnic adults with marine larvae, and C) adults that breed in inland waters and hence are independent from the ocean (e.g. several Sesamidae). If we take a perspective solely related to deutocerebral olfaction (as mediated by the first pair of antennae), the levels of terrestrial adaptation may be grouped as $\mathrm{TO}_{0}$ - not functional at all (terrestrial isopods); $\mathrm{TO}_{1}$ - functional in water and non-functional on land (as suggested for C. armatum); $\mathrm{TO}_{2}$ - functional in water as well as on land $=>$ amphibious (needs to be tested like in the amphibious beetle L. maculosus); and $\mathrm{TO}_{3}$ not functional in water but functional on land (Coenobitidae and presumably G. natalis). 
903 system, we nevertheless conclude that the existing classification systems must be improved to 904 describe the degree of terrestrial adaptation for an animal as a whole. In fact, it seems crucial that 905 multiple biological aspects such as development, mating, foraging, biorhythm, physiology as well 906 as anatomy be taken into account for an adequate evaluation of terrestriality of each species. 
907

908

909

910

911

912

913

914

915

916

917

918

919

920

921

922

923

924

925

926

927

928

929

930

Acknowledgements

We would like to express our gratitude to Guido Dehnhardt and the staff of the Marine Science Center in Rostock for free provision of diving equipment and the permission to sample Carcinus maenas on-site. We cordially thank Beate Johl (Zoological Institute and Museum at the University of Greifswald) for her assistance of analyzing the first antennae in specimens of the marine brachyurans of the Mediterranean Xantho hydrophilus, X. poressa, and Percnon gibbesi. We greatly appreciate the generous logistic and conceptual support by B. S. Hansson (Max Planck Institute for Chemical Ecology, Jena, Germany) and Mr. Mike Misso and Dr. Michael Smith from the Christmas Island National Park authorities during the collection of specimens of G. natalis. Glenda Jones and Sandra Banks are gratefully acknowledged for handling the research permits.

\section{References}

Ahyong ST., O'Meally D. 2004. Phylogeny of the Decapoda Reptantia: Resolution using three molecular Loci and Morphology. The Raffles Bulletin of Zoology 52:673-693.

Altevogt R. 1957. Untersuchungen zur Biologie, Ökologie und Physiologie Indischer Winkerkrabben. Zeitschrift für Morphologie und Ökologie der Tiere 46:1-110.

Altevogt R. 1959. Ökologische und Ethologische Studien an Europas einziger Winkerkrabbe Uca tangeri Eydoux. Zeitschrift für Morphologie und Ökologie der Tiere 48:123-146.

Beltz BS., Kordas K., Lee MM., Long JB., Benton JL., Sandeman DC. 2003. Ecological, evolutionary, and functional correlates of sensilla number and glomerular density in the olfactory system of decapod crustaceans. The Journal of Comparative Neurology 455:260-269.

Berón de Astrada M., Bengochea M., Sztarker J., Delorenzi A., Tomsic D. 2013. Behaviorally Related Neural Plasticity in the Arthropod Optic Lobes. Current Biology 23:1389-1398. 
931 Berón de Astrada M., Medan V., Tomsic D. 2011. How visual space maps in the optic neuropils $932 \quad$ of a crab. The Journal of Comparative Neurology 519:1631-1639.

933 Berón de Astrada M., Tomsic D. 2002. Physiology and morphology of visual movement detector

934

935

936

937

938

939

940

941

942

943

944

945

946

947

948

949

950

951

952

953

954

955

956

957 neurons in a crab (Decapoda: Brachyura). Journal of Comparative Physiology A 188:539-551.

Blaustein DN., Derby CD., Simmons RB., Beall AC. 1988. Structure of the brain and medulla terminalis of the spiny lobster Panulirus argus and the crayfish Procambarus clarkii, with an emphasis on olfactory centers. Journal of Crustacean Biology:493-519.

Bliss DE., Mantel LH. 1968. Adaptations of Crustaceans to Land: A Summary and Analysis of New Findings. American Zoologist 8:673-685.

Bliss DE., Welsh JH. 1952. The neurosecretory system of brachyuran Crustacea. Biological Bulletin 103:157-169.

Borradaile LA. 1916. Crustacea. Part II. Porcellanopagurus: An instance of carcinization. In, British Antarctic (Terra Nova) Expedition, 1910. In: Natural History Report, Zoology. 111126.

Brösing A., Richter S., Scholtz G. 2007. Phylogenetic analysis of the Brachyura (Crustacea, Decapoda) based on characters of the foregut with establishment of a new taxon. Journal of Zoological Systematics and Evolutionary Research 45:20-32.

Burggren WW., McMahon BR. 1988. Circulation. In: Burggren WW, McMahon BR eds. Biology of the Land Crabs. Cambridge: Cambridge University Press, 298-332.

Cape SS., Rehm KJ., Ma M., Marder E., Li L. 2008. Mass spectral comparison of the neuropeptide complement of the stomatogastric ganglion and brain in the adult and embryonic lobster, Homarus americanus. Journal of Neurochemistry 105:690-702.

Christie AE., Sousa GL., Rus S., Smith CM., Towle DW., Hartline DK., Dickinson PS. 2008. Identification of A-type allatostatins possessing-YXFGI/Vamide carboxy-termini from the nervous system of the copepod crustacean Calanus finmarchicus. General and Comparative Endocrinology 155:526-533. 
958 Christie AE., Stemmler EA., Dickinson PS. 2010. Crustacean neuropeptides. Cellular and 959 Molecular Life Sciences 67:4135-4169.

960

Derby CD., Steullet P., Horner AJ., Cate HS. 2001. The sensory basis of feeding behaviour in 961 the Caribbean spiny lobster, Panulirus argus. Marine and Freshwater Research 52:1339_

Derby CD., Sorensen PW. 2008. Neural Processing, Perception, and Behavioral Responses to Natural Chemical Stimuli by Fish and Crustaceans. Journal of Chemical Ecology 34:898914.

Derby CD., Weissburg MJ. 2014. The Chemical Senses and Chemosensory Ecology of Crustaceans. In: Derby CD, Thiel M eds. Crustacean Nervous Systems and Their Control of Behavior. Oxford ; New York, NY: Oxford University Press,.

Detto T., Backwell PRY., Hemmi JM., Zeil J. 2006. Visually mediated species and neighbour recognition in fiddler crabs (Uca mjoebergi and Uca capricornis). Proceedings of the Royal Society of London B: Biological Sciences 273:1661-1666.

Detto T. 2007. The fiddler crab Uca mjoebergi uses colour vision in mate choice. Proceedings of the Royal Society of London B: Biological Sciences 274:2785-2790.

Detto T., Backwell PRY. 2009. The fiddler crab Uca mjoebergi uses ultraviolet cues in mate choice but not aggressive interactions. Animal Behaviour 78:407-411.

Diesel R., Schubart CD. 2000. Die außergewöhnliche Evolutionsgeschichte jamaikanischer Felsenkrabben. Biologie in unserer Zeit 30:136-147.

Diesel R., Schubart CD., Schuh M. 2000. A reconstruction of the invasion of land by Jamaican crabs (Grapsidae: Sesarminae). Journal of Zoology 250:141-160.

Dircksen H., Skiebe P., Abel B., Agricola HJ., Buchner K., Muren JE., Nässel DR. 1999. Structure, distribution, and biological activity of novel members of the allatostatin family in the crayfish Orconectes limosus. Peptides 20:695-712.

Dixon CJ., Ahyong ST., Schram FR. 2003. A new hypothesis of decapod phylogeny. Crustaceana 76:935-975. 
985 Dockray GJ. 2004. The expanding family of-RFamide peptides and their effects on feeding 986 behaviour. Experimental Physiology 89:229-235.

987 Duve H., Johnsen AH., Maestro JL., Scott AG., Jaros PP., Thorpe A. 1997. Isolation and 988 identification of multiple neuropeptides of the allatostatin superfamily in the shore crab Carcinus maenas. European Journal of Biochemistry 250:727-734.

Duve H., Johnsen AH., Scott AG., Thorpe A. 2002. Allatostatins of the tiger prawn, Penaeus monodon (Crustacea: Penaeidea). Peptides 23:1039-1051.

Elofsson R., Hagberg M. 1986. Evolutionary aspects on the construction of the first optic neuropil (lamina) in Crustacea. Zoomorphology 106:174-178.

Fu Q., Christie AE., Li L. 2005. Mass spectrometric characterization of crustacean hyperglycemic hormone precursor-related peptides (CPRPs) from the sinus gland of the crab, Cancer productus. Peptides 26:2137-2150.

Ghiradella HT., Case JF., Cronshaw J. 1968a. Fine Structure of the Aesthetasc Hairs of Coenobita compressus Edwards. Journal of Morphology 124:361-385.

Ghiradella HT., Case JF., Cronshaw J. 1968b. Structure of Aesthetascs in Selected Marine and Terrestrial Decapods: Chemoreceptor Morphology and Environment. American Zoologist

Gleeson RA., McDowell LM., Aldrich HC. 1996. Structure of the aesthetasc (olfactory) sensilla of 1003 1004 the blue crab, Callinectes sapidus: transformations as a function of salinity. Cell and Tissue Research 284:279-288. perspectives and future directions. Current Opinion in Neurobiology 12:721-727. Land Crabs. Cambridge: Cambridge University Press, 211-248. Vaupel Klein JC eds. Proceedings of the fourth international crustacean congress, vol I, 
1011

1012

1013

1014

1015

1016

1017

1018

1019

1020

1021

1022

1023

1024

1025

1026

1027

1028

1029

1030

1031

1032

1033

1034

1035

1036

1037

Amsterdam, The Netherlands, 20-24 July 1998. Leiden: Brill Academic Publishers, 823842.

Greenaway P. 2003. Terrestrial adaptations in the anomura (Crustacea: Decapoda). Memoirs of Museum Victoria 60:13-26.

Greenberg MJ., Price DA. 1992. Chapter 3 Relationships among the FMRFamide-like peptides. In: The Peptidergic Neuron. Elsevier, 25-37.

Groh KC., Vogel H., Stensmyr MC., Grosse-Wilde E., Hansson BS. 2014. The hermit crab's nose-antennal transcriptomics. Frontiers in Neuroscience 7.

Grünert U., Ache BW. 1988. Ultrastructure of the aesthetasc (olfactory) sensilla of the spiny lobster, Panulirus argus. Cell and Tissue Research 251:95-103.

von Hagen H-O. 1962. Freilandstudien zur sexual und Fortpflanzungs-biologie von Uca tangeri in Andalusien. Zeitschrift für Morphologie und Ökologie der Tiere 51:611-725.

Hallberg E., Hansson BS. 1999. Arthropod sensilla: Morphology and phylogenetic considerations. Microscopy Research and Technique 47:428-439.

Hallberg E., Johansson KUI., Elofsson R. 1992. The aesthetasc concept: Structural variations of putative olfactory receptor cell complexes in crustacea. Microscopy Research and Technique 22:325-335.

Hallberg E., Skog M. 2011. Chemosensory Sensilla in Crustaceans. In: Breithaupt T, Thiel M eds. Chemical Communication in Crustaceans. New York: Springer, 103-121.

Hansson BS., Harzsch S., Knaden M., Stensmyr MC. 2011. The neural and behavioral basis of chemical communication in terrestrial crustaceans. In: Breithaupt T, Thiel M eds. Chemical Communication in Crustaceans. New York: Springer, 149-173.

Hanström B. 1925. The Olfactory Centers in Crustaceans. The Journal of Comparative Neurology 38:221-250.

Harms JW. 1932. Die Realisation von Genen und die consekutive Adaptation. II. Birgus latro (L.) Als Landkrebs und seine Beziehungen zu den Coenobiten. Zeitschrift für Wissenschaften Zoologie 140:168-290. 
1038 Hartnoll RG. 1988. Evolution, Systematics, and Geographical Distribution. In: Burggren WW, 1039 McMahon BR eds. Biology of the Land Crabs. Cambridge: Cambridge University Press, $1040 \quad 6-54$.

1041 Harzsch S., Miller J., Benton JL., Dawirs RR., Beltz BS. 1998. Neurogenesis in the thoracic 1042 neuromeres of two crustaceans with different types of metamorphic development. The Journal of Experimental Biology 201:2465-2479.

1044

1045

1046

1047

1048

1049

1050

1051

1052

1053

1054

1055

1056

1057

1058

1059

1060

1061

1062

1063

1064
Harzsch S., Miller J., Benton JL., Beltz BS. 1999. From Embryo to Adult: Persistent Neurogenesis and Apoptotic Cell Death Shape the Lobster Deutocerebrum. The Journal of Neuroscience 19:3472-3485.

Harzsch S. 2002. The phylogenetic significance of crustacean optic neuropils and chiasmata: A re-examination. The Journal of Comparative Neurology 453:10-21.

Harzsch S., Rieger V., Krieger J., Seefluth F., Strausfeld NJ., Hansson BS. 2011. Transition from marine to terrestrial ecologies: Changes in olfactory and tritocerebral neuropils in landliving isopods. Arthropod Structure \& Development 40:244-257.

Harzsch S., Anger K., Dawirs RR. 1997. Immunocytochemical detection of acetylated alphatubulin and Drosophila synapsin in the embryonic crustacean nervous system. The International Journal of Developmental Biology 41:477-484.

Harzsch S., Dawirs RR. 1996. Maturation of the compound eyes and eyestalk ganglia during larval development of the brachyuran crustaceans Hyas araneus L (Decapoda, Majidae) and Carcinus maenas L (Decapoda, Portunidae). Zoology-Analysis of Complex Systems 99:189-204.

Harzsch S., Hansson BS. 2008. Brain architecture in the terrestrial hermit crab Coenobita clypeatus (Anomura, Coenobitidae), a crustacean with a good aerial sense of smell. BMC Neuroscience 9:58.

Harzsch S., Müller CHG. 2007. A new look at the ventral nerve centre of Sagitta: implications for the phylogenetic position of Chaetognatha (arrow worms) and the evolution of the bilaterian nervous system. Frontiers in Zoology 4:14. 
1065 Harzsch S., Sandeman DC., Chaigneau J. 2012. Morphology and development of the central 1066 nervous system. In: Forest J, von Vaupel Klein JC eds. Treatise on Zoology-Anatomy, 1067 Taxonomy, Biology. The Crustacea. Leiden: Brill, 9-236.

1068

Hay ME. 2011. Crustaceans as Powerful Models in Aquatic Chemical Ecology. In: Breithaupt T, Thiel M eds. Chemical Communication in Crustaceans. New York: Springer, 41-62.

1070

Hazlett BA. 2011. Chemical Cues and Reducing the Risk of Predation. In: Breithaupt T, Thiel M 1071 eds. Chemical Communication in Crustaceans. New York: Springer, 355-370.

Helluy SM., Benton JL., Langworthy KA., Ruchhoeft ML., Beltz BS. 1996. Glomerular 1073 organization in developing olfactory and accessory lobes of American lobsters: Stabilization of numbers and increase in size after metamorphosis. Journal of Neurobiology 29:459-472.

Hemmi JM., Tomsic D. 2012. The neuroethology of escape in crabs: from sensory ecology to 1077 neurons and back. Current Opinion in Neurobiology 22:194-200.

Hemmi JM., Zeil J. 2003. Robust judgement of inter-object distance by an arthropod. Nature 421:160-163.

Hodgson ES. 1953. A Study of Chemoreception in Aqueous and Gas Phases. The Biological Bulletin 105:115-127.

1082 Homberg U. 1994. Distribution of neurotransmitters in the insect brain. Gustav Fischer Verlag. 1083 Homberg U., Christensen TA., Hildebrand JG. 1989. Structure and Function of the 1084 Deutocerebrum in Insects. Annual Review of Entomology 34:477-501. 1085 Honma Y., Takano K., Chiba A., Oka S. 1996. Immunohistochemical Localization of 1086 Neuropeptides in the Cephalic Ganglion of the Land Crab Chiromantes haematocheir. Fisheries Science 62:909-913. Neuropeptidomic analysis of the brain and thoracic ganglion from the Jonah crab, 
1091 Hyatt GW. 1975. Physiological and behavioral evidence for color discrimination by fiddler crabs 1092 (Brachyura, Ocypodidae, genus Uca). In: Vernberg FJ ed. Physiological Ecology of 1093 Estuarine Organisms. Columbia, South Carolina: University of South Carolina Press, 333-365.

1095

1096

1097

1098

1099

1100

1101

1102

1103

1104

Johansson KUI., Hallberg E. 1992. The organization of the olfactory lobes in Euphausiacea and Mysidacea (Crustacea, Malacostraca). Zoomorphology 112:81-89.

Jundi B El., Huetteroth W., Kurylas AE., Schachtner J. 2009. Anisometric brain dimorphism revisited: Implementation of a volumetric 3D standard brain in Manduca sexta. The Journal of Comparative Neurology 517:210-225.

Kenning M., Harzsch S. 2013. Brain anatomy of the marine isopod Saduria entomon Linnaeus, 1758 (Valvifera, Isopoda) with special emphasis on the olfactory pathway. Frontiers in Neuroanatomy 7.

Kenyon FC. 1896. The brain of the bee. A preliminary contribution to the morphology of the nervous system of the arthropoda. Journal of Comparative Neurology 6:133-210.

Klagges BRE., Heimbeck G., Godenschwege TA., Hofbauer A., Pflugfelder GO., Reifegerste R., Reisch D., Schaupp M., Buchner S., Buchner E. 1996. Invertebrate Synapsins: A Single Gene Codes for Several Isoforms in Drosophila. Journal of Neuroscience 16:3154-3165.

Koehl MAR. 2011. Hydrodynamics of Sniffing by Crustaceans. In: Breithaupt T, Thiel M eds. Chemical Communication in Crustaceans. Springer New York, 85-102.

Koontz MA., Schneider D. 1987. Sexual dimorphism in neuronal projections from the antennae of silk moths (Bombyx mori, Antheraea polyphemus) and the gypsy moth (Lymantria dispar). Cell and Tissue Research 249:39-50.

Korte R. 1965. Durch polarisiertes Licht hervorgerufene Optomotorik bei Uca tangeri. Experientia 21:98-98.

Krång A-S., Knaden M., Steck K., Hansson BS. 2012. Transition from sea to land: olfactory function and constraints in the terrestrial hermit crab Coenobita clypeatus. Proceedings of the Royal Society B: Biological Sciences 279:3510-3519. 
1118 Kreissl S., Strasser C., Galizia CG. 2010. Allatostatin immunoreactivity in the honeybee brain. The Journal of Comparative Neurology 518:1391-1417.

Krieger J., Sandeman RE., Sandeman DC., Hansson BS., Harzsch S. 2010. Brain architecture of the largest living land arthropod, the Giant Robber Crab Birgus latro (Crustacea, Anomura, Coenobitidae): evidence for a prominent central olfactory pathway? Frontiers in Zoology 7:25.

Krieger J., Sombke A., Seefluth F., Kenning M., Hansson BS., Harzsch S. 2012. Comparative brain architecture of the European shore crab Carcinus maenas (Brachyura) and the common hermit crab Pagurus bernhardus (Anomura) with notes on other marine hermit crabs. Cell and Tissue Research:1-23.

Land M., Layne J. 1995. The visual control of behaviour in fiddler crabs. II: Tracking control systems in courtship and defence. Journal of Comparative Physiology A: Neuroethology, Sensory, Neural, and Behavioral Physiology 177:91-103.

Layne JE., Barnes WJP., Duncan LMJ. 2003a. Mechanisms of homing in the fiddler crab Uca rapax 1. Spatial and temporal characteristics of a system of small-scale navigation. Journal of Experimental Biology 206:4413-4423.

Layne JE., Barnes WJP., Duncan LMJ. 2003b. Mechanisms of homing in the fiddler crab Uca rapax 2. Information sources and frame of reference for a path integration system. Journal of Experimental Biology 206:4425-4442.

Loesel R. 2004. Comparative Morphology of Central Neuropils in the Brain of Arthropods and its Evolutionary and Functional Implications. Acta Biologica Hungarica 55:39-51.

Loesel R., Wolf H., Kenning M., Harzsch S., Sombke A. 2013. Architectural Principles and Evolution of the Arthropod Central Nervous System. In: Minelli A, Boxshall G, Fusco G eds. Arthropod Biology and Evolution. Berlin Heidelberg: Springer, 299-342.

Ma M., Chen R., Sousa GL., Bors EK., Kwiatkowski MA., Goiney CC., Goy MF., Christie AE., Li L. 2008. Mass spectral characterization of peptide transmitters/hormones in the nervous 
system and neuroendocrine organs of the American lobster Homarus americanus. General and Comparative Endocrinology 156:395-409.

Ma M., Bors EK., Dickinson ES., Kwiatkowski MA., Sousa GL., Henry RP., Smith CM., Towle by mass spectrometry and functional genomics. General and Comparative Endocrinology 161:320-334.

Ma M., Szabo TM., Jia C., Marder E., Li L. 2009b. Mass spectrometric characterization and physiological actions of novel crustacean C-type allatostatins. Peptides 30:1660-1668.

Ma M., Gard AL., Xiang F., Wang J., Davoodian N., Lenz PH., Malecha SR., Christie AE., Li L. 2010. Combining in silico transcriptome mining and biological mass spectrometry for

Mellon Jr. D. 2007. Combining Dissimilar Senses: Central Processing of Hydrodynamic and Chemosensory Inputs in Aquatic Crustaceans. The Biological Bulletin 213:1-11. olfactory midbrain. Microscopy Research and Technique 24:231-259. From Biology to Engineering. Wien: Springer-Verlag, 159-170. 
1170 Mercier AJ., Friedrich R., Boldt M. 2003. Physiological functions of FMRFamide-like peptides

1171 (FLPs) in crustaceans. Microscopy Research and Technique 60:313-324.

1172 Montgomery SH., Ott SR. 2015. Brain composition in Godyris zavaleta, a diurnal butterfly,

1173 Reflects an increased reliance on olfactory information. Journal of Comparative

$1174 \quad$ Neurology 523:869-891.

1175 Nässel DR. 1993. Neuropeptides in the insect brain: a review. Cell and Tissue Research 273:129.

1177 Nässel DR., Homberg U. 2006. Neuropeptides in interneurons of the insect brain. Cell and $1178 \quad$ Tissue Research 326:1-24.

1179 Ng PKL., Guinot D., Davie PJF. 2008. Systema Brachyurorum: Part I. An annotated checklist of 1180 extant brachyuran crabs of the world. The Raffles Bulletin of Zoology 17:1-286.

1181 Orchard M. 2012. Crabs of Christmas Island. Christmas Island, Indian Ocean: Christmas Island $1182 \quad$ Natural History Association.

1183 Ott SR. 2008. Confocal microscopy in large insect brains: Zinc-formaldehyde fixation improves 1184 synapsin immunostaining and preservation of morphology in whole-mounts. Journal of $1185 \quad$ Neuroscience Methods 172:220-230.

1186 Polanska MA., Tuchina O., Agricola H., Hansson BS., Harzsch S. 2012. Neuropeptide 1187 complexity in the crustacean central olfactory pathway: immunolocalization of A-type

1190 Polanska M., Yasuda A., Harzsch S. 2007. Immunolocalisation of crustacean-SIFamide in the 1191 median brain and eyestalk neuropils of the marbled crayfish. Cell and Tissue Research

1193 Powers LW., Bliss DE. 1983. Terrestrial adaptations. In: Vernberg FJ, Vernberg WB eds. The Biology of Crustacea. New York: Academic Press., 272-333.

1195 Price DA., Greenberg MJ. 1989. The hunting of the FaRPs: the distribution of FMRFamide1196 related peptides. The Biological Bulletin 177:198-205. 
1197 Reidenbach MA., Koehl MAR. 2011. The spatial and temporal patterns of odors sampled by 1198 lobsters and crabs in a turbulent plume. The Journal of Experimental Biology 214:31383153.

1200

1201

1202

1203

1204

1205

1206

1207

1208

1209

1210

1211

1212

1213

1214

1215

1216

1217

1218

1219

1220

1221

1222

Richter S., Loesel R., Purschke G., Schmidt-Rhaesa A., Scholtz G., Stach T., Vogt L., Wanninger A., Brenneis G., Döring C., Faller S., Fritsch M., Grobe P., Heuer CM., Kaul S., Möller OS., Müller CHG., Rieger V., Rothe BH., Stegner MEJ., Harzsch S. 2010. Invertebrate neurophylogeny: suggested terms and definitions for a neuroanatomical glossary. Frontiers in Zoology 7:29.

Rittschof D., Sutherland JP. 1986. Field studies on chemically mediated behavior in land hermit crabs: Volatile and nonvolatile odors. Journal of Chemical Ecology 12:1273-1284.

Rospars JP., Hildebrand JG. 2000. Sexually Dimorphic and Isomorphic Glomeruli in the Antennal Lobes of the Sphinx Moth Manduca sexta. Chemical Senses 25:119-129.

Sandeman DC. 1967. The Vascular Circulation in the Brain, Optic Lobes and Thoracic Ganglia of the Crab Carcinus. Proceedings of the Royal Society of London B: Biological Sciences 168:82-90.

Sandeman DC., Sandeman RE., Derby CD., Schmidt M. 1992. Morphology of the Brain of Crayfish, Crabs, and Spiny Lobsters: A Common Nomenclature for Homologous Structures. The Biological Bulletin 183:304-326.

Sandeman DC., Luff SE. 1973. The Structural Organization of Glomerular Neuropile in the Olfactory and Accessory Lobes of an Australian Freshwater Crayfish, Cherax destructor. Zeitschrift für Zellforschung und Mikroskopische Anatomie 142:37-61.

Sandeman DC., Scholtz G., Sandeman RE. 1993. Brain Evolution in Decapod Crustacea. Journal of Experimental Zoology 265:112-133.

Schachtner J., Schmidt M., Homberg U. 2005. Organization and evolutionary trends of primary olfactory brain centers in Tetraconata (Crustacea+Hexapoda). Arthropod Structure \& Development 34:257-299. 
1223 Schmidt M. 2015. Malacostraca. In: Schmidt-Rhaesa A, Harzsch S, Purschke G eds. Structure and Evolution of Invertebrate Nervous Systems. Oxford University Press, in press.

1225

1226

1227

1228

1229

1230

1231

1232

1233

1234

1235

1236

1237

1238

1239

1240

1241

1242

1243

1244

1245

1246

1247

1248

Schmidt M., Ache BW. 1997. Immunocytochemical analysis of glomerular regionalization and neuronal diversity in the olfactory deutocerebrum of the spiny lobster. Cell and Tissue Research 287:541-563.

Schmidt M., Mellon D. 2011. Neuronal Processing of Chemical Information in Crustaceans. In: Breithaupt T, Thiel M eds. Chemical Communication in Crustaceans. Springer New York, $123-147$.

Scholtz G., Richter S. 1995. Phylogenetic systematics of the reptantian Decapoda (Crustacea, Malacostraca). Zoological Journal of the Linnean Society 113:289-328.

Schubart CD., Cuesta JA., Diesel R., Felder DL. 2000. Molecular Phylogeny, Taxonomy, and Evolution of Nonmarine Lineages within the American Grapsoid Crabs (Crustacea: Brachyura). Molecular Phylogenetics and Evolution 15:179-190.

Schubart CD., Cannicci S., Vannini M., Fratini S. 2006. Molecular phylogeny of grapsoid crabs (Decapoda, Brachyura) and allies based on two mitochondrial genes and a proposal for refraining from current superfamily classification. Journal of Zoological Systematics and Evolutionary Research 44:193-199.

Schubart CD., Cuesta JA., Felder DL. 2002. Glyptograpsidae, a New Brachyuran Family from Central America: Larval and Adult Morphology, and a Molecular Phylogeny of the Grapsoidea. Journal of Crustacean Biology 22:28-44.

Schubart CD., Diesel R., Hedges SB. 1998. Rapid evolution to terrestrial life in Jamaican crabs. Nature 393:363-365.

Skiebe P. 1999. Allatostatin-like immunoreactivity in the stomatogastric nervous system and the pericardial organs of the crab Cancer pagurus, the lobster Homarus americanus, and the crayfish Cherax destructor and Procambarus clarkii. The Journal of Comparative Neurology 403:85-105. 
1249 Snow PJ. 1973. Ultrastructure of the aesthetasc hairs of the littoral decapod, Paragrapsus

1250

1251

1252

1253

1254

1255

1256

1257

1258

1259

1260

1261

1262

1263

1264

1265

1266

1267

1268

1269

1270

1271

1272

1273

1274

1275 gaimardii. Cell and Tissue Research 138:489-502.

Sombke A., Harzsch S. 2015. Immunolocalization of histamine in the optic neuropils of Scutigera coleoptrata (Myriapoda: Chilopoda) reveals the basal organization of visual systems in Mandibulata. Neuroscience Letters 594:111-116.

Sombke A., Harzsch S., Hansson BS. 2011. Organization of Deutocerebral Neuropils and Olfactory Behavior in the Centipede Scutigera coleoptrata (Linnaeus, 1758) (Myriapoda: Chilopoda). Chemical Senses 36:43-61.

Spencer M., Linberg KA. 1986. Ultrastructure of aesthetasc innervation and external morphology of the lateral antennule setae of the spiny lobster Panulirus interruptus (Randall). Cell and Tissue Research 245:69-80.

Spiller WG. 1898. A contribution to the study of secondary degeneration following cerebral lesions. The Journal of Nervous and Mental Disease 25:1-19.

Stay B., Tobe SS. 2007. The role of allatostatins in juvenile hormone synthesis in insects and crustaceans. Annual Review of Entomology 52:277-299.

Stay B., Tobe SS., Bendena WG. 1995. Allatostatins: identification, primary structures, functions and distribution. Advances in Insect Physiology 25:267-337.

Stensmyr MC., Erland S., Hallberg E., Wallén R., Greenaway P., Hansson BS. 2005. Insect-Like Olfactory Adaptations in the Terrestrial Giant Robber Crab. Current Biology 15:116-121.

Števčić Z. 1971. The Main Features of Brachyuran Evolution. Systematic Zoology 20:331-340.

Strausfeld NJ. 2012. Arthropod Brains: Evolution, Functional Elegance, and Historical Significance. Belknap Press of Harvard University Press.

Streinzer M., Kelber C., Pfabigan S., Kleineidam CJ., Spaethe J. 2013. Sexual dimorphism in the olfactory system of a solitary and a eusocial bee species. Journal of Comparative Neurology 521:2742-2755.

Sullivan JM., Benton JL., Sandeman DC., Beltz BS. 2007. Adult Neurogenesis: A Common Strategy Across Diverse Species. The Journal of Comparative Neurology 500:574-584. 
1276 Sztarker J., Strausfeld NJ., Andrew D., Tomsic D. 2009. Neural organization of first optic

1277

1278

1279

1280

1281

1282

1283

1284

1285

1286

1287

1288

1289

1290

1291

1292

1293

1294

1295

1296

1297

1298

1299

1300

1301

1302

neuropils in the littoral crab Hemigrapsus oregonensis and the semiterrestrial species Chasmagnathus granulatus. The Journal of Comparative Neurology 513:129-150.

Sztarker J., Strausfeld NJ., Tomsic D. 2005. Organization of optic lobes that support motion detection in a semiterrestrial crab. The Journal of Comparative Neurology 493:396-411.

Techa S., Chung JS. 2015. Ecdysteroids Regulate the Levels of Molt-Inhibiting Hormone (MIH) Expression in the Blue Crab, Callinectes sapidus. PLoS ONE 10:e0117278.

Thacker RW. 1994. Volatile shell-investigation cues of land hermit crabs: Effect of shell fit, detection of cues from other hermit crab species, and cue isolation. Journal of Chemical Ecology 20:1457-1482.

Thacker RW. 1996. Food choices of land hermit crabs (Coenobita compressus H. Milne Edwards) depend on past experience. Journal of Experimental Marine Biology and Ecology 199:179-191.

Thacker RW. 1998. Avoidance of recently eaten foods by land hermit crabs, Coenobita compressus. Animal Behaviour 55:485-496.

Thiel M., Breithaupt T. 2011. Chemical Communication in Crustaceans: Research Challenges for the Twenty-First Century. In: Breithaupt T, Thiel M eds. Chemical Communication in Crustaceans. New York: Springer, 3-22.

Tierney AJ., Thompson CS., Dunham DW. 1986. Fine structure of aesthetasc chemoreceptors in the crayfish Orconectes propinquus. Canadian Journal of Zoology 64:392-399.

Tsang LM., Schubart CD., Ahyong ST., Lai JCY., Au EYC., Chan T-Y., Ng PKL., Chu KH. 2014. Evolutionary History of True Crabs (Crustacea: Decapoda: Brachyura) and the Origin of Freshwater Crabs. Molecular Biology and Evolution 31:1173-1187.

Tsvileneva VA., Titova VA., Kvashina TV. 1985. Brain topography of the shore crab Hemigrapsus sanguineus. Journal of Evolutionary Biochemistry and Physiology 21:394-400.

Tuchina O., Groh KC., Talarico G., Müller CHG., Wielsch N., Hupfer Y., Svatoš A., Grosse-Wilde E., Hansson BS. 2014. Morphology and Histochemistry of the Aesthetasc-Associated 
1303 Epidermal Glands in Terrestrial Hermit Crabs of the Genus Coenobita (Decapoda: $1304 \quad$ Paguroidea). PLoS ONE 9:e96430.

1305 Tuchina O., Koczan S., Harzsch S., Rybak J., Wolff G., Strausfeld NJ., Hansson BS. 2015.

1306 Central projections of antennular chemosensory and mechanosensory afferents in the 1307 brain of the terrestrial hermit crab (Coenobita clypeatus; Coenobitidae, Anomura). $1308 \quad$ Frontiers in Neuroanatomy 9:94.

1309 Utting M., Agricola HJ., Sandeman RE., Sandeman DC. 2000. Central complex in the brain of 1310 crayfish and its possible homology with that of insects. The Journal of Comparative $1311 \quad$ Neurology 416:245-261.

1312 Vannini M., Ferretti J. 1997. Chemoreception in two species of terrestrial hermit crabs 1313 (Decapoda: Coenobitidae). Journal of Crustacean Biology 17:33-37.

1314 Vilpoux K., Sandeman RE., Harzsch S. 2006. Early embryonic development of the central 1315 nervous system in the Australian crayfish and the Marbled crayfish (Marmorkrebs). Development Genes and Evolution 216:209-223.

Vitzthum H., Homberg U., Agricola H. 1996. Distribution of Dip-allatostatin I-like immunoreactivity

Walls ML., Layne JE. 2009. Direct Evidence for Distance Measurement via Flexible Stride Integration in the Fiddler Crab. Current Biology 19:25-29.

Wasserthal LT., Seibt U. 1976. Fine structure, function and cleaning of the aesthetascs on the antennules of the shrimp Hymenocera picta (Gnathophyllidae). Zeitschrift für Tierpsychologie 42:186-199.

Weissburg MJ. 2011. Waterborne Chemical Communication: Stimulus Dispersal Dynamics and Orientation Strategies in Crustaceans. In: Breithaupt T, Thiel M eds. Chemical Communication in Crustaceans. Springer New York, 63-83. Cambridge: Cambridge University Press, 55-96. 
1330 Wolff GH., Harzsch S., Hansson BS., Brown S., Strausfeld NJ. 2012. Neuronal organization of the hemiellipsoid body of the land hermit crab, Coenobita clypeatus: Correspondence with the mushroom body ground pattern. The Journal of Comparative Neurology

Wyatt TD. 2011. Pheromones and Behavior. In: Breithaupt T, Thiel M eds. Chemical Communication in Crustaceans. New York: Springer, 23-38. 520:2824-2846.

Wolff GH., Strausfeld NJ. 2015. Genealogical Correspondence of Mushroom Bodies across Invertebrate Phyla. Current Biology 25:38-44.

Yasuda-Kamatani Y., Yasuda A. 2006. Characteristic expression patterns of allatostatin-like peptide, FMRFamide-related peptide, orcokinin, tachykinin-related peptide, and SIFamide in the olfactory system of crayfish Procambarus clarkii. The Journal of

Zajac J., Mollereau C. 2006. RFamide peptides. Editorial Introduction. Peptides 27:941-942. Comparative Neurology 496:135-147.

Yin GL., Yang JS., Cao JX., Yang WJ. 2006. Molecular cloning and characterization of FGLamide allatostatin gene from the prawn, Macrobrachium rosenbergii. Peptides 27:1241-1250. A: Neuroethology, Sensory, Neural, and Behavioral Physiology 192:1-25.

Zeil J., Hemmi JM. 2014. Path Integration, Vision, and Decision-Making in Fiddler Crabs. In: Derby CD, Thiel M eds. Nervous Systems and Control of Behavior. The Natural History of the Crustacea. New York: Oxford University Press, 484-508.

Zeil J., Al-Mutairi M. 1996. The variation of resolution and of ommatidial dimensions in the compound eyes of the fiddler crab Uca lactea annulipes (Ocypodidae, Brachyura, Decapoda). The Journal of Experimental Biology 199:1569-1577. 


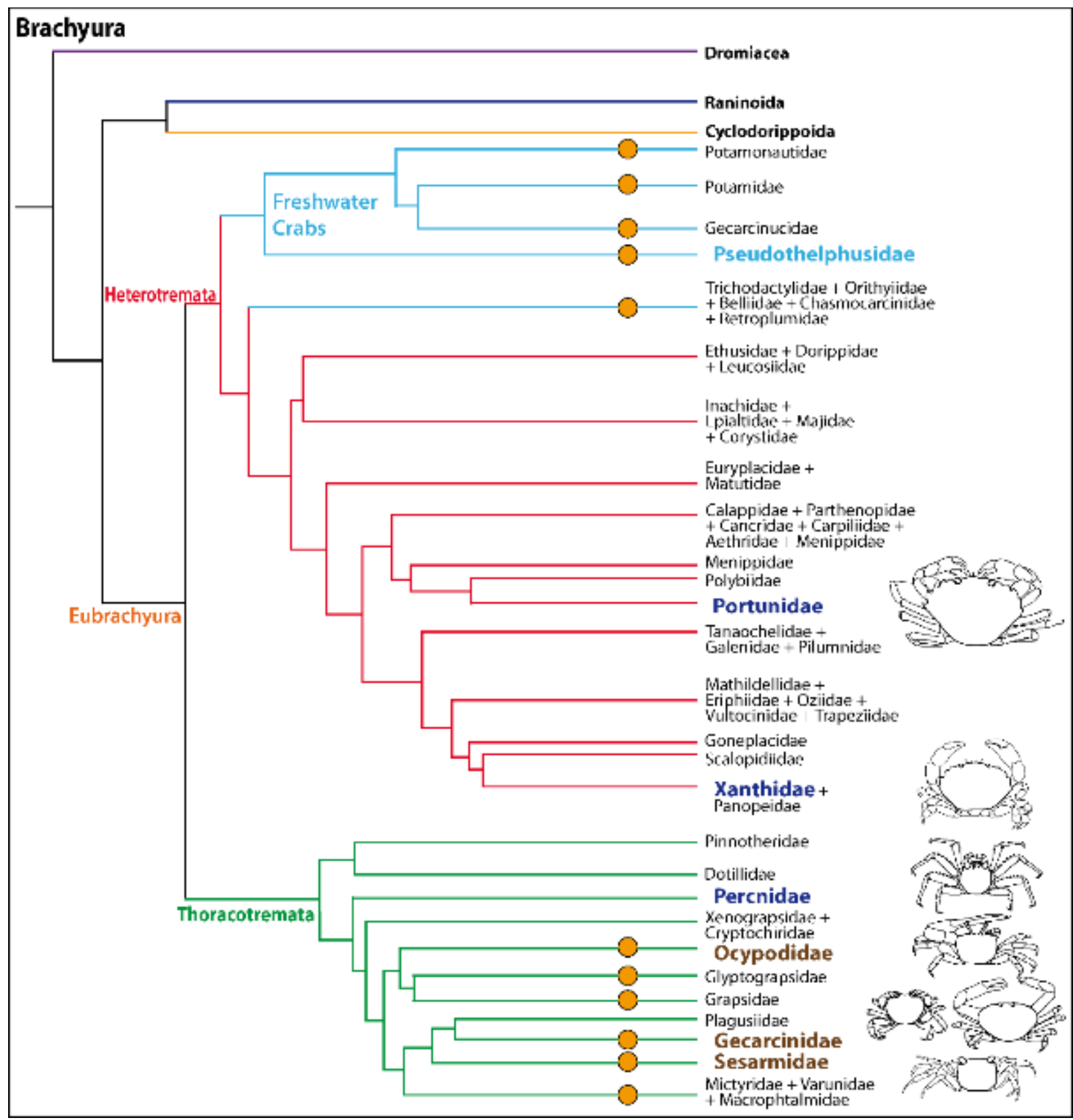

\section{Figure 1.) Simplified phylogenetic relationships among Brachyura after Tsang et al. (2014)} showing higher degrees of terrestrial adaptation $\left(T_{i}>T_{2}\right)$ are indicated by orange circles. Groups of investigated species are highlighted by indented and larger (bold) letters and are color-coded according to their lifestyles (pale blue $=$ freshwater crabs, dark blue $=$ marine, brown $=$ terrestrial $)$. 

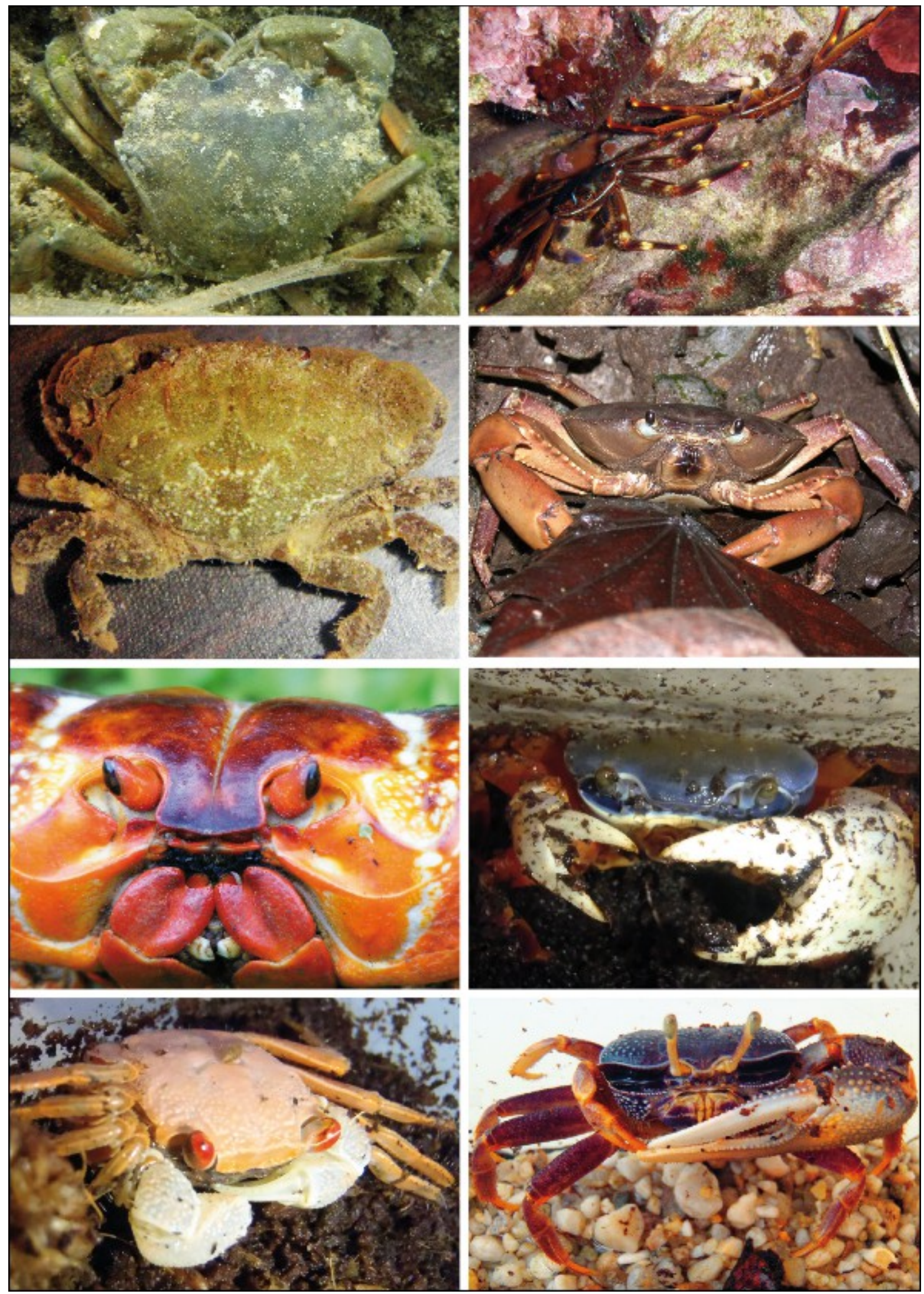

\section{Figure 2.) Brachyuran species analyzed:}

1361 Portraits of individuals of investigated brachyuran species in living state. A-C. Marine Brachyura: A. Carcinus 
1363 Spain, 2013), C. Xantho hydrophilus (infralittoral rock bottom, $5 \mathrm{~m}$ depth, Cala Llenya, Spain, 2012). D-H. 1364 Terrestrial Brachyura: D. Epilobocera sinuatifrons (Guajataca, Puerto Rico, 2004), E. Gecarcoidea natalis (At the 1365 Pink House, Christmas Island, Australia, 2011), F. Cardisoma armatum, G. Geosesarma tiomanicum, H. Uca 1366 tangeri. Portraits of F to $\mathrm{H}$ in living state were taken in the laboratory in Greifswald in 2013. 


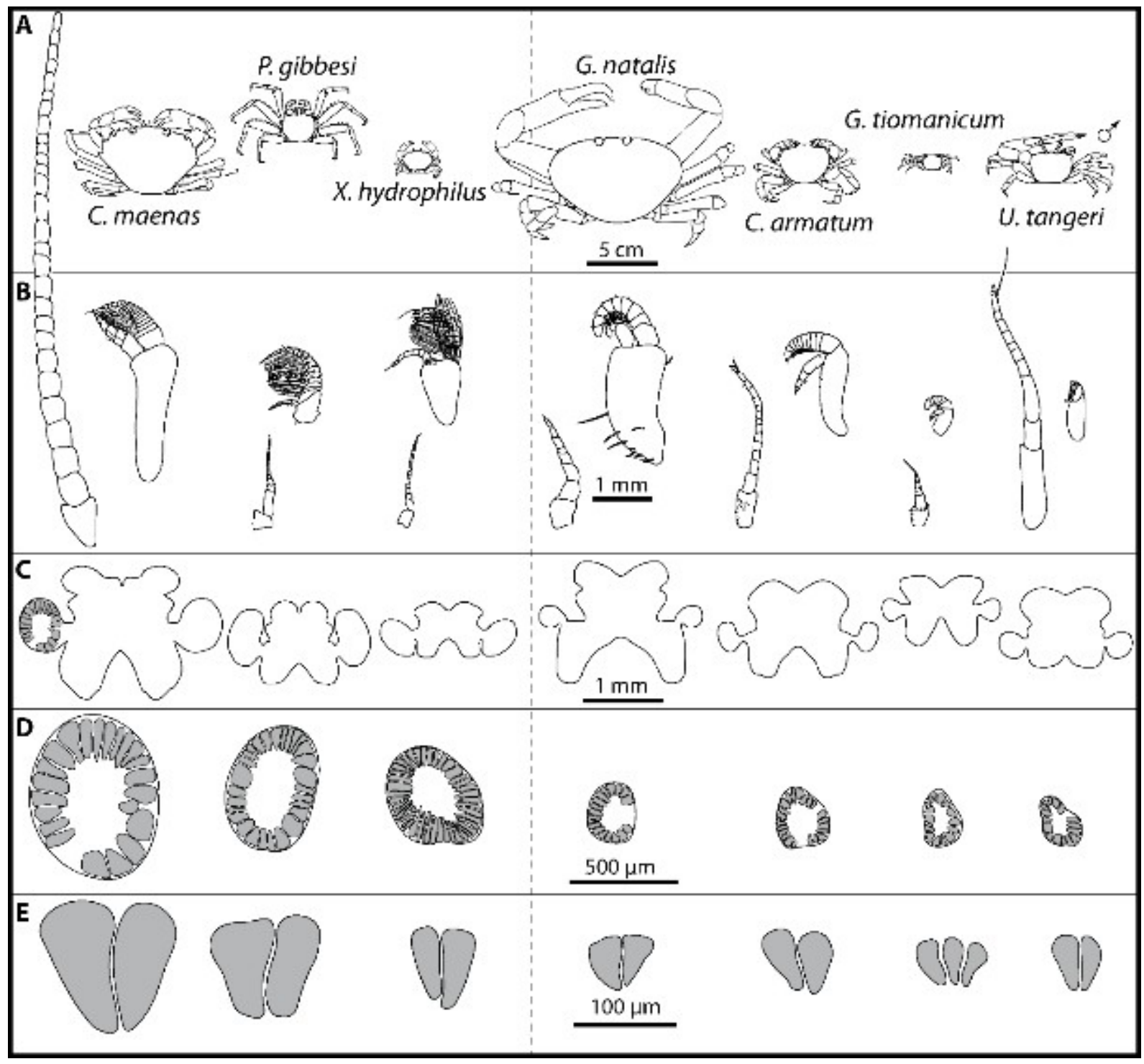

Figure 3.) Comparative draft of studied animals: their brains, first antennae, deutocerebral chemosensory lobes (DCLs) and olfactory glomeruli

Note that drawings are equally scaled in each line. Each column corresponds to same species as follows: Carcinus maenas, Percnon gibbesi, Xantho hydrophilus, as representatives for marine brachyurans are given and opposed (separated by a dashed line) toGecarcoidea natalis, Cardisoma armatum, Geosesarma tiomanicum, and Uca tangeri representing brachyuran species featuring terrestrial lifestyles to different degrees. Note that for animals featuring a markedly size-specific sexual dimorphism, only the males are drawn. A: Dorsal view of habitus in all studied species. B: Distal antennomeres of the first antennae (antennules) of all species featuring the minor median and major lateral flagella which bear the aeasthetascs. C: Outlines of central brains based on the synapsin immunoreactivity. The lateral protocerebrum and nerves are not displayed. D: Outlines of DCLs and peripheral arrangement of olfactory glomeruli as they appear in horizontal sections. Note that the position of DCL within the brain is indicated in C. maenas in line C. E: Examples of shape and organization of randomly chosen olfactory glomeruli of all studied species as they appear in horizontal sections. 


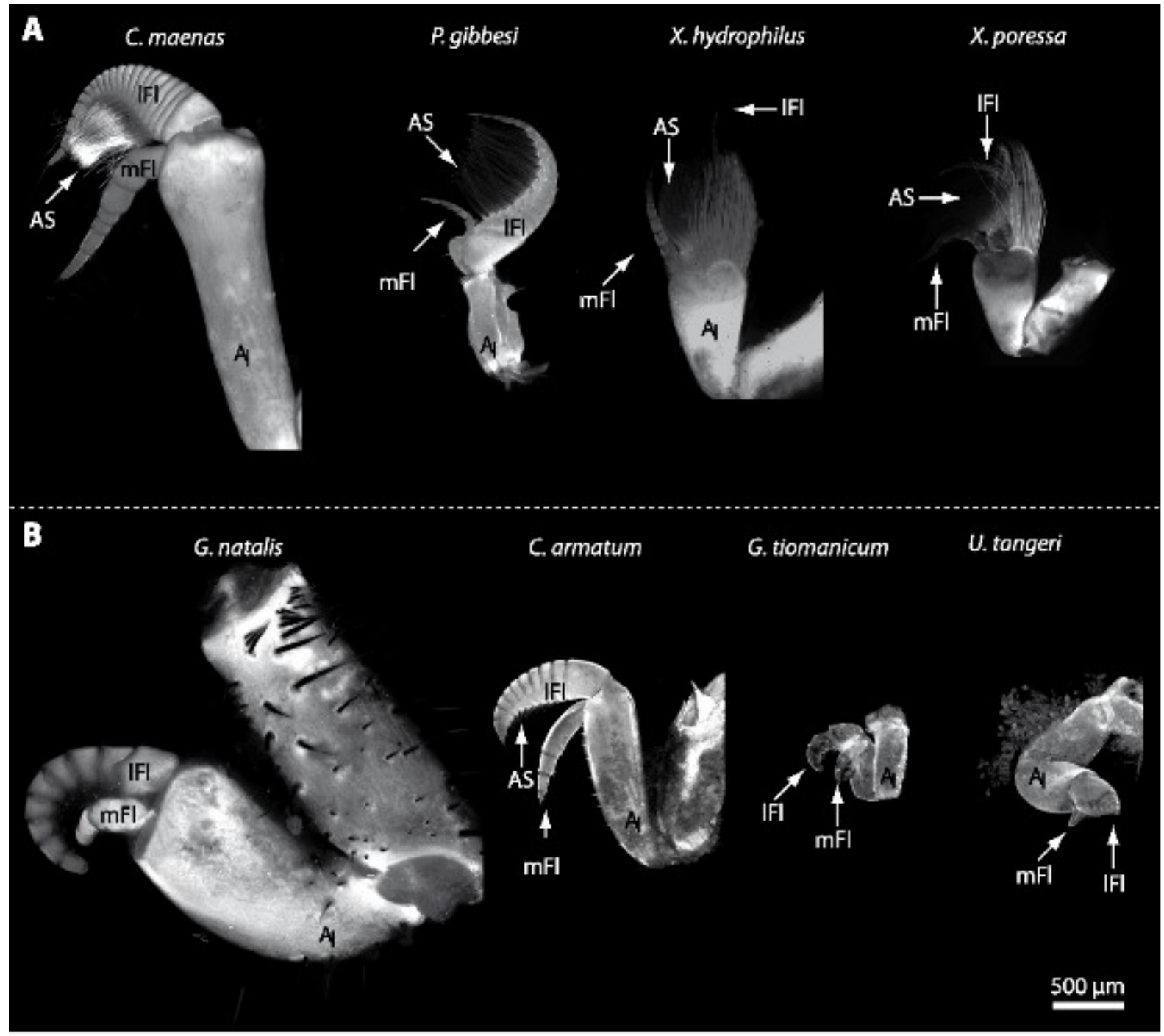

Figure 4.) First antenna in studied brachyuran species

A: UV-autofluorescence micrograph shows equally scaled first antenna $\left(\mathrm{A}_{\mathrm{I}}\right)$ from four marine species Carcinus maenas, Percnon gibbesi, Xantho hydrophilus and Xantho poressa; and B: from four terrestrial species Gecarcoidea natalis, Cardisoma armatum, Geosesarma tiomanicum and Uca tangeri. Abbreviations: AS, aesthetascs; IFl, lateral flagellum; $\mathrm{mFl}$, median flagellum. 

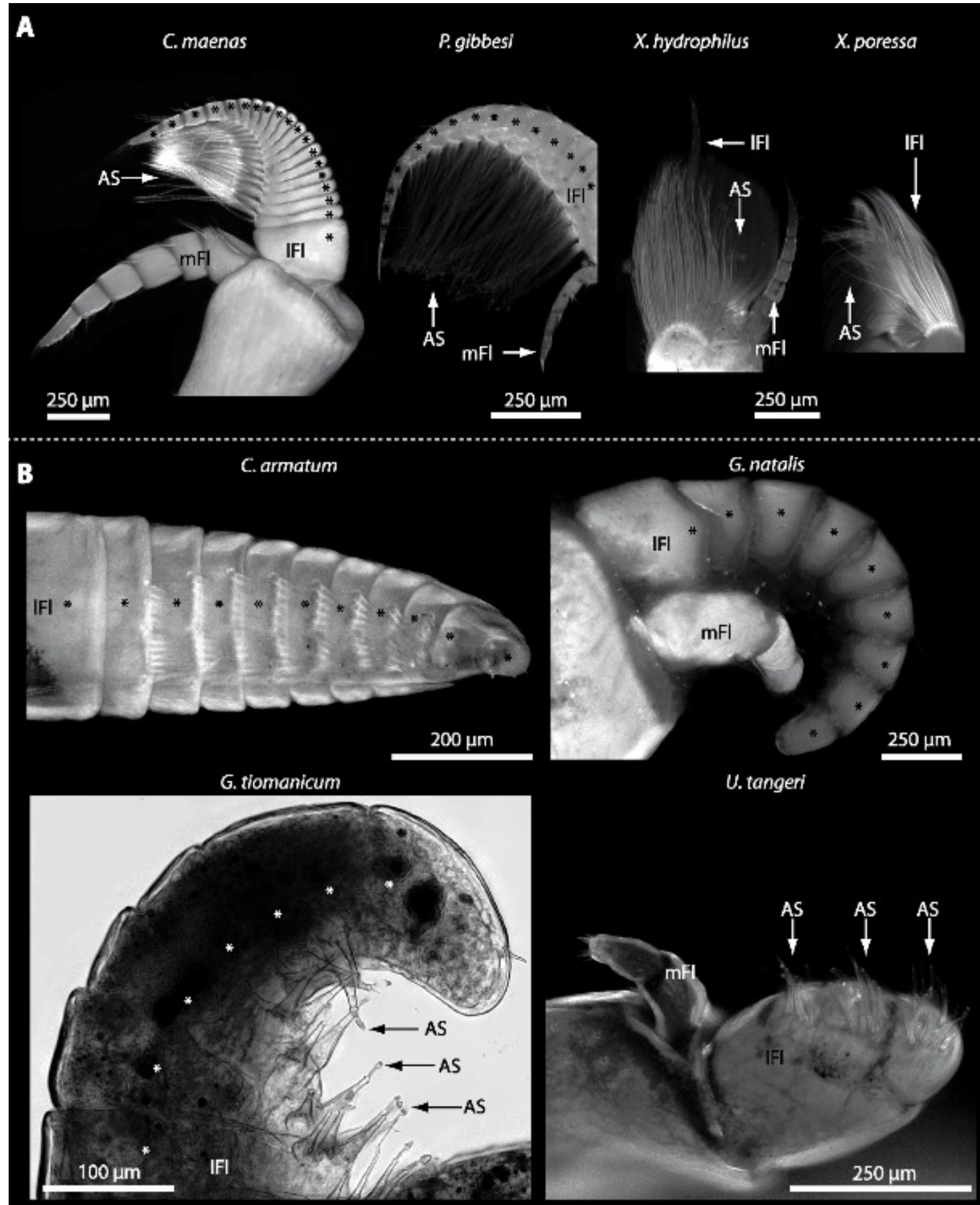

\section{Figure 5.) Flagella and aesthetascs on first antenna in different brachyuran species}

A: UV-autofluorescence micrograph shows lateral and median flagellum as well as the aesthetascs from four marine species: Carcinus maenas, Percnon gibbesi, Xantho hydrophilus, and Xantho poressa and B: from four terrestrial species Cardisoma armatum, Gecarcoidea natalis, Geosesarma tiomanicum, and Uca tangeri. A micrograph using transmitted light shows the lateral flagellum and aesthetascs from Geosesarma tiomanicum.. Asterisks identify single annuli of the lateral flagellum. Abbreviations: AS, aesthetascs; $1 \mathrm{Fl}$, lateral flagellum; $\mathrm{mFl}$, median flagellum. 


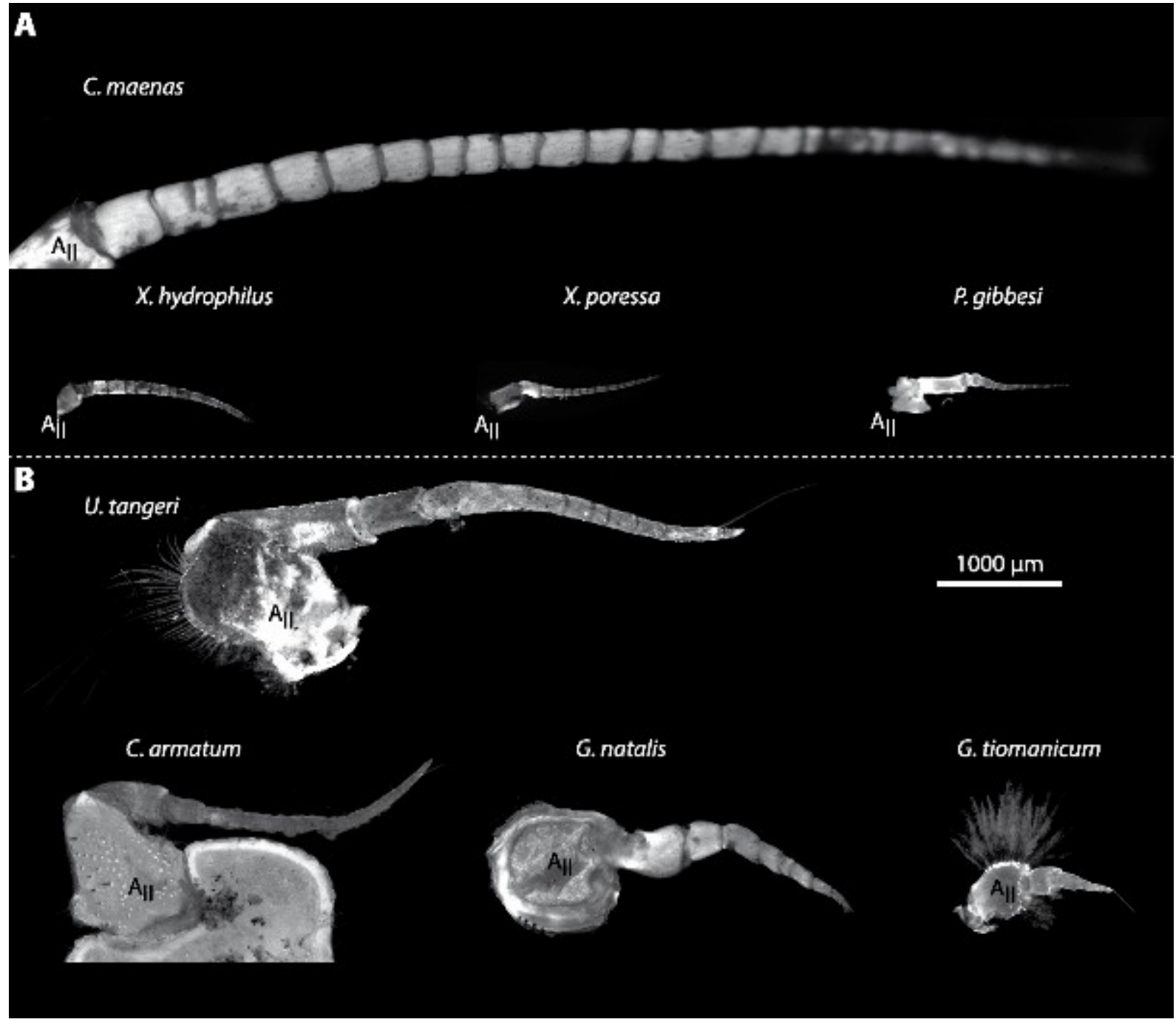

1391 Figure 6.) Second antenna of studied brachyuran species

1392 A: UV-autofluorescence micrograph shows the equally scaled second antenna $\left(\mathrm{A}_{\text {III }}\right)$ from four marine species 1393 Carcinus maenas, Percnon gibbesi, Xantho hydrophilus and Xantho poressa and B: from four terrestrial species 1394 Gecarcoidea natalis, Cardisoma armatum, Geosesarma tiomanicum and Uca tangeri. 

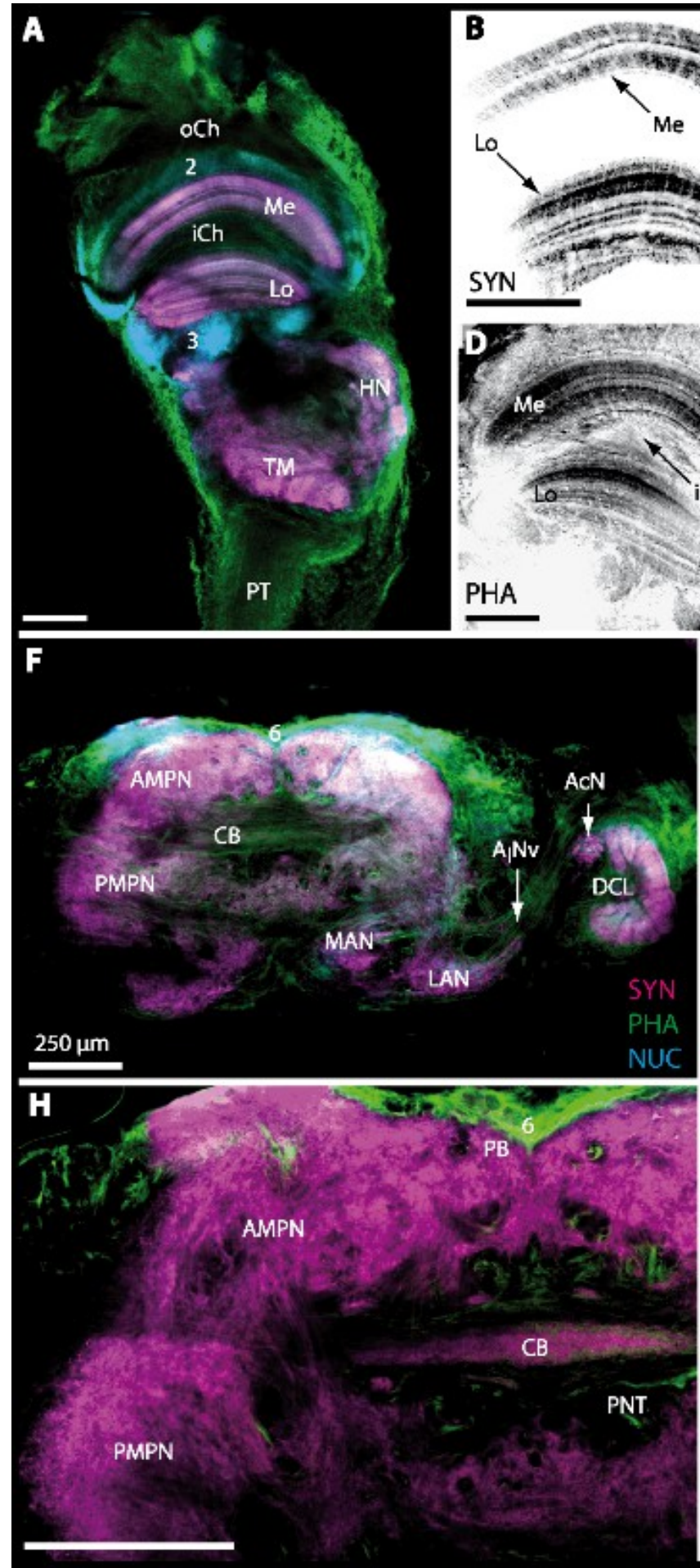
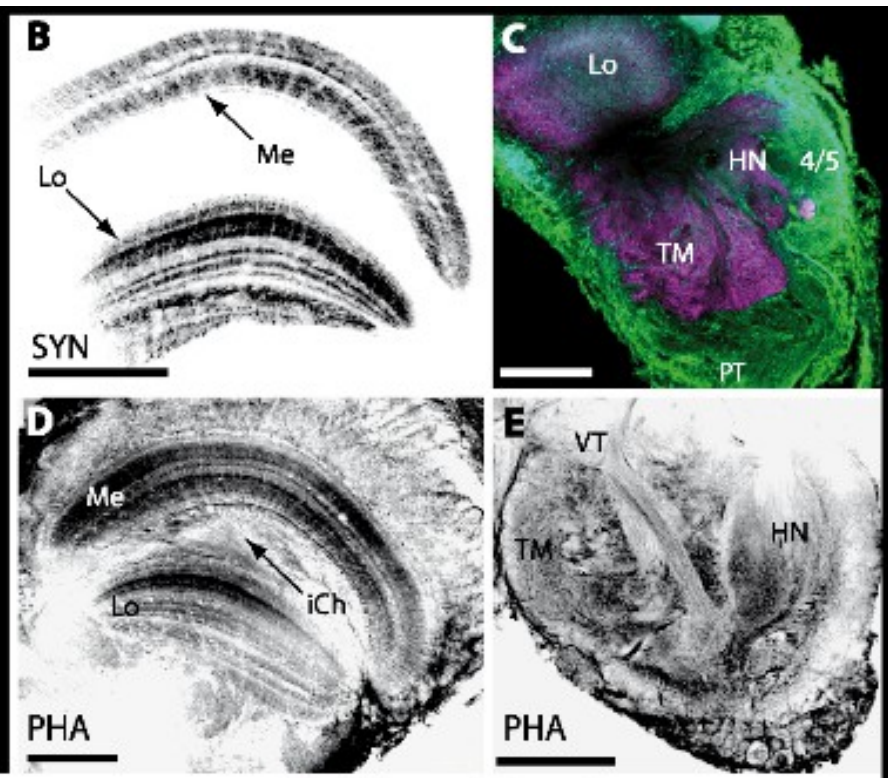

G
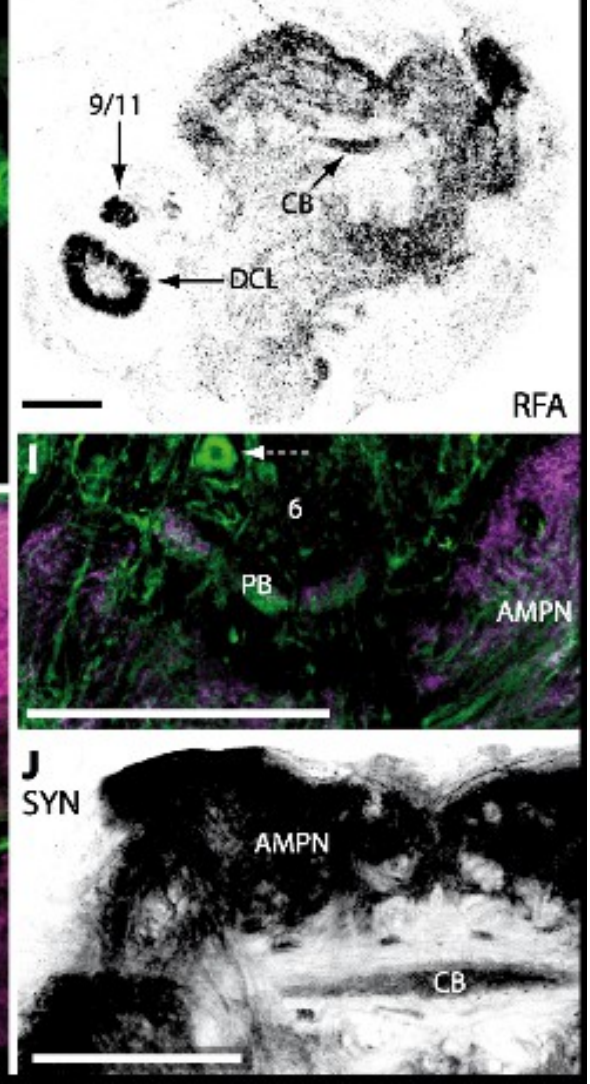

A to E: Micrographs of triple-labeled optical horizontal sections showing visual neuropils and the lateral protocerebrum. Lamina was lost through dissection. F to $\mathbf{~}$ : brain and details of specific brain areas such as, median protocerebrum and deutocerebrum in $\mathrm{H}$ and protocerebral bridge $(\mathrm{PB})$ in I. The arrow with a dashed line marks a giant neuron in I. Note that $\mathbf{B}, \mathbf{D}, \mathbf{E}, \mathbf{G}$, and $\mathbf{J}$ show inverted single-channel micrographs of different labelings (indicated by abbreviations). Abbreviations of immunhistochemical labelings and histochemical markers: NUC, 
1403 (2), (3), (4/5), (6), and (9/11); $\mathrm{A}_{\mathrm{I}} \mathrm{Nv}$, antenna I nerve; AcN, accessory neuropil; AMPN, anterior medial protocerebral 1404 neuropil; CB, central body, DCL, deutocerebral chemosensory lobe; HN, hemiellipsoid body; iCh, inner visual chiasm; LAN, lateral antenna I neuropil; Lo, lobula; MAN, median antenna I neuropil; Me, medulla; oCh, outer visual chiasm; PMPN, posterior medial protocerebral neuropil; PNT, projection neuron tract; PT, protocerebral tract; TM, terminal medulla; VT, visual tract. Scale bars $=250 \mu \mathrm{m}$.
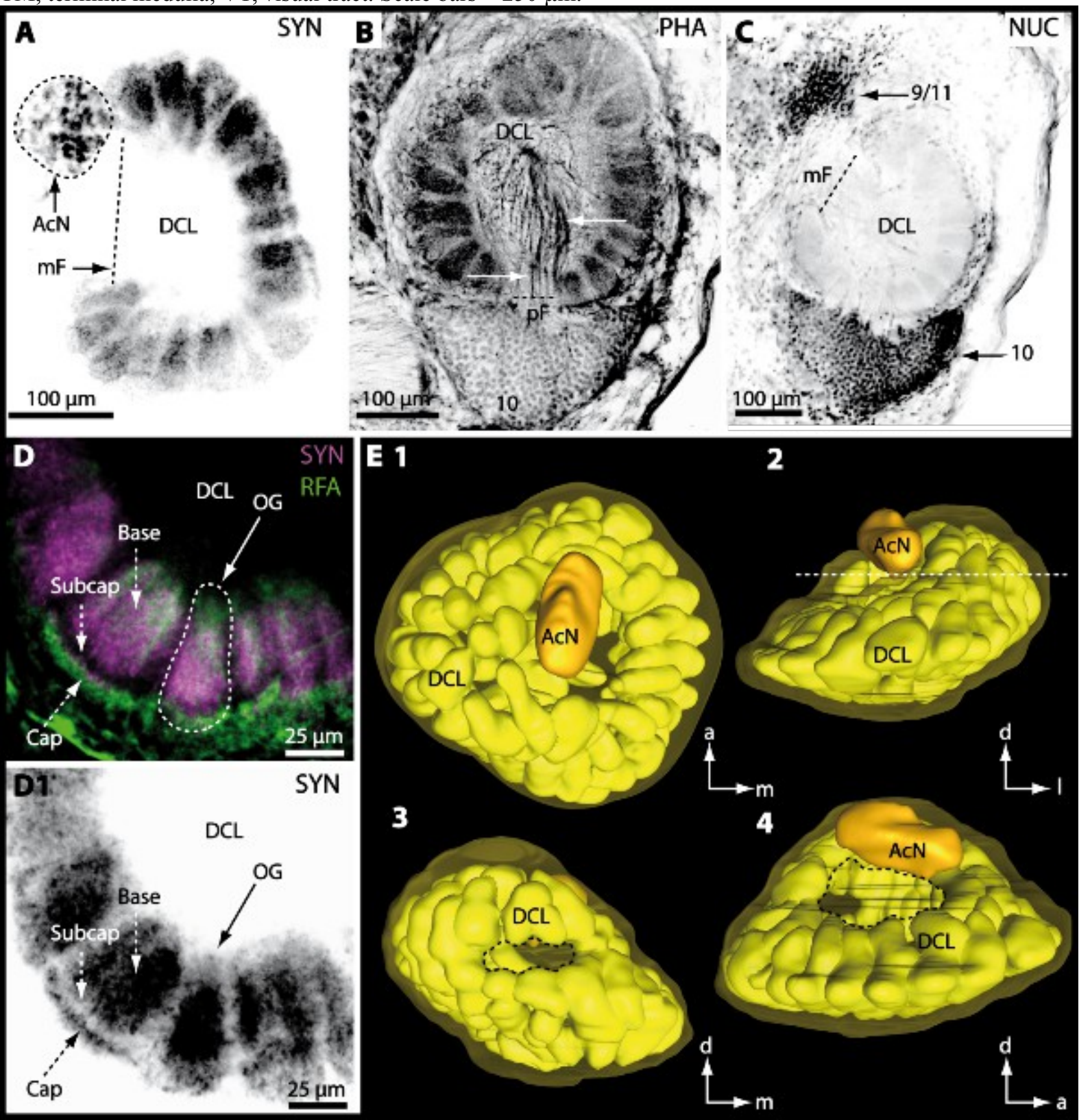

Figure 8.) Optical horizontal sections and 3D-reconstruction of deutrocerebral chemosensory lobe (DCL) in Cardisoma armatum

A-C: Inverted single-channel micrographs of DCL. White arrows in B mark axons of projection neurons. D and D1: Detailed picture of the olfactory glomeruli (OG) with double-labeling in D and inverted single-channel picture in D1. E: 3D-reconstruction of DCL, olfactory glomeruli and accessory neuropil $(\mathrm{AcN})$ shown in four different orientations. 1: from dorsal. 2: from anterior. Dashed line represents the horizon of section given in A. 3: from 1414 posterior. Dashed line indicates the posterior foramen $(\mathrm{pF})$. 4: centro-lateral view. Dashed line indicates the median (black); PHA, actin-labeling using phalloidin (black); RFA, labeling against RFamide (green); SYN, labeling against 
1417 synapsin (magenta or black). Other abbreviation: 10 and 9/11, cell clusters (10) and (9/11); a, anterior; Base, base 1418 domain of OG; Cap, cap domain of OG; d, dorsal; 1, lateral; m, median; Subcap, subcap domain of OG.
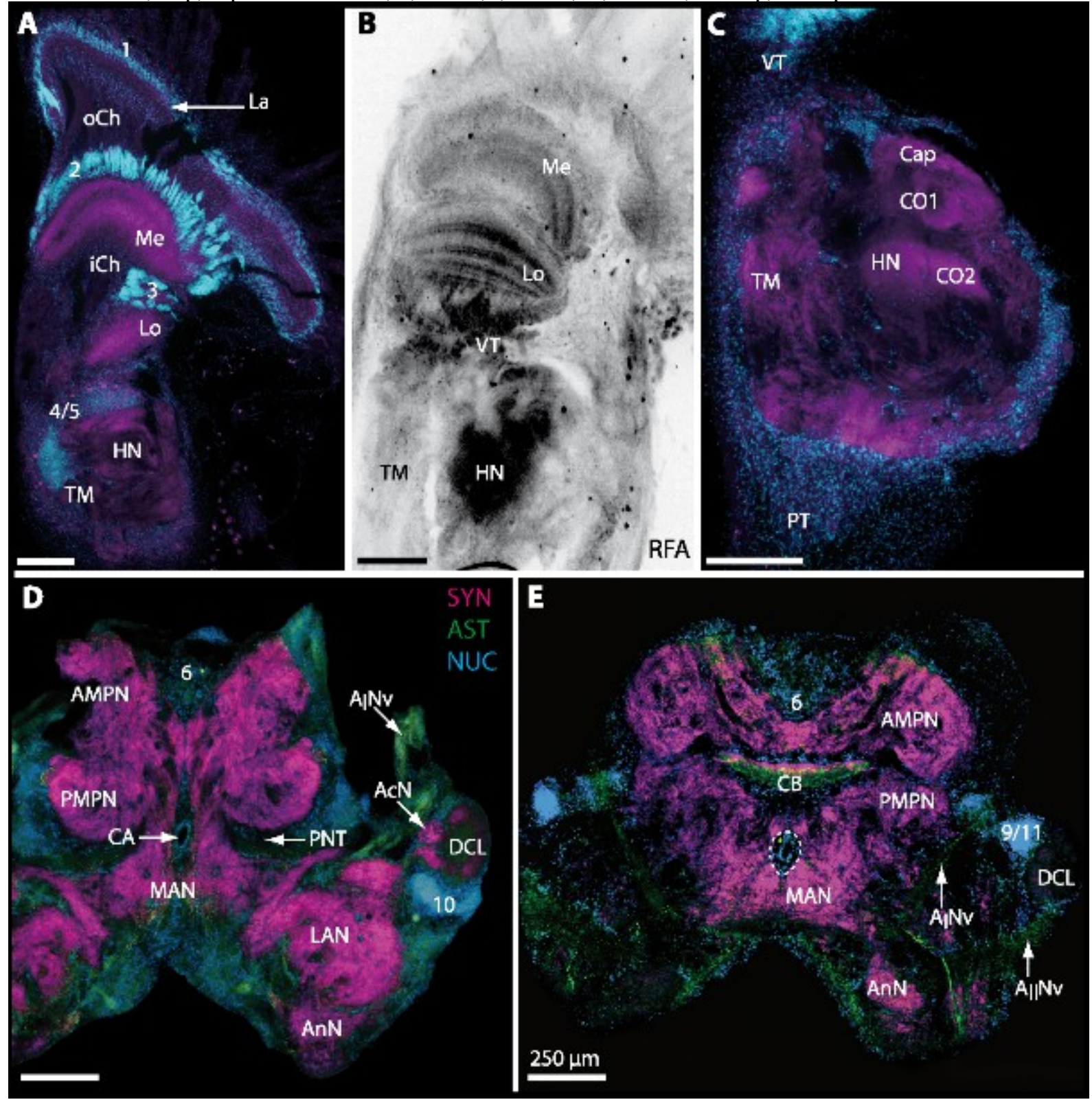

1419 Figure 9.) Micrographs of triple-labeled vibratome sections of central brain and lateral protocerebrum in

1421 A to C: Visual neuropils and lateral protocerebrum. Note that in A and C, two out of three channels are shown while 1422 B shows an inverted single-channel micrograph. D and E show two triple-labeled horizontal vibratome sections of central brain (D) and further ventral of central brain (E). Dashed line in E indicates the cerebral artery. Abbreviations of immunhistochemical labelings and histochemical marker: AST, labeling against allatostatin (green); NUC, nuclear marker (cyan); RFA, labeling against RFamide (black); SYN, labeling against synapsin (magenta). Other abbreviations: $1,2,3,4 / 5,6,9 / 11$, and 10, cell clusters (1), (2), (3), (4/5), (6), (9/11), and (10); $\mathrm{A}_{\mathrm{I}} \mathrm{Nv}$, antenna I nerve; $\mathrm{A}_{\mathrm{II}} \mathrm{Nv}$, antenna II nerve; AcN, accessory neuropil; AMPN, anterior medial protocerebral neuropil; AnN, antenna II neuropil; CA, cerebral artery; CB, central body; DCL, deutocerebral chemosensory lobe; iCh, inner visual chiasm; HN, hemiellipsoid body; La, lamina; LAN, lateral antenna I neuropil; Lo, lobula; MAN, median antenna I neuropil; Me, medulla; oCh, outer visual chiasm; PMPN, posterior medial protocerebral neuropil; PNT, projection neuron tract; PT, protocerebral tract; TM, terminal medulla; VT, visual tract. Scale bars $=250 \mu \mathrm{m}$. 


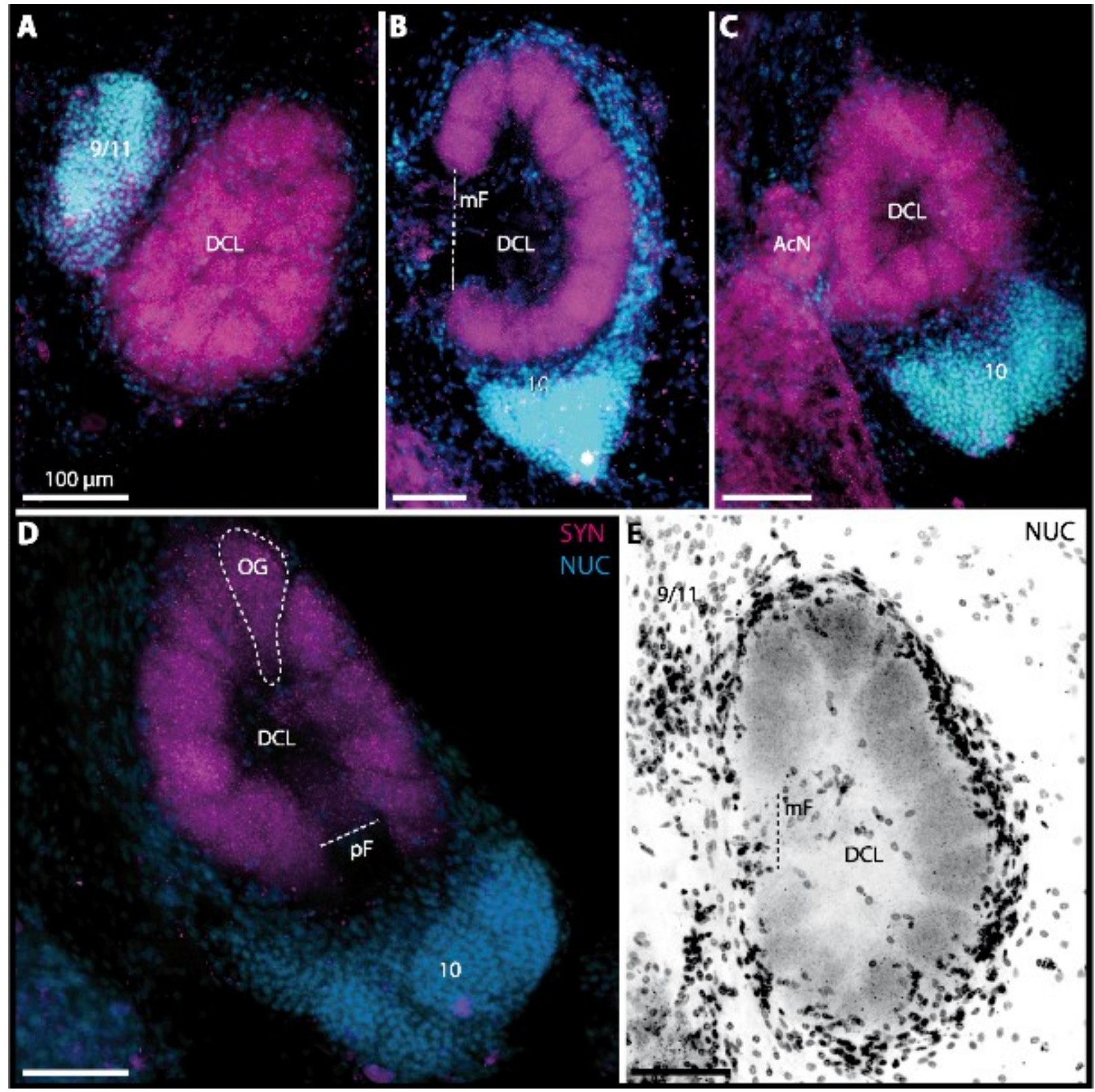

Figure 10.) Vibratomy of double-labeled horizontal sections the deutocerebral chemosensory lobe (DCL) in

A-D: DCL featuring olfactory glomeruli (OG). Note that only an inverted single-channel micrograph is given in $\mathbf{E}$ showing nuclear staining in the periphery of DCL. Abbreviations of immunhistochemical labeling and histochemical staining: NUC, nuclear marker (cyan or black); SYN, labeling against synapsin (magenta). Other abbreviations: 10 and 9/11, cell clusters (10) and (9/11); AcN, accessory neuropil; mF, median foramen; OG, olfactory glomerulus; $\mathrm{pF}$, posterior foramen. Scale bars $=100 \mu \mathrm{m}$. 

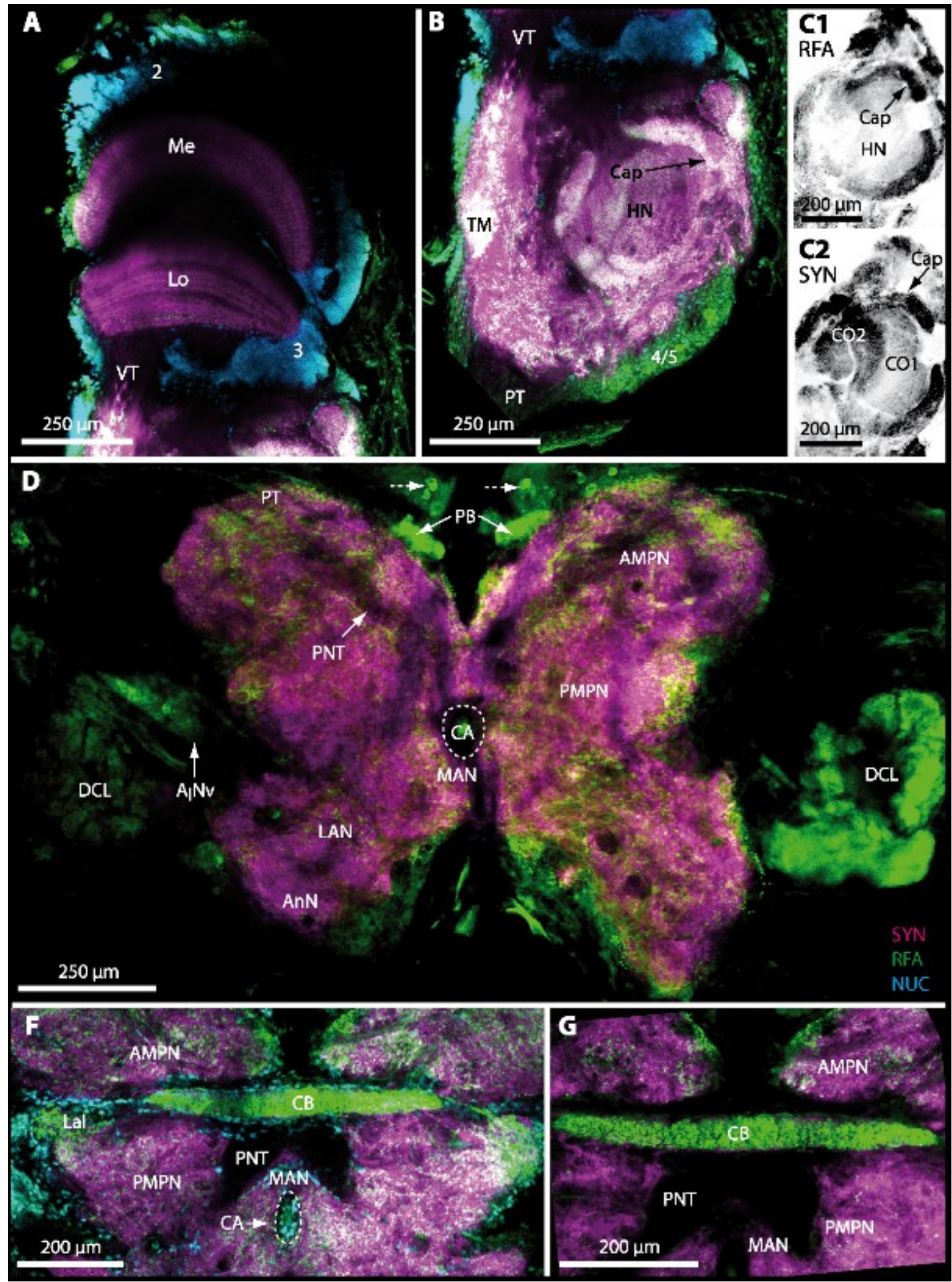

1439 Figure 11.) Triple-labeled micrographs of optical horizontal sections showing the central brain, lateral 1440 protocerebrum, and specific brain areas in Geosesarma tiomanicum 
1441 1442 1443 1444 1445 1446 1447 1448 1449 1450 1451
A to C: Micrographs of optical sections of visual neuropils (A) and the TM/HN-complex (B, $\mathrm{C} 1$ and $\mathrm{C} 2)$. Note that in $\mathrm{C} 1$ and $\mathrm{C} 2$, inverted single-channel micrographs are shown. D to E: Brain (D) and central body and adjacent protocerebral and deutocerebral neuropils are given in $\mathrm{E}$ and $\mathrm{F}$ in higher detail. Arrows with dashed lines in $\mathrm{D}$ mark giant neurons featuring distinct RFA-like immunoreactivity. Abbreviations of immunhistochemical labelings and histochemical markers: NUC, nuclear marker (cyan); PHA, actin-marker using phalloidin (green); RFA, labeling against RFamide (green or black); SYN, labeling against synapsin (magenta or black). Other abbreviations: 2, 3, and 4/5, cell clusters (2), (3), and (4/5); $\mathrm{A}_{I} \mathrm{Nv}$, antenna I nerve; AMPN, anterior medial protocerebral neuropil; AnN, antenna II neuropil; CA, cerebral artery; Cap, cap neuropil; CB, central body; DCL, deutocerebral chemosensory lobe; HN, hemiellipsoid body; Lal, lateral accessory lobe; LAN, lateral antenna I neuropil; Lo, lobula; MAN, median antenna I neuropil; Me, medulla; PB, protocerebral bridge; PMPN, posterior medial protocerebral neuropil; PNT, projection neuron tract; PT, protocerebral tract; TM, terminal medulla; VT, visual tract.
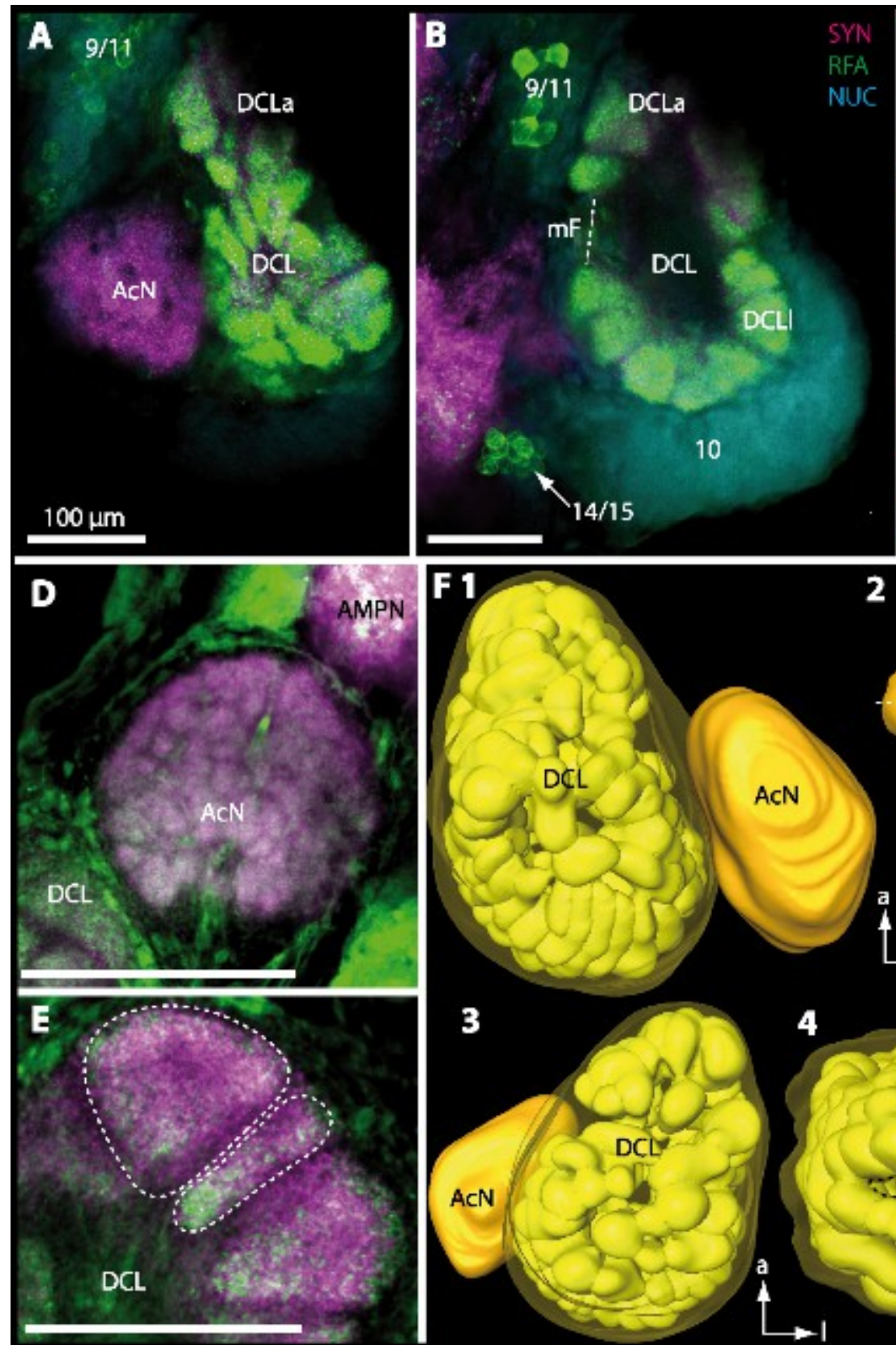
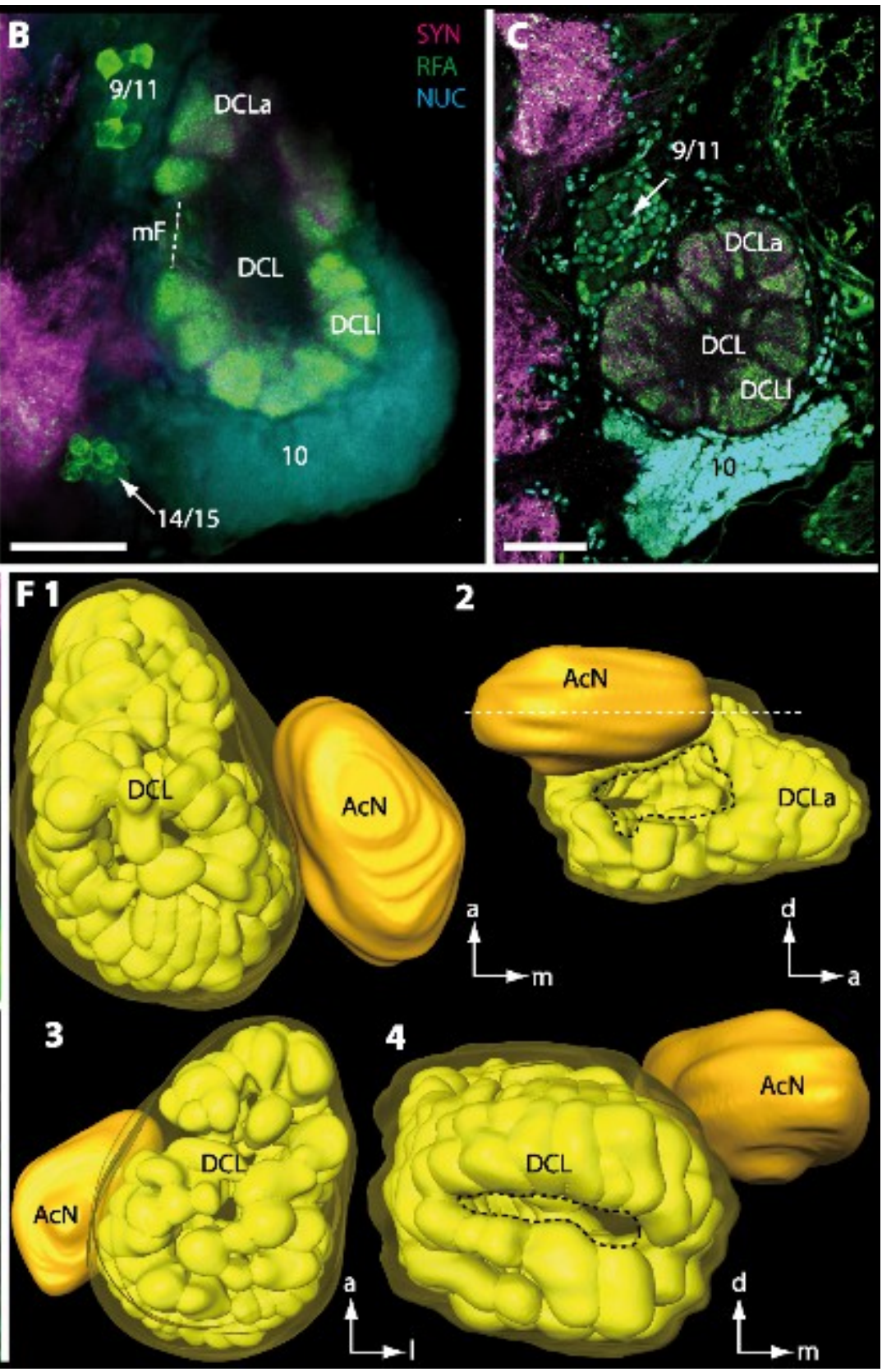
Figure 12.) Optical horizontal sections and 3D-reconstruction of deutrocerebral chemosensory lobe (DCL) in

1454 A-E: Triple labeled optical sections of DCL and adjacent neuropils and cell clusters. Deutocerebral accessory lobe $(\mathrm{AcN})$ is shown in D. Olfactory glomeruli $(\mathrm{OG})$ are indicated by white dashed lines in $\mathrm{E}$ in higher detail. F: 3Dreconstruction of DCL, olfactory glomeruli, and accessory neuropil in four different orientations - 1: from dorsal. 2: centro-lateral view. White dashed line indicates orientation of section given in A. Black dashed line indicates median foramen $(\mathrm{mF})$. 3: from ventral. 4: from posterior. Dashed line highlights posterior foramen $(\mathrm{pF})$. Abbreviations of the immunhistochemical labelings and histochemical marker: NUC, nuclear marker (cyan); RFA, labeling against RFamide (green); SYN, labeling against synapsin (magenta). Other abbreviations: 10, 9/11, and 14/15, cell cluster (10), (9/11), and (14/15); a, anterior; AMPN, anterior medial protocerebral neuropil; d, dorsal; DCLa, anterior sublobe of the DCL; DCLl, lateral sublobe of the DCL; 1, lateral; m, median. Scale bars $=100 \mu \mathrm{m}$. 


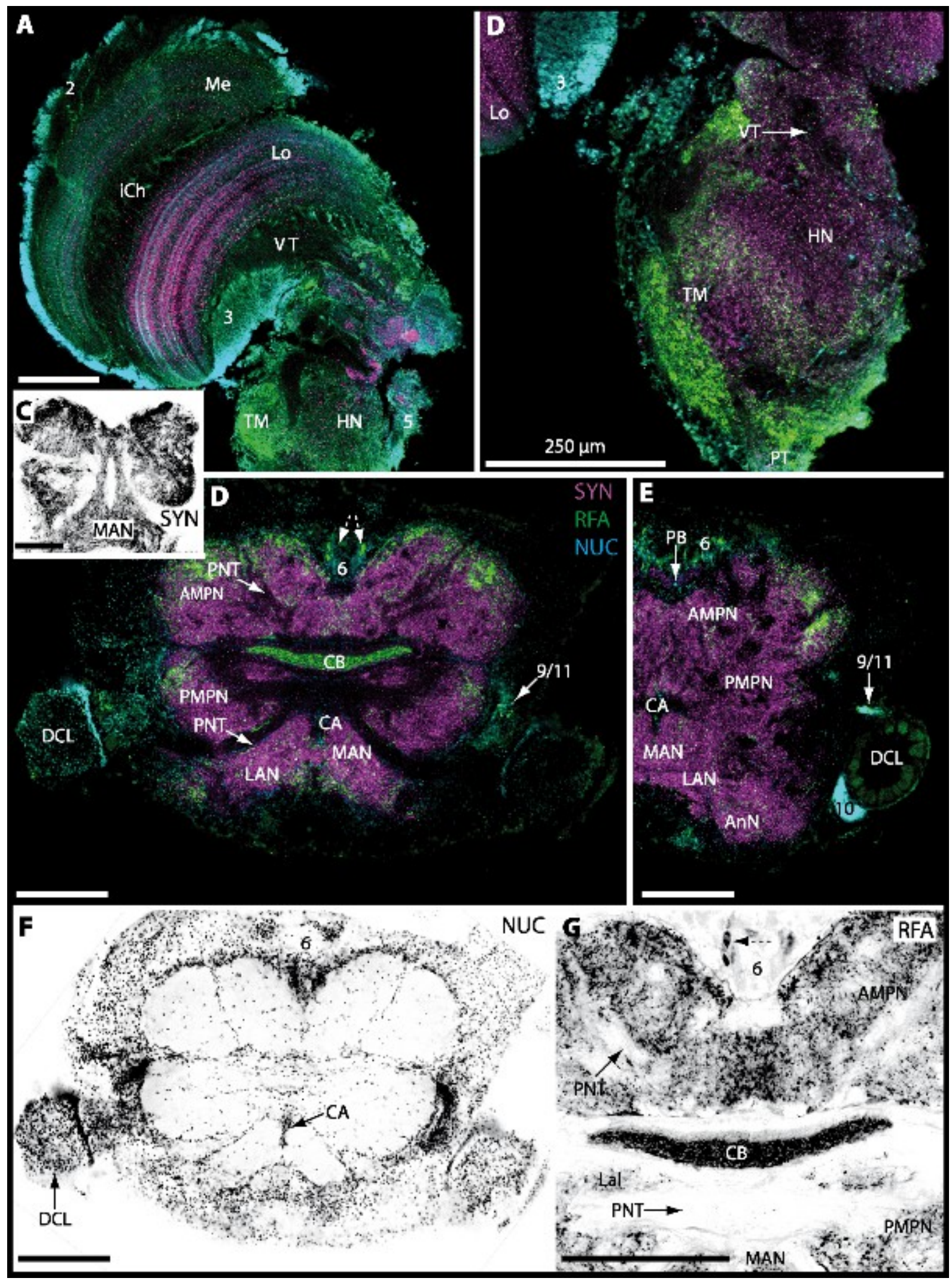

1463 Figure 13.) Triple-labeled optical horizontal sections of central brain, lateral protocerebrum, and specific 1464 brain areas in Uca tangeri 
1465 1466 1467 1468 1469 1470 1471 1472 1473 1474 1475

A and B: Vertical section showing the visual neuropils (A) and the TM/HN-complex (B). C to G show vertical sections of the brain and specific brain areas. Note that in C, F, and G, inverted single-channel micrographs are displayed. Arrows with dashed lines in D and G mark large neurons in cell cluster (6) featuring distinct RFA-like immunoreactivity. Abbreviations of immunhistochemical labelings and histochemical markers: NUC, nuclear marker (cyan or black); RFA, labeling against RFamide (green or black); SYN, labeling against synapsin (magenta or black). Other abbreviations: 2, 3, 5, 6, 10, and 9/11, cell clusters (2), (3), (5), (10), and (9/11); AMPN, anterior medial protocerebral neuropil; AnN, antenna II neuropil; CA, cerebral artery; CB, central body; DCL, deutocerebral chemosensory lobe; HN, hemiellipsoid body; $\mathrm{iCh}$, inner visual chiasm; Lal, lateral accessory neuropil; LAN, lateral antenna I neuropil; Lo, lobula; MAN, median antenna I neuropil; Me, medulla; PB, protocerebral bridge; PMPN, posterior medial protocerebral neuropil; PNT, projection neuron tract; PT, protocerebral tract; TM, terminal medulla; VT, visual tract. Scale bars $=250 \mu \mathrm{m}$.

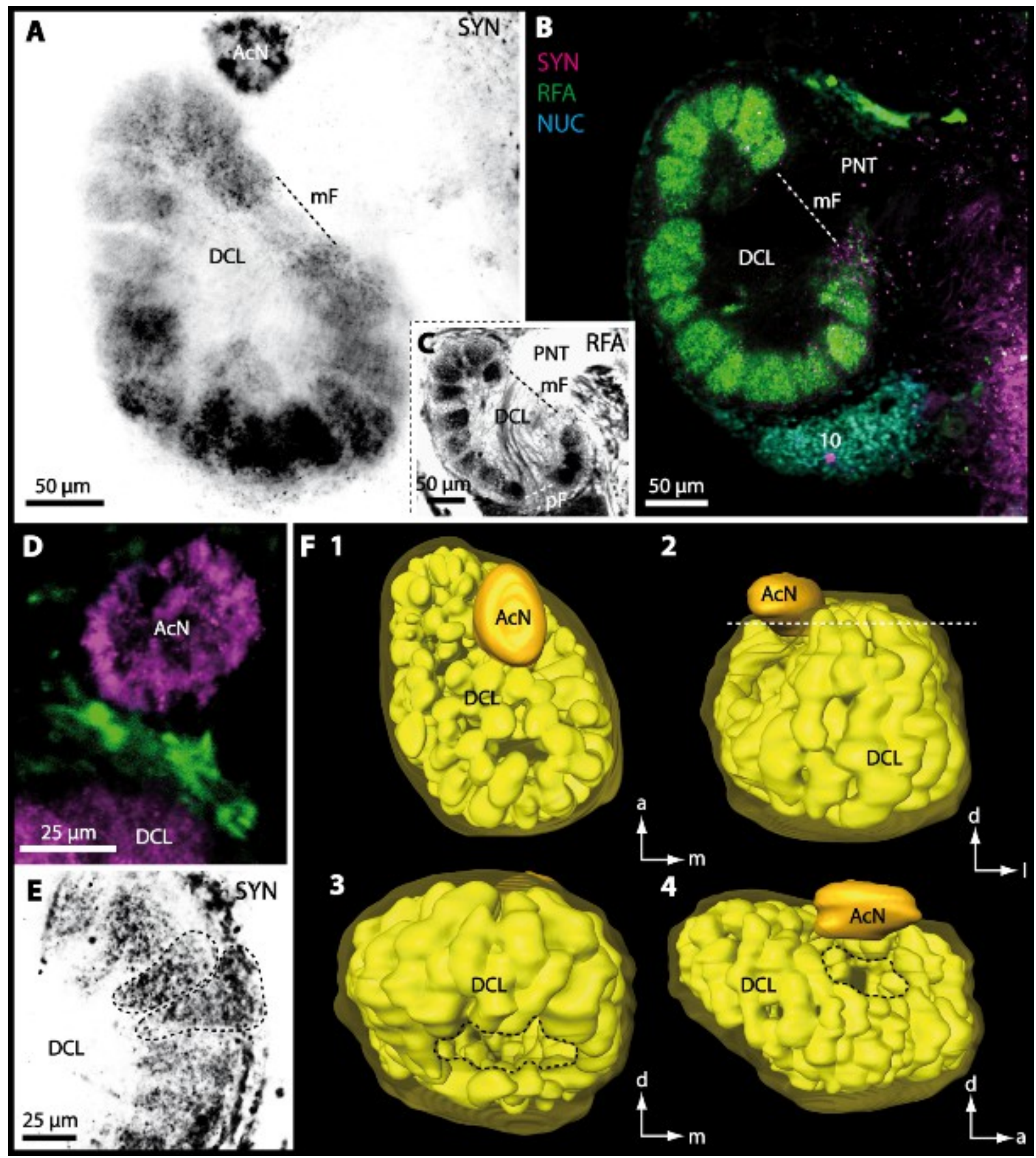


1476 1477

1478

1479

1480

1481

1482

1483

1484

1485

1486

Figure 14.) Optical horizontal sections and 3D-reconstruction of deutocerebral chemosensory lobe (DCL) in Uca tangeri

A, C and E: Inverted single-channel micrographs of DCL. Dashed lines in E indicate two olfactory glomeruli (OG). B and D: Triple-labeled optical sections of DCL in B and accessory lobe (AcN) in D. F: 3D-reconstruction of DCL, its $\mathrm{OG}$ and $\mathrm{AcN}$ in four different perspectives. 1: from dorsal. 2: from anterior. Dashed line represents horizon of section represented in A. 3: from posterior. Dashed line outlines posterior foramen (pF). 4: centro-median view. Dashed line highlights median foramen $(\mathrm{mF})$. Abbreviations of immunhistochemical labelings and histochemical markers:

NUC, nuclear marker (cyan); RFA, labeling against RFamide (green or black); SYN, labeling against synapsin (magenta or black). Abbreviation: 10, cell cluster (10); a, anterior; d, dorsal; 1, lateral; m, median; $\mathrm{mF}$, median foramen; PNT, projection neuron tract.
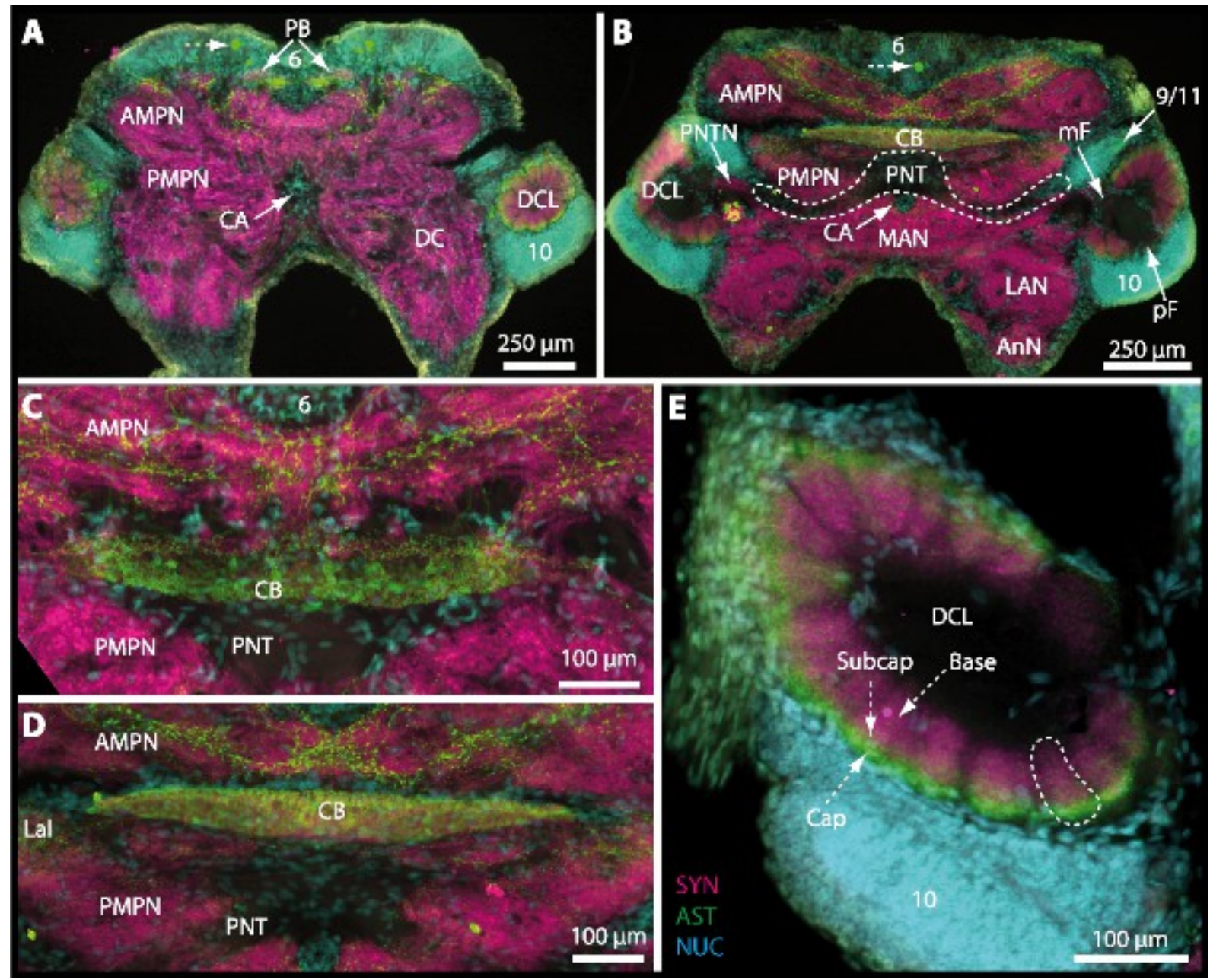

Figure 15.) Vibratomy of triple-labeled horizontal vibratome sections of central brain and specific brain areas

\section{in Epilobocera sinuatifrons}

A and B: Two brain sections (100 $\mu \mathrm{m})$ from dorsal (A) to ventral (B) are shown. Arrows with dashed lines in A and B point at specific neurons within cell cluster (6) featuring distinct AST-like immunoreactivity. Dashed line highlights the position of the projection neuron tract (PNT). C and D show neuropils of the central complex from dorsal (C) to ventral (D) in more detail. Higher detailed insight from deutocerebral chemosensory lobe (DCL) is given in E. Dashed line outlines a single olfactory glomerulus (OG). Abbreviations of immunhistochemical labelings and histochemical markers: AST, labeling against allatostatin (green); NUC, nuclear marker (cyan); SYN, labeling against synapsin (magenta). Other abbreviations: 6, 10, and 9/11, cell clusters (6), (10), and (9/11); AMPN, anterior medial protocerebral neuropil; AnN, antenna II neuropil; Base, base domain of OG; CB, central body; Cap, cap domain of OG; DC, deutocerebrum; Lal, lateral accessory neuropil; LAN, lateral antenna I neuropil; 
$1498 \mathrm{MAN}$, median antenna I neuropil; $\mathrm{mF}$, median foramen; PB, protocerebral bridge; $\mathrm{pF}$, posterior foramen; PMPN, 1499 posterior medial protocerebral neuropil; PNTN, projection neuron tract neuropil; Subcap, subcap domain of OG.
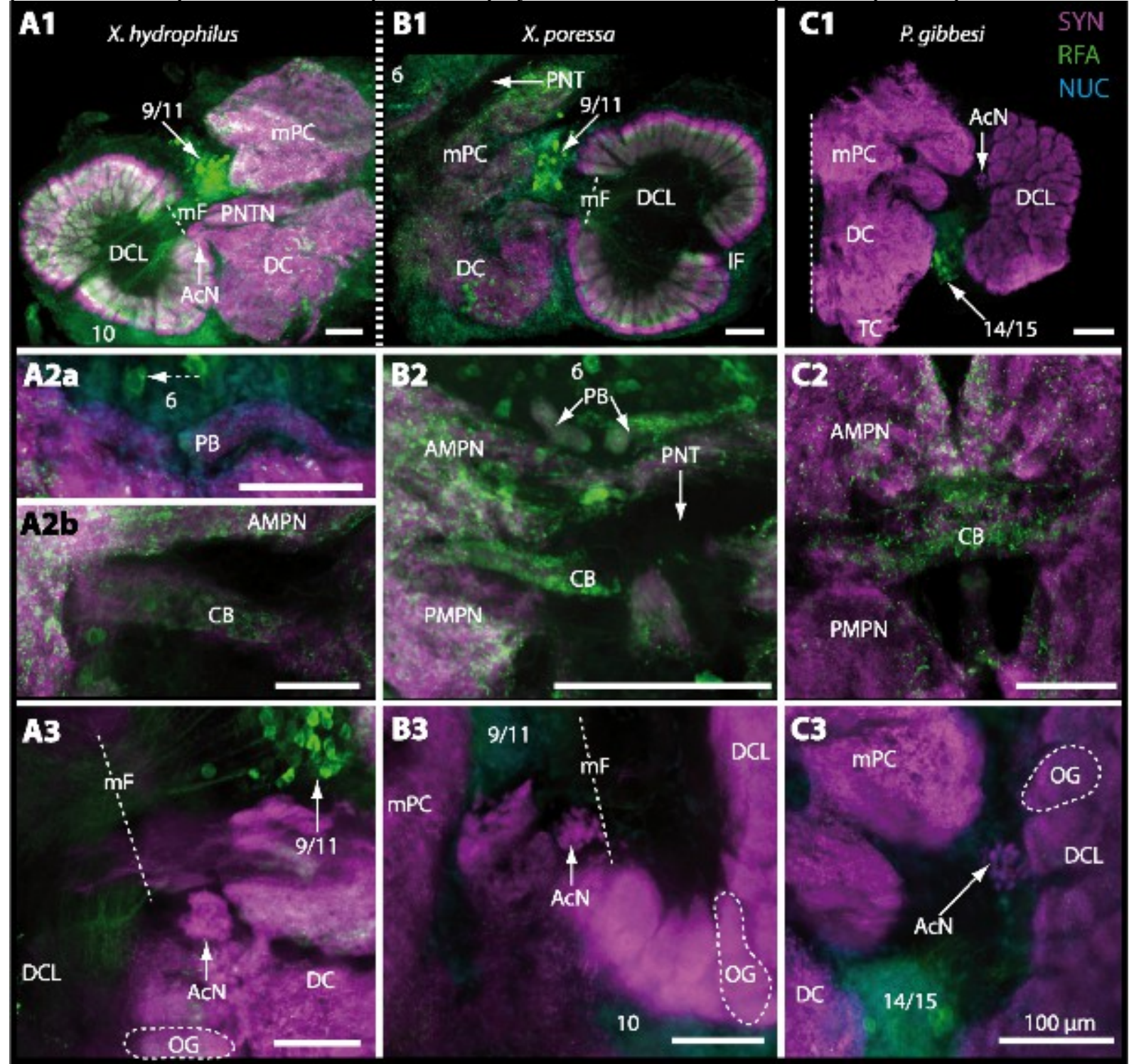

Figure 16.) Vibratomy of triple-labeled horizontal sections $(100 \mu \mathrm{m})$ of central brains and specific brain areas in Xantho hydrophilus, Xantho poressa, and Percnon gibbesi

Note that species are represented column by column (A to C). Comparable brain areas are given line by line (1 to 3 ). A1 to C1 display equally scaled micrographs of horizontal vibratome sections of one hemisphere per species. A2aC2 show neuropils of central complex in more detail. Arrow with a dashed line in A2a identifies one of a subset of somata within cell cluster (6) featuring distinct RFA-like immunoreactivity. A3-C3 display neuropils and somata of primary olfactory pathway in deutocerebrum (DC). Abbreviations of immunhistochemical labelings and histochemical markers: NUC, nuclear marker (cyan); RFA, labelling against RFamide (green); SYN, labelling against synapsin (magenta). Other abbreviations: 6, 10, 9/11, and 14/15, cell clusters (6), (10), (9/11), and (14/15); $\mathrm{AcN}$, accessory neuropil; AMPN, anterior medial protocerebral neuropil; CA, cerebral artery; CB, central body; DCL, deutocerebral chemosensory lobe; $\mathrm{IF}$, lateral foramen; $\mathrm{mF}$, median foramen; $\mathrm{mPC}$, median protocerebrum; OG, olfactory glomerulus; PB, protocerebral bridge; PMPN, posterior medial protocerebral neuropil; PNT, projection neuron tract; PNTN, projection neuron tract neuropil; TC, tritocerebrum. Scale bars $=100 \mu \mathrm{m}$. 


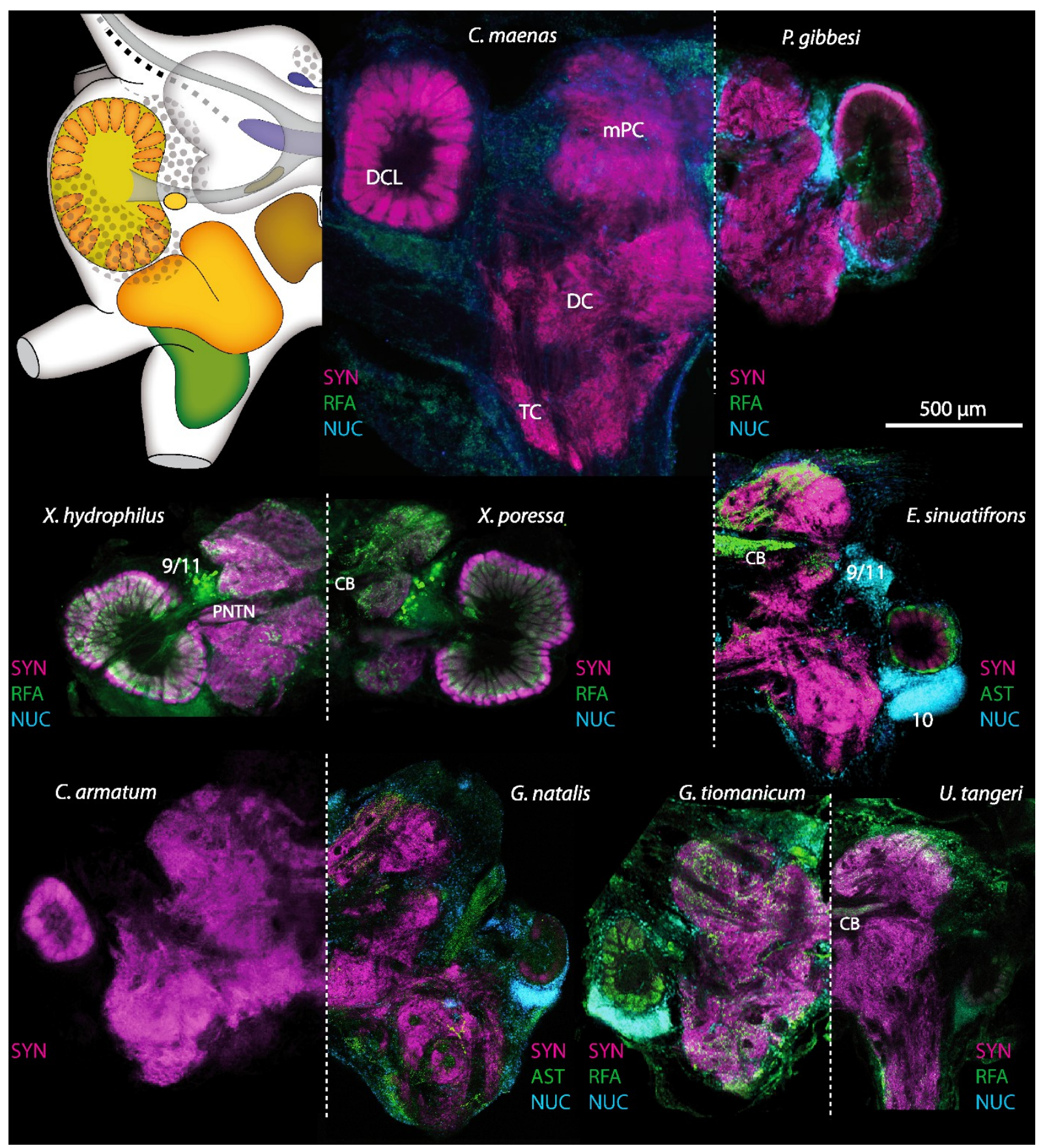

1513 Figure 17.) Collage of triple-labeled and equally scaled optical sections of brain hemispheres in Carcinus 1514 maenas, Percnon gibbesi, Xantho hydrophilus, Xantho poressa, Epilobocera sinuatifrons, Cardisoma armatum, 1515 Gecarcoidea natalis, Geosesarma tiomanicum, and Uca tangeri.

1516 The schematic drawing of the brain hemisphere in C. maenas (dorsal view) is modified from Krieger et al. (2012). 1517 Abbreviations of immunhistchemical labelings and histochemical markers: NUC, nuclear marker (cyan); RFA, 1518 labeling against RFamide (green or black); SYN, labeling against synapsin (magenta or black); AST, labeling against 1519 allatostatin (green). 9/11 and 10, cell clusters (9/11) and (10); Other abbreviations: CB, central body; DC,

1520 deutocerebrum; DCL, deutocerebral chemosensory lobe; mPC, median protocerebrum; PNTN, projection neuron 
1521

1522

1523

tract neuropil; TC, tritocerebrum. Note that for the comparison of sizes, the pairings of brain hemispheres are summarized somewhat arbitrarily, showing the exclusive marine species and the freshwater crab E. sinuatifrons on the upper two panels, and the four land crabs are displayed below.
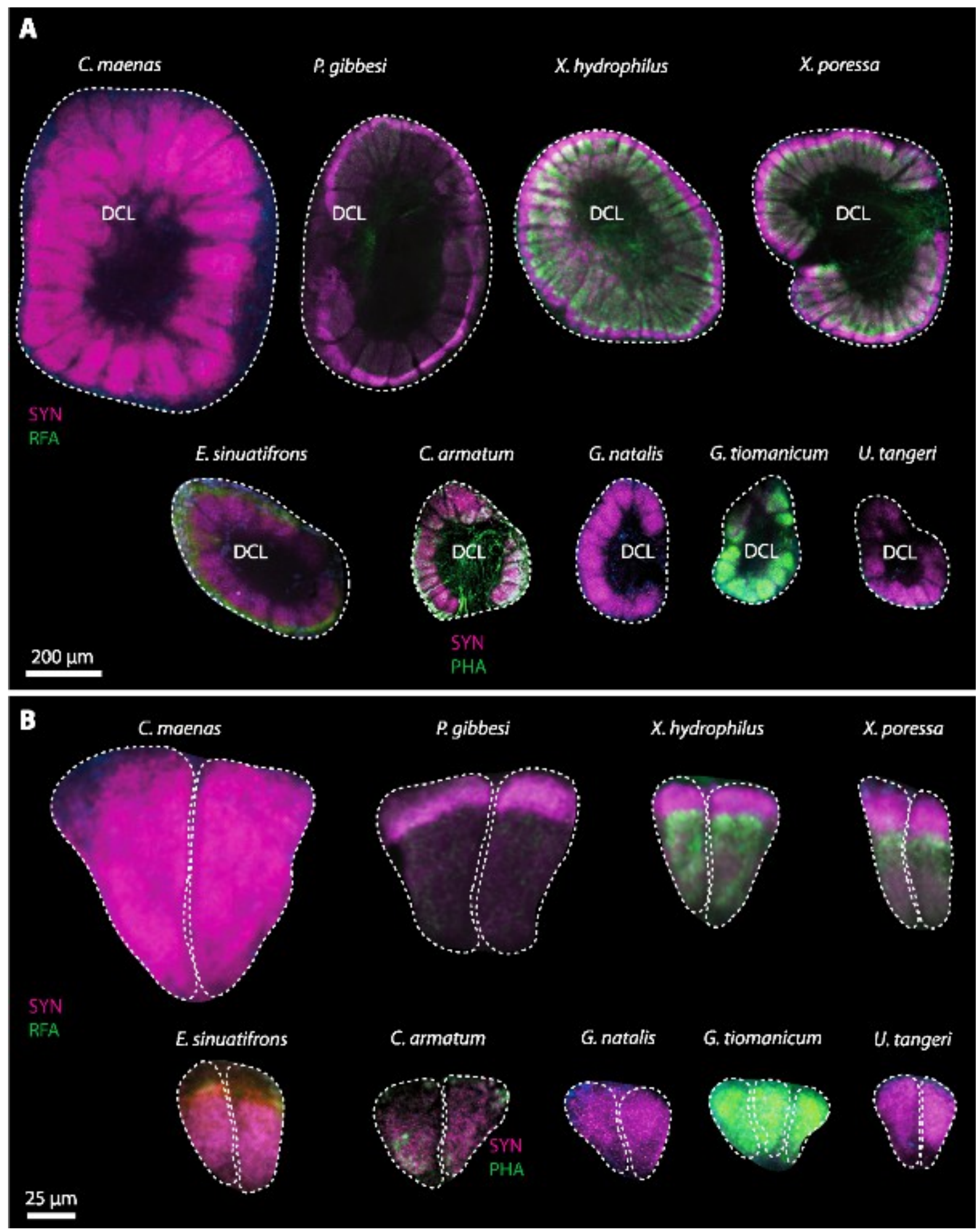
1524 Figure 18.) Collage of double-labeled and equally scaled horizontal sections of deutocerebral chemosensory 1525 lobe (DCL in A) and its olfactory glomeruli (OG in B) in all species studied.

1526 Deutocerebral chemosensory lobes and their olfactory glomeruli of exclusively marine species are shown followed by the neuropils of the freshwater brachyuran Epilobocera sinuatifrons and those of brachyuran species featuring different degrees of terrestrialization(in A and B, respectively). Abbreviations of immunhistochemical labelings and histochemical markers: PHA, actin labeling using phalloidin; RFA, labeling against RFamide (green); SYN, labeling against synapsin (magenta). 